University of Windsor

Scholarship at UWindsor

\title{
Substance Use and Sexual Risk Taking in Emerging Adults with a History of Bullying Victimization
}

Daniel Provenzano

University of Windsor

Follow this and additional works at: https://scholar.uwindsor.ca/etd

\section{Recommended Citation}

Provenzano, Daniel, "Substance Use and Sexual Risk Taking in Emerging Adults with a History of Bullying Victimization" (2018). Electronic Theses and Dissertations. 7561.

https://scholar.uwindsor.ca/etd/7561

This online database contains the full-text of PhD dissertations and Masters' theses of University of Windsor students from 1954 forward. These documents are made available for personal study and research purposes only, in accordance with the Canadian Copyright Act and the Creative Commons license-CC BY-NC-ND (Attribution, Non-Commercial, No Derivative Works). Under this license, works must always be attributed to the copyright holder (original author), cannot be used for any commercial purposes, and may not be altered. Any other use would require the permission of the copyright holder. Students may inquire about withdrawing their dissertation and/or thesis from this database. For additional inquiries, please contact the repository administrator via email (scholarship@uwindsor.ca) or by telephone at 519-253-3000ext. 3208. 


\title{
Substance Use and Sexual Risk Taking in Emerging Adults with a History of Bullying Victimization
}

By

\section{Daniel A. Provenzano}

\author{
A Thesis \\ Submitted to the Faculty of Graduate Studies \\ through the Department of Psychology \\ in Partial Fulfillment of the Requirements for \\ the Degree of Master of Arts \\ at the University of Windsor
}

Windsor, Ontario, Canada 2018

(C) 2018 Daniel A. Provenzano 
Substance Use and Sexual Risk Taking in Emerging Adults with a History of

Bullying Victimization

by

Daniel A. Provenzano

APPROVED BY:

\begin{tabular}{c} 
D. Levin \\
School of Social Work \\
\hline $\begin{array}{c}\text { P. Fritz } \\
\text { Department of Psychology }\end{array}$ \\
\hline $\begin{array}{c}\text { M. Boroughs, Advisor } \\
\text { Department of Psychology }\end{array}$
\end{tabular}

September 13, 2018 


\section{DECLARATION OF ORIGINALITY}

I hereby certify that I am the sole author of this thesis and that no part of this thesis has been published or submitted for publication.

I certify that, to the best of my knowledge, my thesis does not infringe upon anyone's copyright nor violate any proprietary rights and that any ideas, techniques, quotations, or any other material from the work of other people included in my thesis, published or otherwise, are fully acknowledged in accordance with the standard referencing practices. Furthermore, to the extent that I have included copyrighted material that surpasses the bounds of fair dealing within the meaning of the Canada Copyright Act, I certify that I have obtained a written permission from the copyright owner(s) to include such material(s) in my thesis and have included copies of such copyright clearances to my appendix.

I declare that this is a true copy of my thesis, including any final revisions, as approved by my thesis committee and the Graduate Studies office, and that this thesis has not been submitted for a higher degree to any other University or Institution. 


\begin{abstract}
Bullying victimization has been commonly linked with a range of psychosocial problems. To deal with distress, victims engage in coping behaviours that may be adaptive, maladaptive, or both. However, it may be difficult for youth to cope in ways that are adaptive. Instead, youth may engage in a variety of coping behaviours that are maladaptive. Considering that emerging adulthood often coincides with engaging in substance use and sexual risk taking, some youth may engage in these health risk behaviours as ways to cope with the psychosocial problems associated with bullying victimization. Therefore, the purpose of the current study was to examine which psychosocial problems may function as developmental pathways linking bullying victimization with both substance use and sexual risk taking in a sample of emerging adults $\left(N=515 ; 305\right.$ women, 210 men; $\left.M_{\text {age }}=20.20, S D=1.67\right)$. Path analysis provided some support for hypotheses. Bullying victimization had significant direct effects on substance use and sexual risk taking. In addition, bullying victimization had significant indirect effects on substance use through lower self-esteem and depressive symptoms and significant indirect effects on sexual risk taking through lower self-esteem and anxiety symptoms. Secondary analyses suggest that youth with a history of polyvictimization (i.e., bullying and childhood maltreatment) are at even greater risk for engaging in substance use and sexual risk taking. Youth with a history of bullying victimization and polyvictimization may use maladaptive coping strategies such as substance use and sexual risk taking to manage or reduce negative affective experiences.
\end{abstract}

Keywords: bullying; self-esteem; depression; anxiety; substance use; sexual risk taking 


\section{ACKNOWLEDGEMENTS}

First, I would like to thank my supervisor, Dr. Michael Boroughs, for helping me to get this research project off the ground, continuing to refine it over the last year, and providing advice and guidance along the way. He was always willing to schedule meetings to discuss my thesis even when the meetings went beyond the scheduled time and his laissez faire mentoring style allowed this thesis to be my own work. I am looking forward to the next four years and cooking up a killer dissertation.

I would like to thank my committee members, Dr. Patti Fritz and Dr. Dana Levin, for their thoughtful questions, comments, and suggestions that challenged me to think critically and helped to improve my thesis. I would also like to thank Dr. Kendall Soucie for helping me with some of the statistical analyses. Of course, none of this research would have been possible without the help of hundreds of undergraduate students from the University of Windsor. Thank you to them for taking the time to complete the study and allowing me to learn a little bit about their life experiences.

Finally, a special thank you to my family for supporting me in my endeavours and allowing me to choose my own path in life. I always knew that they believed in me even when I did not believe in myself. And a special thank you to Kristen Potter. I never would have made it here without her. 


\section{TABLE OF CONTENTS}

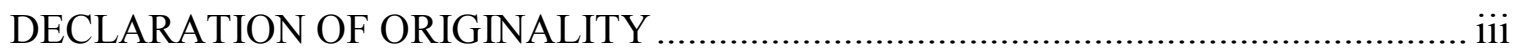

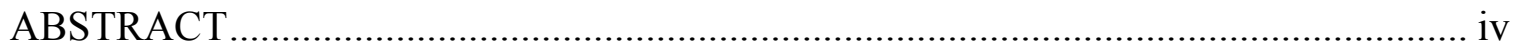

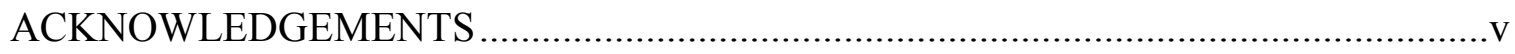

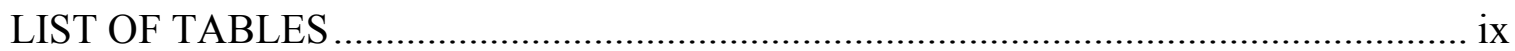

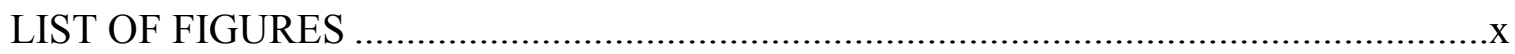

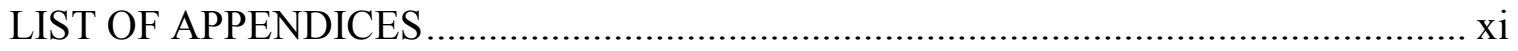

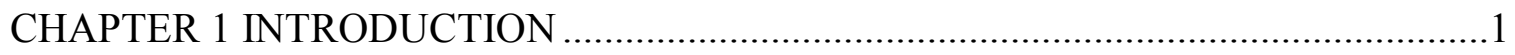

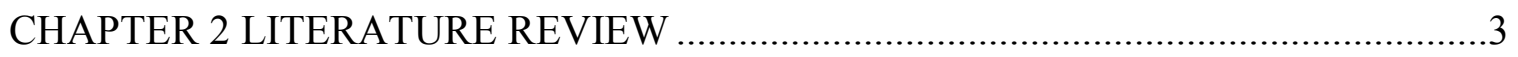

Bullying Victimization and Mental Health Problems.......................................................

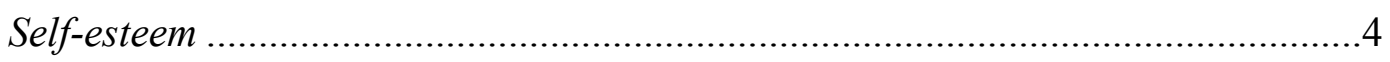

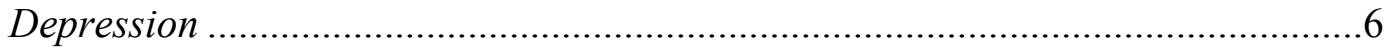

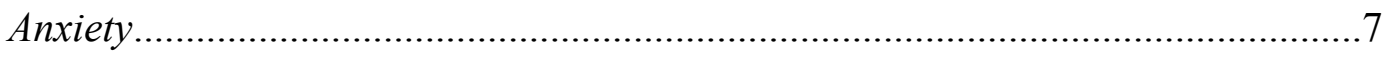

Bullying Victimization and Health Risk Behaviours...................................................

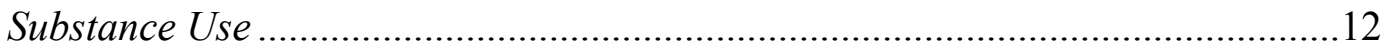

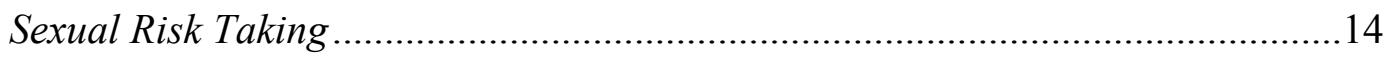

Polyvictimization and Health Risk Behaviours .........................................................17

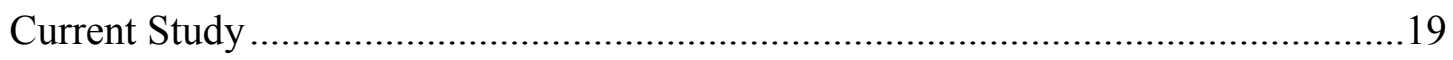

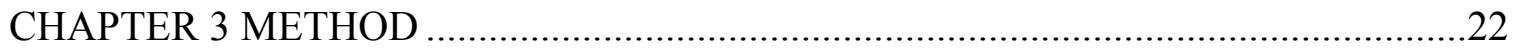

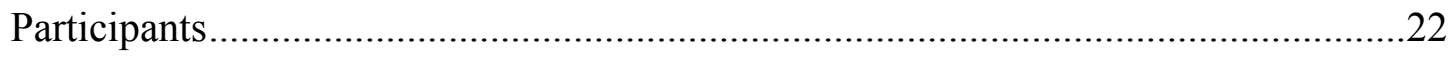

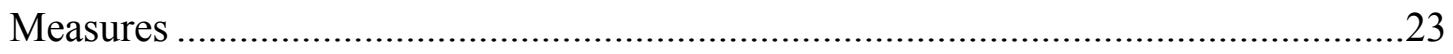

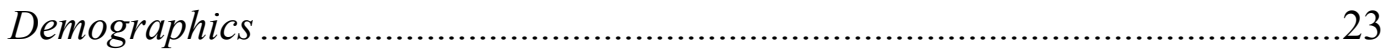

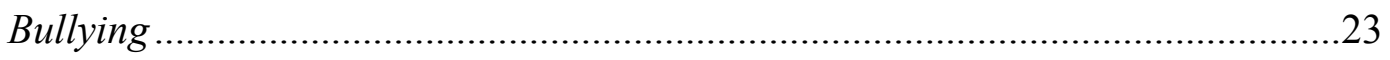




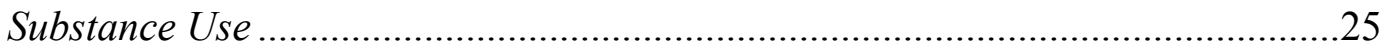

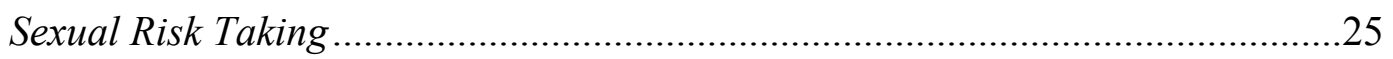

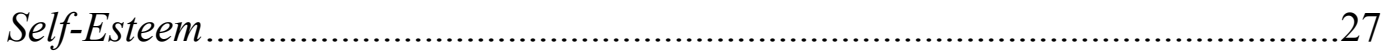

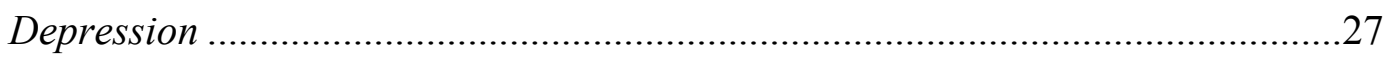

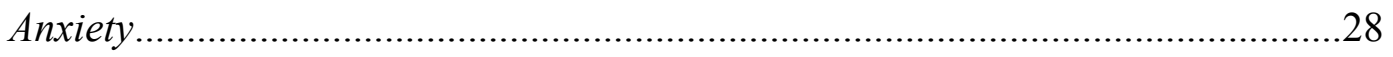

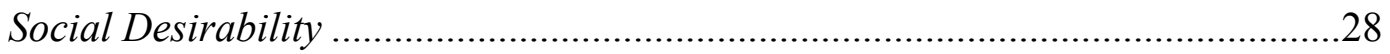

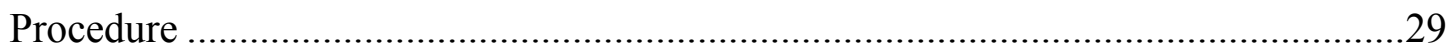

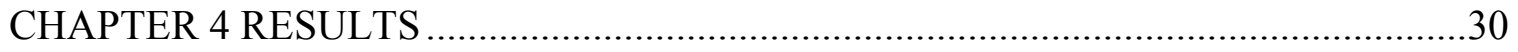

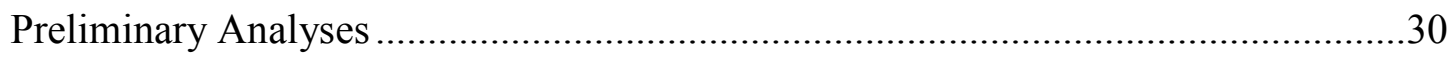

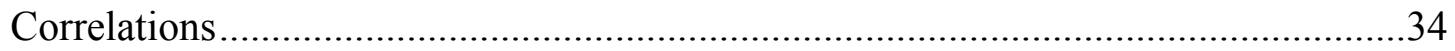

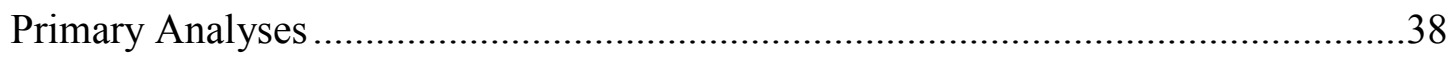

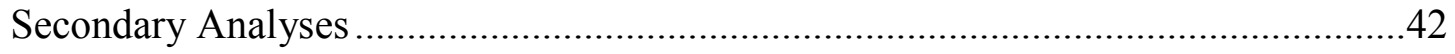

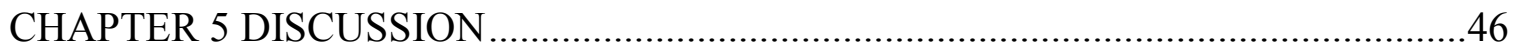

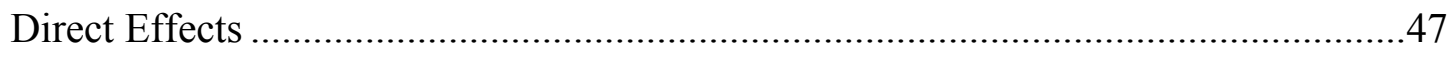

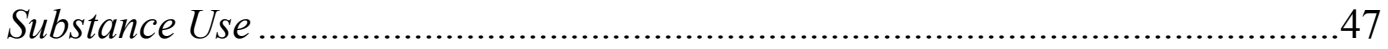

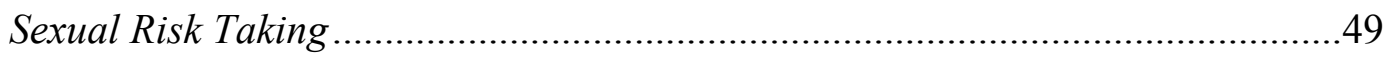

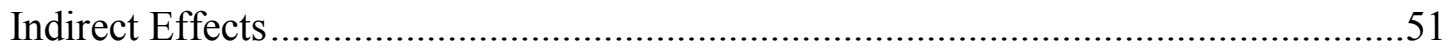

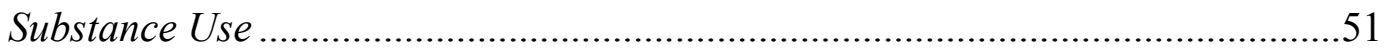

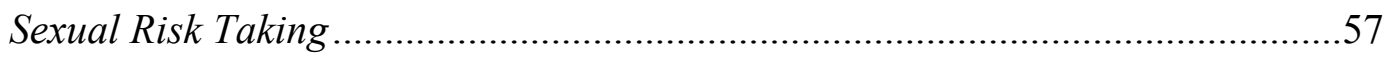

Polyvictimization and Health Risk Behaviours ............................................................61

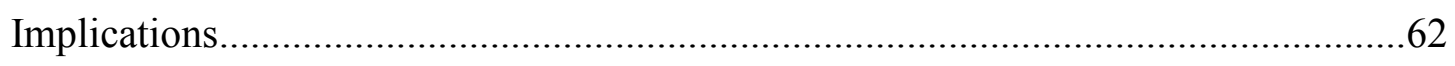

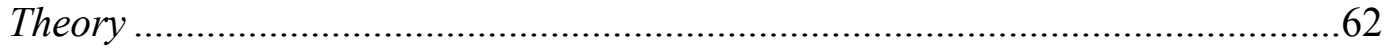


Practice

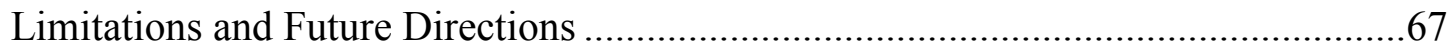

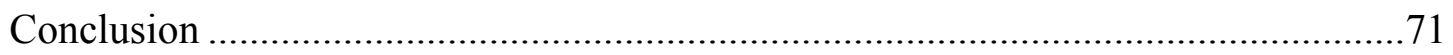

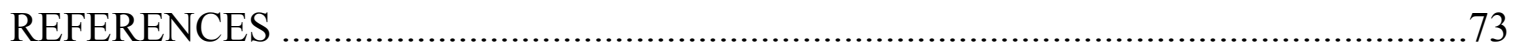

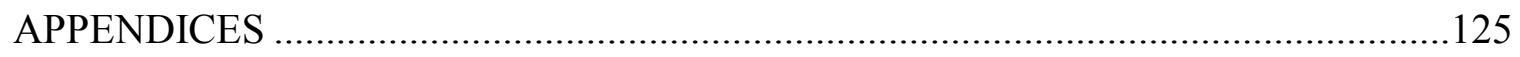

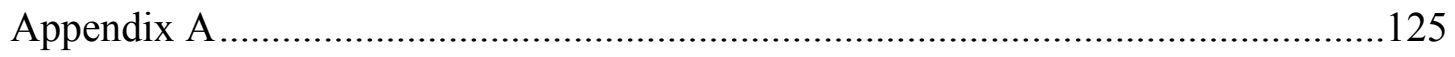

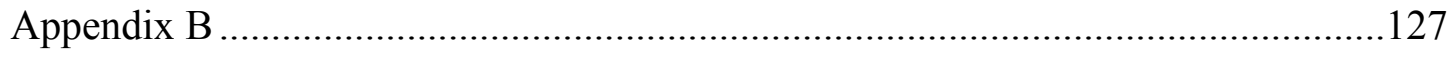

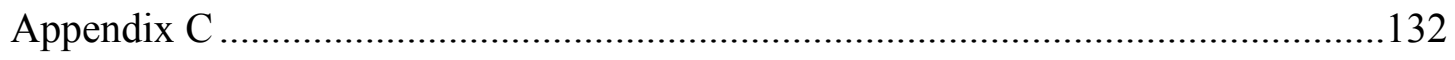

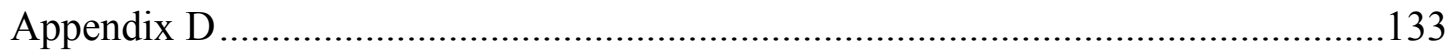

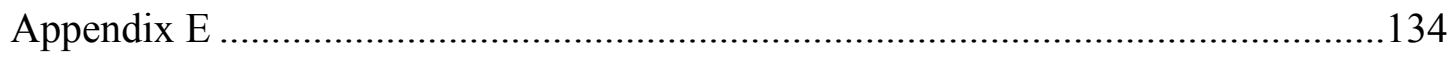

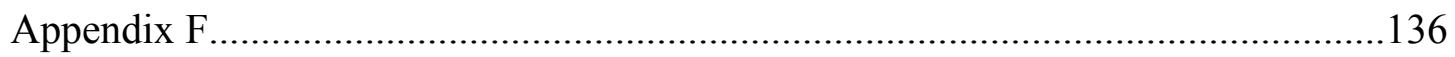

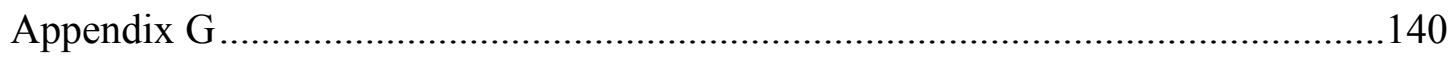

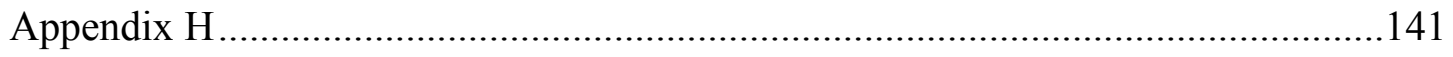

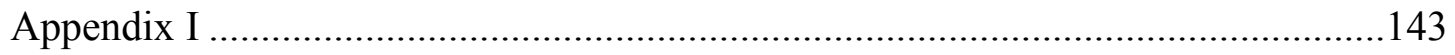

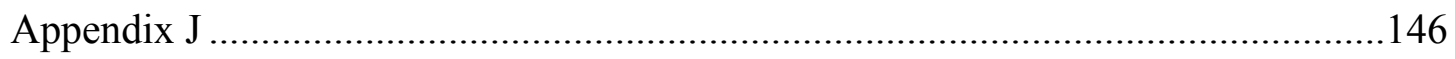

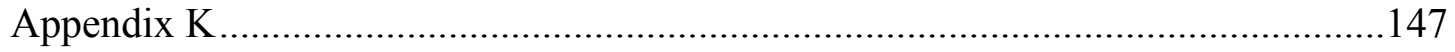

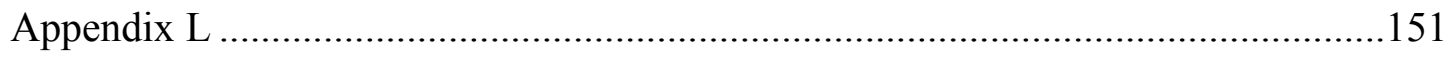

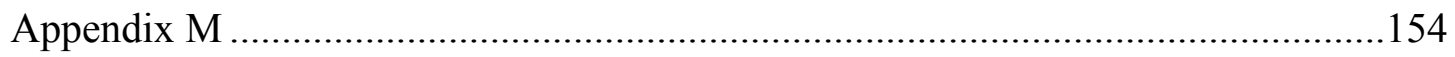

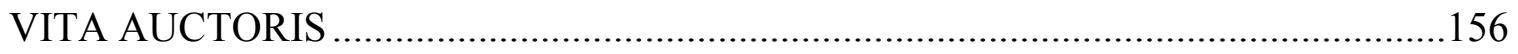




\section{LIST OF TABLES}

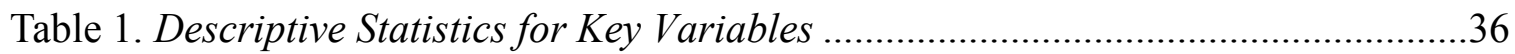

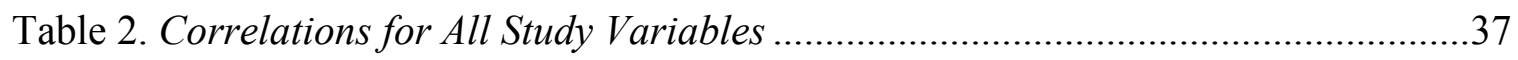

Table 3. Direct Paths among Bullying Victimization, Mental Health Outcomes, and Health Risk Behaviours..............................................................................................4

Table 4. Summary of Hypotheses, Data Analyses, and Results .....................................45 


\section{LIST OF FIGURES}

Figure 1. Significant direct paths for the overall model... 


\section{LIST OF APPENDICES}

Appendix A. Demographics.

Appendix B. Revised Olweus Bully/Victim Questionnaire

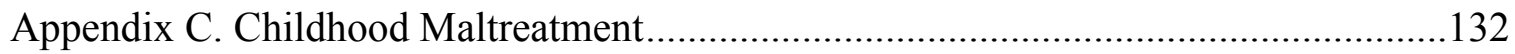

Appendix D. Alcohol Use Disorders Identification Test.........................................133

Appendix E. Cannabis Use Disorder Identification Test-Revised................................134

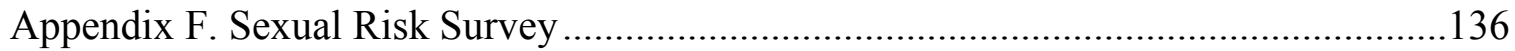

Appendix G. Rosenberg Self-Esteem Scale ......................................................... 140

Appendix H. Center for Epidemiological Studies Depression Scale-Revised ...............141

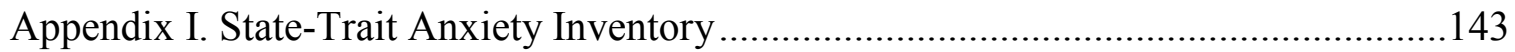

Appendix J. Balanced Inventory of Desirable Responding ......................................146

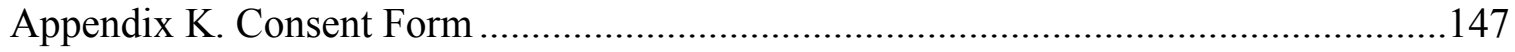

Appendix L. Debriefing Form and Community Resources ........................................151

Appendix M. Recruitment Advertisements .................................................... 154 


\section{CHAPTER 1}

\section{INTRODUCTION}

Bullying perpetration and victimization are a public health crisis affecting millions of children, adolescents, and young adults worldwide each year with prevalence rates reaching as high as $60 \%$ depending on how bullying is defined and measured (Craig et al., 2009; Chester et al., 2015; Due et al., 2005; Lund \& Ross, 2016; Nansel et al., 2001; Volk, Craig, Boyce, \& King, 2006). Bullying is defined as one or more powerful individuals intentionally and repeatedly using a broad range of negative behaviours of a physical, psychological, and/or social nature (or combination thereof) that are directed toward less powerful individuals that (a) cause significant harm, (b) cause damage to their property, (c) create a hostile environment where the victim fears significant harm and/or damage to property, (d) interfere with educational and/or occupational processes, and (e) include cyberbullying (Olweus, 2010; Solberg, Olweus, \& Endresen, 2007). Bullying is a subcategory of peer victimization (hereafter referred to as bullying victimization to include those who are bullied and bully-victims [i.e., those who bully others and are bullied by others], but to distinguish from bullying perpetration [i.e., pure bullies]) that also includes other peer to peer harmful behaviours such as physical and sexual assault, dating violence, and gang violence (Finkelhor, Turner, \& Hamby, 2012). The ubiquity of bullying victimization is concerning, considering that past studies have found negative physical and mental health outcomes linked with a history of being bullied (e.g., Arseneault, Bowes, \& Shakoor, 2010; Copeland et al., 2014; Wolke \& Lereya, 2015). To deal with the negative health outcomes generated by victimization, bullied individuals may engage in coping behaviours that are adaptive (e.g., confronting 
the stressor), maladaptive (e.g., avoiding the stressor), or both. Bullying is often characterized as a repeated act of aggression against a less powerful individual, which makes it more difficult for youth to cope in ways that are considered adaptive (Donoghue, Almeida, Brandwein, Rocha, \& Callahan, 2014) and increases the likelihood that youth turn to coping behaviours that are considered maladaptive (Hunter, MoraMerchan, \& Ortega, 2004).

Emerging adulthood often coincides with engaging in substance use and sexual risk taking (e.g., using substances prior to or during sexual behaviour, unprotected sexual intercourse, and/or having multiple sexual partners; Epstein, Bailey, Manhart, Hill, \& Hawkins, 2014; Martino, Ellickson, \& McCaffery, 2008; White et al., 2006). These health risk behaviours may serve as two ways for youth to cope with the negative emotional and psychological effects of bullying victimization (Topper, Castellanos-Ryan, Mackie, \& Conrod, 2011). Although a growing body of research is investigating coping strategies within the context of bullying, much of the research to date has focused on the consequences of bullying among children with less emphasis on the consequences of bullying among adolescents and emerging adults (Holt, Green, Tsay-Vogel, Davidson, \& Brown, 2016; Kritsotakis, Papanikolaou, Androulakis, \& Philalithis, 2017). Therefore, in order to address this gap in the literature, one goal of the current study was to examine whether or not bullying victimization is associated with substance use and sexual risk taking in emerging adults. In addition, few studies have examined the underlying mechanisms by which bullying victimization may be linked with greater substance use and sexual risk taking (Earnshaw et al., 2017). Youth may experience a range of mental health consequences as a result of being victimized, which in turn may contribute to the 
development and maintenance of health risk behaviours as ways to cope with these consequences (Hawker \& Boulton, 2000; Kelly et al., 2015; Hong et al., 2014). Thus, a second goal of the current study was to explore which psychosocial problems may function as developmental pathways (i.e., mediators) linking bullying victimization with both substance use and sexual risk taking.

\section{CHAPTER 2}

\section{LITERATURE REVIEW}

\section{Bullying Victimization and Mental Health Problems}

Emerging adulthood is a transitional period of development characterized by important psychosocial changes marked in part by increased independence from parents; further identity development; frequent residence changes; the salience of peer and romantic relationships; and fundamental shifts in attitudes, values, and beliefs (Arnett, 2000, 2004). Interpersonal relationships become increasingly important as youth seek autonomy from parents, their social networks expand as they enter new social environments (e.g., high school, university, the workplace), and they place greater emphasis on social status, peer acceptance, and conformity (La Greca \& Harrison, 2005; Steinberg \& Monohan, 2007; Swenson, Nordstrom, \& Hiester, 2008). Furthermore, as emerging adults spend more time with their peers, they are likely to experience conflict or negative peer interactions (Telzer, Fuligni, Lieberman, Miernicki, \& Galván, 2015). Peer to peer relational problems such as bullying victimization is a significant interpersonal stressor that has damaging effects on psychological adjustment and may be a causal risk factor (among others) associated with multiple problematic outcomes (La Greca \& Landoll, 2011; Olweus, 1993a). For instance, bullying victimization has been 
commonly linked with a range of adjustment difficulties such as low self-esteem, depression, and anxiety (Hawker \& Boulton, 2000; Kelly et al., 2015). Social-cognitive models suggest that negative social experiences, and the way these experiences are perceived and interpreted, can contribute to psychological distress (e.g., Fennell, 1997; Hammen, 1999; Wells \& Carter, 2002). I will review the links established in the literature between internalizing problems such as low self-esteem, depression, and anxiety with a history of being bullied.

Self-esteem. During emerging adulthood, there is an increased focus on the self as youth are in the process of forming and exploring their identity largely based on cues from their social environment (Arnett, 2004; Patchin \& Hinduja, 2010; Valkenburg, Peter, \& Schouten, 2006). That is, individuals may derive how they feel about themselves based on the feedback they receive from others (Leary, 1999). Youth tend to seek behaviours and environments that create a positive view of the self and avoid those that create a negative view of the self (Patchin \& Hinduja, 2010). Social support (or lack thereof) from peers is essential to increasing (or decreasing) one's level of self-esteem (Sentse, Kretschmer, \& Salmivalli, 2015). Rosenberg (1965) defined self-esteem as a "favourable or unfavourable attitude toward the self" (p. 3) related to a global evaluation of one's own personal worth or value that is influenced by the social world (Patchin \& Hinduja, 2010; Tsaousis, 2016). Thus, self-esteem appears to develop through an individual's social interactions with others where interpersonal conflicts likely signal less peer acceptance and more peer rejection, which may have a negative effect on selfesteem (Leary, 2005; Rosenberg, Schooler, Schoenbach, \& Rosenberg, 1995). Not surprisingly, previous studies have reported that youth who are bullied by peers report 
lower self-esteem than those not involved in bullying (e.g., Brighi, Guarini, Melotti, Galli, \& Genta, 2012; Brighi et al., 2012; Egan \& Perry, 1998; Hawker \& Boulton, 2000; Jones, Bilge-Johnson, Rabinovitch, \& Fishel, 2014; Kowalski \& Limber, 2013; Olweus, 1993a; Overbeek, Zeevalkink, Vermulst, \& Scholte, 2010; Russell, Ryan, Toomey, Diaz, \& Sanchez, 2011; Tsaousis, 2016).

The adverse effect of bullying victimization on self-esteem may be explained, in part, by positive or negative self appraisals of being accepted or rejected by peers and a sense of high or low social competence that influence one's attitudes about the self (Harter, 1999). Bullying victimization may result in feelings of low self-esteem because it reinforces negative appraisals of how a victim is perceived by their peers (i.e., they are not well-liked; Lopez \& DuBois, 2005). Victims may also incorporate hurtful comments or disparaging remarks into their self-concept, diminishing their self-esteem and contributing to social withdrawal from peers (Casey-Cannon, Hayward, \& Gowen, 2001; Salmivalli, Kaukiainen, Kaistaniemi, \& Lagerspetz, 1999). Furthermore, bullying victimization may reduce self-esteem as victims feel a poor sense of belongingness and connectedness when rejected by others, particularly peers at this developmental stage (Smart-Richman \& Leary, 2009). Finally, being victimized may result in lower selfesteem as youth feel that they lack the social skills necessary to communicate and interact with peers and engage in positive interactions (Lopez \& DuBois, 2005). Taken together, individuals who are bullied may be an increased risk for developing lower self-esteem.

One mental health outcome often associated with self-esteem is depression. Although self-esteem and depression are related, they are theoretically and empirically distinct (Sowislo \& Orth, 2013). Proneness to depression may be rooted in stressful life 
events that involve social relational experiences (Dohrenwend et al., 1992). Therefore, similar to self-esteem, individuals with a history of being bullied may often experience depression.

Depression. The incidence and prevalence of depression increases substantially from childhood to early adulthood, which may be influenced by recurring abuse, ongoing conflicts or frustrations, and traumatic events related to peer relationships (Birmaher \& Brent, 2007; Laugharne, Lillee, \& Janca, 2010; Zisook et al., 2007). Being bullied is likely to represent a traumatic experience that may be a potential risk factor for depression. Both cross-sectional and longitudinal research designs find bullying victimization to be associated with depression (e.g., Bowes, Joinson, Wolke, \& Lewis, 2016; Holt et al., 2014; Klomek, Marrocco, Kleinman, Schonfeld, \& Gould, 2007; Lereya, Copeland, Costello, \& Wolke, 2015; Menesini, Modena, \& Tani, 2009; Russell et al., 2011; Schwartz, Lansford, Dodge, Pettit, \& Bates, 2015; Ttofi, Farrington, Lösel, \& Loeber, 2011; Reid, Holt, Bowman, Espelage, \& Green, 2016; Turner, Exum, Brame, \& Holt, 2013). Research further suggests that in addition to traditional victimization, cybervictimization may also be related to depression (Luk, Wang, \& Simons-Morton, 2010). Specifically, bullying victimization through the Internet (e.g., emails, social networking websites) and phone (e.g., text messages) was also related to elevated depression symptoms (e.g., Schenk \& Fremouw, 2012). Furthermore, being an infrequent target of bullying predicted risk for some symptoms of depression, whereas being a constant target of bullying predicted risk for a diagnosis of clinical depression (Klomek et al., 2007). Thus, bullying victimization appears to demonstrate a dose-response relationship whereby experiencing higher levels of bullying produced more severe mental 
health problems (Evans, Smokowski, \& Cotter, 2014). In fact, compared to other mental health problems, bullying victimization is most strongly related (i.e., the largest effect size) to depression (Hawker \& Boulton, 2000). However, the reasons for the association between bullying victimization and depression remain unclear (Sinclair et al., 2012). There is some evidence that experiences of bullying victimization reduce positive cognitions and promoted negative cognitions (e.g., learned helplessness; see Abramson, Metalsky, \& Alloy, 1989; Gibb \& Alloy, 2006), which may contribute to the onset of depression (Sinclair et al., 2012). Bullying victimization constitutes painful and negative self-relevant feedback to victims about their low social status in the peer group or undesirable personal characteristics, often engendering feelings of depression (Sowislo \& Orth, 2013; Sinclair et al., 2012). Overall, the data suggests that feelings of depression are a consequence of bullying victimization.

Often comorbid with depression is anxiety, which may be a precursor to psychological disorders such as depression (Costello, Egger, \& Angold, 2005; Grant, Beck, Farrow, \& Davila, 2007). Thus, interpersonal stressors such as bullying victimization may also play a causal role in the experience of anxiety symptoms and disorders.

Anxiety. Youths' peer relationships may influence the development and maintenance of anxiety symptoms and disorders (Le Greca \& Landoll, 2011). Although the importance of peer relationships peaks during adolescence (Brown, 2004), involvement with and dependence on peers may decrease only slightly in emerging adulthood (Arnett, 2000). Nevertheless, problematic peer relationships such as bullying victimization may represent a traumatic event and potential risk factor that contributes to 
feelings of anxiety that persist over time and interfere with functioning in young people (La Greca \& Landoll, 2011). Cross-sectional and longitudinal studies suggest that youth who are victimized by their peers (through traditional and cyber forms) are at an increased risk for various anxiety symptoms and disorders, with generalized anxiety and social anxiety disorders being most prevalent (e.g., Copeland, Wolke, Angold, \& Costello, 2013; Espelage, Hong, \& Mebane, 2016; Holt et al., 2014; Jones, Robinson, Oginni, Rahman, \& Rimes, 2017; Kowalski \& Limber, 2013; Lereya et al., 2015; Reid et al., 2016; Schenk \& Fremouw, 2012; Sourander et al., 2007; Stapinski et al., 2014). In addition, youth who were bullied were two to three times more likely to develop an anxiety disorder than nonvictims (Kumpulainen, Rasanen, \& Puura, 2001; Salmon, James, Cassidy, \& Javaloyes, 2000; Stapinski et al., 2014). Victims of homophobic bullying (e.g., being called gay) experienced higher levels of psychological distress, particularly anxiety and depression, compared to youth who were bullied for other reasons (Swearer, Turner, Givens, \& Pollack, 2008). Unlike depression, the reasons for the association between bullying victimization and anxiety are less ambiguous. Worrying about potentially harmful future events is one of the most notable features of anxiety (Hallam, 1992). Youth who are victimized may come to perceive or expect the school environment or world to be an unsafe or dangerous place resulting in hypervigilance, negative expectations in future social situations, and fear of future victimization, which may elevate anxiety in general over time (Boulton, Trueman, \& Murray, 2008; Roth, Coles, \& Heimberg, 2002; Tillfors, Persson, Willen, \& Burk, 2012). Furthermore, victims of bullying make negative evaluations about their own perceived social incompetence and ability to have positive social experiences, which may exacerbate social anxiety and 
avoidance of social interactions (Storch, Masia-Warner, Crisp, \& Klein, 2005). Taken together, anxiety appears to be a negative mental health outcome of bullying victimization.

In sum, self-esteem, depression, and anxiety in general are all associated with a history of being bullied. Although the data suggests that exposure to bullying victimization precedes the development of these psychosocial problems, it may also be that these psychosocial problems predispose some young people to bullying victimization (Boulton, Smith, \& Cowie, 2010; Kaltiala-Heino \& Fröjd, 2011; Siegel, La Greca, \& Harrison, 2009). The bidirectional nature between bullying victimization and harmful mental health outcomes is beyond the scope of this study, which will focus on the prospective impact of bullying victimization on young people's mental health. Problems with one or more of these mental health concerns may occur concurrently among some emerging adults at a time when they are developmentally more likely to engage in risk behaviours (Arnett, 2000). Thus, when experiencing an interpersonal stressor such as bullying victimization, individuals may engage in various coping strategies (Newman, Holden, \& Delville, 2011). Next, I will review coping in response to bullying victimization.

\section{Bullying Victimization and Health Risk Behaviours}

Coping refers to a range of diverse cognitions, emotions, and behaviors used to manage, minimize, or reduce the demands of stressful or threatening experiences and situations (Lazarus \& Folkman, 1984). Although coping strategies have been conceptualized along a variety of different dimensions, one common framework is the approach-avoidance model (Roth \& Cohen, 1986; Skinner, Edge, Altman, \& Sherwood, 
2003). Approach coping involves strategies that confront the source of the stressor as direct attempts are made to change stressful experiences (Kochenderfer-Ladd \& Skinner, 2002). In contrast, avoidance coping involves strategies that divert efforts away from a stressor, as direct attempts are not made to stop the stressor, but instead involve managing cognitive or emotional reactions (Kochenderfer-Ladd \& Skinner, 2002). These two modes of coping can vary in saliency over time and may be activated at any particular time depending on the context (Roth \& Cohen, 1986). Individuals may then develop a preference for approach or avoidance coping even when the situation demands the opposite of the preferred response (Roth \& Cohen, 1986).

Roth and Cohen (1986) suggest that approach and avoidance coping each have their own costs and benefits. Approach coping can lead to quicker resolution of the trauma, but distress is heightened in the short-term, whereas avoidance coping can lead to long-term intrusive thoughts about the trauma, but distress is reduced in the short-term (Roth \& Cohen, 1986). Selecting a coping strategy to utilize, though often accomplished implicitly, may largely depend on the level of perceived control (Spirito, Stark, Grace, \& Stamoulis, 1991). Approach strategies may be used if the problem or conflict is considered or perceived to be within an individual's coping capabilities, whereas avoidance strategies may be used if the problem or conflict is considered or perceived to beyond an individual's control (Hampel, Manhal, \& Hayer, 2009). Youth may use approach and/or avoidance strategies to deal with various problems, one of which may be bullying victimization. Frequent bullying victimization may represent a situation or experience that is out of the control of the affected person, and thus, avoidance strategies may be used to minimize the distress associated with being victimized. Consistent with 
this expectation, previous studies have found that victims of bullying often use avoidance coping (Lodge \& Feldman, 2007; Newman et al., 2011). Although avoidance coping may help to remove, distance, or distract oneself from distress, it may serve as a maladaptive means for regulating emotional experiences (Fuendeling, 1998). The use of this strategy over time does not promote the practice of healthy coping strategies to distress, and instead encourages alternative pathways to restore affective balance. An effort to return to this balance may increase the likelihood of engaging in high risk behaviours such as substance use or risky sexual activity (Wills \& Hirky, 1996). Problematic alcohol and drug use can often co-occur with sexual risk taking with emerging adults typically engaging in substance use prior to and/or during sexual behaviour outside of the context of experiencing bullying victimization (e.g., Eaton et al., 2015; King, Nguyen, Kosterman, Bailey, \& Hawkins, 2012; Ritchwood, Ford, DeCoster, Sutton, \& Lochman, 2015). However, substance use and risky sexual behaviour may function as a reaction to psychosocial problems associated with bullying victimization. That is to say, the use of these maladaptive coping strategies provides an immediate reduction in distress via the avoidance of distressing emotions and thoughts linked with a history of being bullied. Moreover, engaging in high risk behaviours is especially prevalent during emerging adulthood (Arnett, 2000), and may function to help alleviate or regulate aversive emotional and psychological experiences associated with bullying victimization (Cerutti, Manca, Presaghi, \& Gratz, 2011; Kianpoor \& Bakhshani, 2012). Therefore, substance use and sexual risk taking may represent two maladaptive pathways for coping with the experiences of a stressor such as being bullied. 
Substance use. Drug and alcohol use function as a maladaptive coping mechanism for stressful life events such as bullying (Ttofi, Farrington, Lösel, Crago, \& Theodorakis, 2016). Stressors that are perceived to be uncontrollable together with the feeling that one is unable to resolve a problem with adaptive coping, which often involves a more timely set of processes (e.g., reaching out for social support, psychological treatment, engaging in many health and wellness behaviours), may lead individuals to use alternative means to manage emotions (Wills \& Cleary, 1995). Given that bullying, by definition, involves a more powerful individual repeatedly harming a less powerful individual, victims may feel that their situation is uncontrollable and may engage in substance use as a maladaptive coping strategy to reduce distress associated with their bullying experiences (Ttofi et al., 2016). Previous research has found that victims of different subtypes of bullying (e.g., physical, relational, and cyber) were more likely to engage in substance use (e.g., alcohol and cannabis consumption; Copeland et al., 2013; Goebert, Else, Matsu, Chung-Do, \& Chang, 2011; Kim, Catalano, Haggerty, \& Abbott, 2011; Kritsotakis et al., 2017; Luk et al., 2010; Mitchell, Ybarra, \& Finkelhor, 2007; Radliff, Wheaton, Robinson, \& Morris, 2012; Rospenda, Richman, Wolff, \& Burke, 2013; Sánchez, Zaragoza Ruiz-Cabello, Romero, \& Maldonado, 2017). However, these studies often use only a few items to gauge whether or not participants have used a particular substance in the past or the frequency of past substance use instead of a comprehensive scale to measure consumption, frequency, and substance-related problems. The current study used comprehensive, psychometrically sound self-report measures of alcohol and cannabis use. Bullying experiences coinciding with substance use may reflect an adolescent's attempt to cope with being victimized (Rusby, Forrester, 
Biglan, \& Metzler, 2005). More specifically, a stress-coping model suggests that stressful experiences are characterized as risk factors for substance use (Wills, Vaccaro, \& Benson, 1995). Substance use is part of an avoidance coping strategy that is commonly used to cope with stressors by promoting positive affect and/or minimizing negative mood states (Wills \& Cleary, 1995).

The desire to manage one's emotional experiences may be important motives underlying alcohol (Simantov, Schoen, \& Klein, 2000) and cannabis use (Comeau, Stewart, \& Loba, 2001). From this perspective, substance use and its psychotropic effects may function as a form of self-medication (Khantzian, 1997). The self-medication hypothesis suggests that individuals may engage in substance use to cope with aversive thoughts and feelings (Khantzian, 1997). The evidence is strong that that psychosocial problems such as low self-esteem, depression, and anxiety promote the use of alcohol and cannabis (Bartsch, King, Vidourek, \& Merianos, 2017; Buckner et al., 2008; Hussong, Ennett, Cox, \& Haroon, 2017; Maslowsky, Schulenberg, O'Malley, \& Kloska, 2014; McKay, Sumnall, Cole, \& Percy, 2012; Marmorstein, White, Loeber, \& StouthamerLoeber, 2010). Substance use may be an adaptive, but short-term coping response that is generally considered to be maladaptive and less effective in the long-term (Kassel, Bornovalova, \& Mehta, 2006; Wagner, Myers, \& McIninch, 1999). In sum, substance use represents one pathway for coping during periods of heightened psychosocial stress, but another health risk behaviour often co-occurring with substance use is sexual risk taking. Sexual risk taking may represent a distinct second pathway that also functions as a strategy for dealing with unpleasant thoughts and feelings. 
Sexual risk taking. Engaging in sexual activity also operates as a coping mechanism among those that experience a stressful life event (Sikkema, Hansen, Meade, Kochman, \& Fox, 2009) such as bullying victimization. Although sexual behaviour is associated with a range of psychological benefits that promote a healthy relationship between people (e.g., intimacy, trust, closeness, and pleasure), risky sexual behaviour can often be distressing and problematic as it can increase the chance of contracting a sexually transmitted infection (STI) and/or the occurrence of unplanned pregnancy (Brody, 2010; Diamond \& Huebner, 2012; Malhotra, 2008). As mentioned previously, the repetitive nature of bullying may lead victimized youth to perceive these negative peer interactions as beyond their control, which in turn may lead them to not only engage in substance use, but also unsafe sexual practices as a maladaptive coping strategy. Previous studies have found links between a history of being bullied and sexual risk taking in both heterosexual and LGBTQ youth. In particular, bullying victimization was associated with an increased likelihood of transactional sex, greater risk for STI's and HIV, unprotected vaginal and anal intercourse, and anal intercourse under the influence of drugs and alcohol (Bouffard \& Koeppel, 2017; Kritsotakis et al., 2017; Li, DiStefano, Mouttapa, \& Gill, 2014; Robinson \& Espelage, 2013; Russell, Ryan, Toomey, Diaz, \& Sanchez, 2011). However, these studies often use only a few items instead of a comprehensive scale to capture a complex health risk outcome such as sexual risk taking. Most measures of sexual risk behaviours have little supporting psychometric data (George, Zawacki, Simoni, Stephens, \& Lindgren, 2005) or focus on a specific behavior or at-risk group (e.g., intravenous drug users, sexual minority men; Bancroft et al., 2003; 
Darke, Hall, Heather, Ward, \& Wodak, 1991). The current study used a comprehensive, psychometrically sound self-report measure of sexual risk taking in a general population.

Although there is a growing body of research exploring sexual risk taking within the context of bullying, there is a lack of a theoretical underpinning for sexual risk taking as a maladaptive coping strategy in response to bullying victimization. Given the potential for theoretical overlap between the experience of being bullied and other developmental traumas, such as childhood maltreatment (i.e., both are aggressive in nature and involve a power imbalance) and similarities in long-term outcomes, the wellestablished childhood maltreatment (i.e., childhood physical and sexual abuse) literature may provide some insight into sexual risk taking as a maladaptive coping strategy for dealing with developmental trauma (Lereya et al., 2015). Previous studies have found that individuals with a history of childhood maltreatment are more likely to engage in sexual risk taking behaviours such as unprotected sexual intercourse; multiple sexual partners, earlier sexual debut, and exchange of sex for money and drugs (Abajobir, Kisely, Maravilla, Williams, \& Najman, 2017; Fergusson, McLeod, \& Horwood, 2013; Senn, Carey, \& Vanable, 2008). Feelings of powerlessness and low self-worth as a result of the abuse experience may affect one's ability to discuss using contraceptives, such as condoms, with their sexual partner(s) (Saewyc, Magee, \& Pettingell, 2004). Negotiation over the use of contraceptives may be viewed as being confrontational with another person, and victims of bullying may refrain from promoting this adaptive sexual health practice in order to avoid conflict (Kritsotakis et al., 2017). Individuals with heightened feelings of isolation stemming from peer rejection may desire sexual fulfilment and sexual activity may become a way of attaining affection and intimacy, potentially leading 
to earlier sexual initiation or multiple sexual partners (Torres \& Gore-Felton, 2007; Wilson \& Widom, 2008). Furthermore, distorted cognitions after an abuse experience may lead victims to give more positive appraisals to risky behaviours that involve sexual activity (Smith, Davis, \& Fricker-Elhai, 2004). Finally, victims may have trouble forming relationships with others, which manifest as involvement in multiple low-quality sexual relationships (Senn, Carey, Vanable, Coury-Doniger, \& Urban, 2007). Taken together, these risky sexual behaviours may help temporarily relieve negative affective experiences that may not otherwise be resolved (Sikkema et al., 2009)

Polusny and Follette (1995) proposed a theoretical model based on emotional avoidance theory. From this perspective, many of the long-term outcomes of childhood maltreatment reflect attempts made by victims to curtail negative emotional experiences through emotional avoidance behaviours that are negatively reinforced by minimizing or reducing intense affective experiences as a result of abuse. In this context, sexual risk taking may serve to regulate emotional distress by providing short-term, pleasurable experiences (Briere \& Runtz, 1993; Messman-Moore, Walsh, \& DiLillo, 2010). Similar to the self-medication hypothesis involving substance use, youth may engage in sexual risk taking as a short-term, maladaptive coping response to internalizing problems such as diminished self-esteem, depression, and anxiety (e.g., Bersamin et al., 2014; Khan et al., 2009; Lehrer, Shrier, Gortmaker, \& Buka, 2006; Nelson, Zhao, Corrado, Mastrogiannnis, \& Lepore, 2017; Paul, McManus, \& Hayes, 2000; Wong, Choi, Chan, \& Fong, 2017). Taken together, multiple problematic outcomes such as low self-esteem and feelings of depression and anxiety may represent missing links between bullying victimization and health risk behaviours (e.g., substance use and sexual risk taking). 
However, bullying victimization alone may not be the only independent risk factor for substance use and sexual risk taking.

\section{Polyvictimization and Health Risk Behaviours}

Youth who experience one form of victimization are at an increased risk for experiencing at least one other form of victimization over time (Finkelhor, Ormrod, Turner, \& Hamby, 2005a). In addition to the bullying victimization that youth may experience at school, violence and abuse can also occur in the home in the form of childhood maltreatment (Finkelhor, Turner, Hamby, \& Ormrod, 2011). Research on the impact of family violence, particularly childhood maltreatment, is compelling with victims experiencing a range of negative physical and psychological health outcomes not only at the time of being victimized, but also later in life (e.g., Irish, Kobayashi, \& Delahanty, 2009; Newbury et al., 2018; Norman et al., 2012; Springer, Sheridan, Kuo, \& Carnes, 2007). Furthermore, victims of bullying and victims of childhood maltreatment tend to experience many of the same health problems (e.g., Lereya et al., 2015). Interestingly, Duncan (2004) emphasized the importance of family relationships as being related to bullying behaviours. Parent-child relationships at home can influence peer relationships at school (Mohr, 2006; Shields \& Cicchetti, 2001). Parents provide children with the first opportunity to observe and experience interpersonal relationships where children develop attitudes and expectations that carries over to future social interactions (Olsen, Parra, \& Bennett, 2010). Due to early experiences of child maltreatment, children may develop negative expectations regarding the self and others as they come to structure and expect interpersonal relationships to consist of abuse and coercion that would match their earlier familial relationship patterns (Cicchetti, 2016). As a result, there is continuity 
in relational functioning whereby social difficulties in the home environment are in line with social difficulties in the peer environment (Cicchetti, 2016). Indeed, there is evidence to suggest that child physical and sexual abuse may increase the risk for bullying victimization in school (e.g., Bowes et al., 2009; Duncan 1999, 2004; Dussich \& Maekoya, 2007). Children who are maltreated are likely to be submissive in an effort to prevent violence from escalating at home (Hong, Espelage, Grogan-Kaylor, \& AllenMeares, 2012). As a result, these children become easy targets for bullies at school (Schwartz, Dodge, \& Coie, 1993), as they are unlikely to defend themselves when victimized by peers (Shields \& Cicchetti, 2001). Moreover, victims of physical and sexual abuse may develop a sense of powerlessness and lower self-confidence, lack of assertiveness, and inability to establish trust with others (Browne \& Finkelhor, 1986). Because of these traits, children may come to expect to be harmed and consequently fail to protect themselves, which may lead to bullying victimization (Hong et al., 2012).

Most studies that have examined youths' exposure to victimization often focus on separate or single forms of victimization that take place at home (e.g., child maltreatment) or at school (e.g., bullying) instead of exploring the possibility that the same individual may experience more than one kind of victimization (Turner, Finkelhor, \& Omrod, 2010). Polyvictimization can be defined as the exposure to multiple forms of victimization, rather than just multiple episodes of the same kind of victimization, across various life domains (e.g., peers, family, community; Finkelhor, Ormrod, \& Turner, 2007). Not surprisingly, polyvictimization may lead to more severe harmful outcomes for victims (Finkelhor et al., 2007, 2011). However, the majority of research on polyvictimization and the cumulative effects of exposure to victimization in different 
domains focuses on mental health outcomes among youth (e.g., Finkelhor et al., 2007; Finkelhor, Turner, Ormond, Hamby, \& Kracke, 2009; Lereya et al., 2015; Margolin, Vickerman, Oliver, \& Gordis, 2010), and little research on these aspects of polyvictimization has been directed toward substance use and sexual risk taking outcomes specifically. For example, Alexander and colleagues (2018) found that polyvictimization was a better predictor of risky sexual behaviour than individual categories of victimization (e.g., childhood maltreatment, property crime, physical assault, peer/sibling victimization, sexual victimization, and witnessing and indirect victimization) among a sample of college women. In addition, the cumulative exposure to violence across life domains (e.g., school, community, child abuse, and exposure to intimate partner violence) was significantly related to more frequent alcohol and marijuana use and was a better predictor of substance use compared to separate exposures to violence (Wright, Fagan, \& Pinchevsky, 2013). Although these studies provide a foundation for the link between polyvictimization and health risk behaviours, more research is needed that focuses on exposure to bullying victimization together with other categories of victimization.

\section{Current Study}

The main purpose of the current study was to investigate the link between a history of being bullied and two common health risk behaviours in emerging adulthood. Additionally, it aimed to identify potential mental health mediators that may serve as developmental pathways linking bullying victimization with both substance use and sexual risk taking. The secondary purpose of the current study was to investigate the link between polyvictimization and health risk behaviours such as substance use and sexual 
risk taking. The approach-avoidance model of coping (Roth \& Cohen, 1986) was applied to bullying victimization to help understand how and why emerging adults cope with a history of being bullied. The following hypotheses were tested through the current study.

Hypothesis 1. Emerging adulthood is a particularly important developmental period in which to study health risk behaviours considering that youth are especially vulnerable to stressors during the transitional period from adolescence to adulthood and at an elevated risk for engaging in substance use and sexual risk taking (Epstein et al., 2014; White et al., 2006). This heightened period of stress may be one reason why health risk behaviours peak during emerging adulthood (Arnett, 2007). Substance and sexual risk taking may serve as maladaptive coping responses to a variety of different stressors (e.g., loss of family member, low parental support, loss of home to natural disaster; Huebner \& Howell, 2003; Sinha, 2009), one of which may be bullying victimization. Given the perceived uncontrollable nature of bullying victimization, victims may use more avoidance, rather than approach, coping processes to reduce the distress associated with being victimized. Despite the short-term benefits of avoidance coping, it may serve as a maladaptive means for managing emotional experiences (Fuendeling, 1998). Attempts made to manage a stressful situation or experience may increase the likelihood of engaging in high-risk behaviours such as substance use or sexual risk taking (Wills \& Hirky, 1996). Based on this, the first hypothesis was that bullying victimization would have significant direct effects on substance use and sexual risk taking.

Hypotheses 2 and 3. One goal of any coping strategy is to decrease negative affective experiences caused by a stressor (Folkman \& Moskowitz, 2004). To this extent, possible mechanisms through which bullying victimization elevates risk for substance use 
and sexual risk taking is by generating feelings of lower self-esteem, depression, and anxiety, which may activate maladaptive coping behaviours such as substance use and sexual risk taking to manage psychological distress (Newman et al., 2011). Although depression has been reported as a mediator between bullying victimization and substance use, other health risk behaviours such as sexual risk taking and common psychosocial problems related to bullying such as low self-esteem and anxiety have not been examined (Earnshaw et al., 2017; Luk et al., 2010; Zapolski, Rowe, Fisher, Hensel, \& BarnesNajor, 2018). Based on this, the current study tested two more hypotheses. The second hypothesis was that bullying victimization would have significant indirect effects on substance use through lower self-esteem, depressive symptoms, and anxiety symptoms. The third hypothesis was that bullying victimization would have significant indirect effects on sexual risk taking through lower self-esteem, depressive symptoms, and anxiety symptoms.

Exploratory research question. Are youth with a history of polyvictimization at greater risk for engaging in substance and sexual risk taking than youth with only a history of bullying victimization? Although extensive research has focused on the negative outcomes associated with particular types of victimization in specific environments (e.g., peer, family, community; Turner, Shattuck, Finkelhor, \& Hamby, 2016), it is becoming clear that there is a sub-group of children and youth who are exposed to several types of victimization across different contexts and experience severe and persistent psychosocial impairment (Finkelhor, Ormrod, \& Turner, 2009; Turner et al., 2016). In fact, experiencing polyvictimization may have a more adverse impact on health than experiencing a single (serious and repeated) type of victimization 
(Finkelhor et al., 2007; Turner et al., 2010). However, studies examining

polyvictimization often include a broad measure of peer victimization, which may or may not include incidents of bullying, instead of a specific measure of bullying victimization (e.g., Revised Olweus Bully/Victim Questionnaire; Olweus, 1996). When using a measure of bullying victimization (e.g., Bullying and Friendship Interview Schedule; Zwierzynska, Wolke, \& Lereya, 2013), Lereya and colleagues (2015) found being bullied by peers in childhood and being maltreated by parents (i.e., polyvictimization) generally led to worse long-term negative mental health outcomes in emerging adulthood (e.g., depression, anxiety, and overall mental health problems) than being bullied or maltreated separately. Therefore, when measuring polyvictimization, the current study also included a specific measure of bullying victimization. However, given the exploratory nature of examining bullying victimization and childhood maltreatment concurrently in relation to substance use and sexual risk taking, there are no specific a priori hypotheses for these analyses.

\section{CHAPTER 3}

\section{METHOD}

\section{Participants}

A sample of 515 emerging adults between the ages of 18 to 25 (305 women, 210 men; $M_{\text {age }}=20.20, S D=1.67$ ) years was recruited through a psychology participant pool (a resource for recruiting undergraduate students to participate in research) and campus flyers from a university in the Southern Ontario region. The ethnicity of the participants included White (70.70\%), Middle-Eastern (14.70\%), Asian (5.4\%), Black (5.20\%), and Latin American (2.50\%). Participants also reported "Other" for ethnicity (3.30\%). The 
majority of participants reported their sexual orientation to be heterosexual or straight (88.90\%). The majority of participants reported their family's socioeconomic status (SES) to be "about the same" (54.60\%) in wealth as the average Canadian, whereas fewer reported "more wealthy" (31.20\%), and "less wealthy" (13.80\%). Two participants did not report their family's SES $(0.40 \%)$.

\section{Measures}

Demographics. All participants completed a demographics questionnaire asking about age, gender, sexual orientation, ethnicity, socioeconomic status, year of study, and program of study (Appendix A).

Bullying. Participants completed the18-item Victimization subscale from the Revised Olweus Bully/Victim Questionnaire (OBVQ), which is a self-report measure of an individual's involvement in bullying as a victim or bully-victim in the past couple of months (Olweus, 1996). However, the Victimization subscale was slightly modified. For example, instead of asking participants if they had been victimized in the past couple of months, participants were asked to consider the worst school year when they experienced bullying when responding to the questionnaire (Boroughs, Safren, \& O'Cleirigh, 2016). This modification was made to accommodate the sample of university students given that bullying tends to decline during this developmental period (Juvonen \& Graham, 2014). Sample items asked about the frequency of specific forms of victimization (e.g., physical, verbal, relational, and cyber) and included: "I was hit, kicked, pushed, shoved around, or locked indoors," "I was called mean names, was made fun of, or teased in a hurtful way," and "Other students told lies or spread false rumours about me and tried to make others dislike me." Items were rated on a 5-point frequency scale $(1=$ Hasn't happened to $5=$ 
Several times a week; Appendix B). Participants who reported being bullied "only once or twice" was used as the cut-off point to differentiate involvement from noninvolvement in bullying victimization. Although this cut-off point is not entirely in line with traditional theoretical definitions (i.e., bullying is repetitive in nature) and assessment measures (Olweus, 1993a; Smith, del Barrio, \& Tokunaga, 2012), the repetitiveness is not an absolutely necessary feature of bullying (Olweus, 1993b, 1999). A single incident of bullying may still be characterized as bullying victimization, particularly with the advent of cyberbullying (Olweus, 2013). Only participants with a history of bullying victimization were included in the analyses. Items were averaged to create a composite victimization variable with higher scores reflecting more victimization. The Cronbach's alpha for the Victimization subscale was $\alpha=.81$ and previous studies suggest the OBVQ demonstrates good reliability and validity (e.g., Hartung, Little, Allen, \& Page, 2011; Solberg \& Olweus, 2003)

Childhood physical and sexual abuse. To assess childhood and adolescent physical abuse (CPA), participants were asked the following questions: "Has a parent or caregiver ever shoved, slapped, punched, and/or hit you with a closed fist during childhood or adolescence (before the age of 17)," "Were you ever left with marks or bruises on your body," (as a follow up question) and "Has a parent or caregiver ever kicked you, choked you; beaten you up; burned or scalded you; and/or attacked or threatened you with an object or weapon during childhood or adolescence (before the age of 17)". Participants who responded "yes" to either the first or third question were considered as having a history of CPA, whereas participants who responded "no" to both questions indicated no history of CPA (adapted from McKinney, Harris, \& Caetano, 
2009; Appendix C). To assess childhood sexual abuse (CSA), participants were asked: "before you turned 13 years old, did you have any sexual contact with someone who was at least 5 years older than you?" and/or "between the ages of 13 and 16, did you have any sexual contact with someone who was at least 10 years older than you?". Participants who responded "yes" to either question were considered as having a history of CSA, whereas participants who responded "no" to both questions indicated no history of CSA. In the younger age range (before age 13 years), CSA is characterized by any unwanted sexual contact with someone who is at least 5 years older. In the older age range (13 to 16 years), CSA is characterized by any sexual contact by someone who is at least 10 years older or any age with the threat of force or harm (adapted from Kilpatrick, 1992; Leserman, 2005; Appendix C). Sexual contact included genital touching, oral sex, and/or penetrative vaginal or anal intercourse.

Substance use. Participants completed the 10-item Alcohol Use Disorders Identification Test (AUDIT), which assesses alcohol consumption, drinking behaviours, and alcohol-related problems (Saunders, Aasland, Babor, de la Fuente, \& Grant, 1993; Appendix D). The AUDIT is comprised of three subscales: Consumption, Dependence, and Alcohol-Related Problems. Subscales were summed to create a total alcohol use score with higher scores indicating more hazardous and harmful alcohol use. Sample items included: "How often do you have a drink containing alcohol?", "During the last year have you found that you were not able to stop drinking once you started?" and "How often during the last year have you had a feeling of guilt or remorse after drinking?". Items were rated on various 5-point scales. The Cronbach's alpha for the scale was $\alpha=$ .83 with good reliability and validity found in previous studies (e.g., Hays, Merz, \& 
Nicholas, 1995; Meneses-Gaya, Zuardi, Loureiro, \& Crippa, 2009). Participants also completed the 8-item Cannabis Use Disorder Identification Test-Revised (CUDIT-R), which assesses cannabis misuse (Adamson et al., 2010; Appendix E). Items were summed to create a total CUDIT-R score with higher scores indicating more hazardous and harmful cannabis use. Sample items included: "How often do you use cannabis?" and "How often during the past 6 months did you fail to do what was normally expected from you because of using cannabis?". Items were rated on various 5-point scales. The Cronbach's alpha for the scale was $\alpha=.86$ with good reliability and validity found in previous studies (e.g., Annaheim, 2013; López-Pelayo, Batalla, Balcells, Colom, \& Gual, 2015). Scores on the AUDIT and CUDIT-R were significantly correlated $(p<.001)$, therefore both scales were combined to create a composite substance use variable. Substance use only consisted of alcohol and cannabis given that these are two of the most commonly used substances during emerging adulthood (Canadian Alcohol and Other Drug Use Monitoring Survey, 2012) and largely the focus when examined in relation to bullying.

Sexual risk taking. Participants completed the 23-item Sexual Risk Survey (SRS), which assesses the number of sexual risk behaviours in the past six months (Turchik \& Garske, 2009; Appendix F). The SRS is comprised of five subscales: Sexual Risk Taking with Uncommitted Partners, Risky Sex Acts, Impulsive Sexual Behaviours, Intent to Engage in Risky Sexual Behaviours, and Risky Anal Sex Acts. Subscales were combined to create a total sexual risk taking score with higher scores indicating more sexual risk taking behaviours. Sample items from each of the five subscales included: "How many people have you had sex with that you know but are not involved in any sort 
of relationship with (i.e., "friends with benefits")", "How many times have you had vaginal intercourse without a latex or polyurethane condom?", "How many times have you had an unexpected and unanticipated sexual experience?", "How many times have you gone out to bars/parties/ social events with the intent of "hooking up" and having sex with someone?", and "How many times have you had anal sex without a condom?". The Cronbach's alphas for the scale was $\alpha=.70$. Given that the SRS is a relatively newer measure of sexual risk taking, there is preliminary evidence of reliability and validity (e.g., Turchik \& Garske, 2009).

Self-esteem. Participants completed the 10-item Rosenberg Self-Esteem Scale, which assesses an individual's level of global self-esteem (Rosenberg, 1979; Appendix G). Items were summed to create a total self-esteem score with higher scores indicating higher levels of self-esteem. Sample items included: "On the whole, I am satisfied with myself" and "I feel that I have a number of good qualities." Items were rated on a 4-point scale $(0=$ Strongly Agree to $3=$ Strongly Disagree $)$. The Cronbach's alpha for the scale was $\alpha=.91$ and has been found to be a reliable and valid measure of self-esteem even across cultures (e.g., Gray-Little, Williams, \& Hancock, 1997; Schmitt \& Allik, 2005).

Depression. Participants completed the 20 -item Center for Epidemiological Studies Depression Scale-Revised (CESD-R; Eaton, Muntaner, Smith, Tien \& Ybarra, 2004; Appendix H), which measures symptoms of depression as defined by the Diagnostic and Statistical Manual of Mental Disorders, $5^{\text {th }}$ Edition (DSM-5; American Psychiatric Association, 2013). Items were summed to create a total CESD-R score with higher scores indicating higher levels of depressive symptoms. Sample items included: "I felt sad" and "I lost interest in my usual activities." Items were rated on a 5-point scale of 
how often individuals experience depressive symptoms $(0=$ Not at all or less than one day to $4=$ Nearly everyday for 2 weeks). The Cronbach's alpha for the scale was $\alpha=.82$ and previous studies suggest good reliability and validity (e.g., Van Dam \& Earleywine, 2011)

Anxiety. Participants completed the 40-item State-Trait Anxiety Inventory, which contains two subscales. The 20 -item State Anxiety subscale (S-Anxiety) assesses an individual's current state of anxiety at a particular moment and the 20-item Trait Anxiety Scale (T-Anxiety) assesses a general propensity to be anxious (Spielberger, Gorsuch, Lushene, Vagg, \& Jacobs, 1983; Appendix I). Items from the T-Anxiety subscale were summed to create a total anxiety score with higher scores indicating higher levels of anxiety symptoms. Sample items included: "I am a steady person" and "I worry too much over something that really doesn't matter." Items were rated on a 4-point scale $(1=$ almost never to $4=$ almost always). The Cronbach's alpha for the T-anxiety subscale was $\alpha=.88$ and possesses good reliability and validity for assessing trait anxiety in clinical and research settings (e.g., Spielberger, 1989; Spielberger et al., 1983).

Social desirability. Participants completed the 40-item Balanced Inventory of Desirable Responding (BIDR), which identify individuals who distort their responses in an effort to portray themselves positively (Paulhus, 1991). The BIDR is composed of two scales: Self-Deceptive Enhancement (i.e., unconscious tendency to present oneself favourably) and Impression Management (i.e., deliberate tendency to present oneself favourably). It is recommended that the effects of impression management should generally be controlled on self-reports, whereas the effects of self-deception should not be controlled when measuring constructs related to adjustment (e.g., self-esteem, anxiety, 
depression) because it undermines predictive power (Paulhus, 1986). Moreover, impression management tends to be a more serious threat to the validity of self-report results than self-deception (Vispoel \& Tao, 2013). Therefore, only the Impression Management scale was used. Sample items included: “I don't gossip about other people's business" and "I never take things that don't belong to me." Items were rated on a 7-point scale $(1=$ not true to $7=$ very true $)$. The scale was dichotomized $(0=$ item scores of 1 to 5 and $1=$ item scores of 6 or 7) according to the guidelines recommended by Paulhus (1991). Dichotomized scores were then summed across all items to form the Impression Management scale. The Cronbach's alpha for the scale was $\alpha=.75$ and previous studies suggest it demonstrates acceptable reliability and validity (e.g., Lanyon \& Carle, 2007; Li \& Bagger, 2007; Paulhus, 1991)

\section{Procedure}

Undergraduate students recruited through the University of Windsor participant pool received a web link to access the study online from their own personal computer. Undergraduate students interested in the current study from outside the participant pool were recruited through an electronic or paper flyer containing information about the study and a web link to access with a unique identification number to access the study online. Following informed consenting procedures, all participants, regardless of pool or outside recruitment, completed a series of questionnaires. Given that some of the questions ask about sensitive information, completing the study online and in the privacy of their own home may encourage participants to respond more honestly and help reduce social desirability bias (Kays, Gathercoal, \& Buhrow, 2012). Directions in the consenting procedure requested that participants choose to complete the measures in a private place 
undistracted and in one sitting. To avoid the possibility of one questionnaire systematically influencing participants' responses on subsequent forms, questionnaires were administered in random order. After completing the questionnaires, participants were debriefed about the nature of the study as well as provided with resources to additional support services through the university and community should the content of the questionnaires cause any distress. Participants were offered 0.5 credit as part of the participant pool. Students outside of the participant pool were entered into a draw to win one of three $\$ 50$ gift cards as compensation.

\section{CHAPTER 4}

\section{RESULTS}

\section{Preliminary Analyses}

Power. An a priori power analysis was conducted using G*Power 3 (Faul, Erdfelder, Lang, \& Buchner, 2007) to determine the required sample size for a logistic regression. An alpha value of .05 , desired power of .80 , and odds ratio of 3.47 were specified (Chen, Cohen, \& Chen, 2010) and the analysis estimated that a total of 127 participants were recommended.

Missing data. Preliminary analyses were conducted using SPSS 24. All variables had less than $2 \%$ missing data. However, variables with missing data did not change the

overall pattern of results as indicated by Little's MCAR test $\left(\chi^{2}(9)=5.34, p=.804\right)$. Path analysis was conducted using Full Information Maximum Likelihood, which utilizes all available data points, reduces the bias in parameter estimates that missing data can introduce (Schafer \& Graham, 2002), and performs well when data are missing completely at random (Enders \& Bandalos, 2001). Logistic regressions were conducted 
using the default listwise deletion, which excludes cases with any missing values, can be effective if there is little missing data (Schafer \& Graham, 2002) and gives unbiased estimates when data are missing completely at random (Allison, 2001).

Univariate assumptions. Data were screened for univariate assumptions of univariate normality, skewness, kurtosis, and outliers. Shapiro-Wilk tests were significant for all variables $(p s<.05)$ indicating that univariate normality was violated. However, in larger samples the Shapiro-Wilk test tends to be sensitive to small deviations from univariate normality (Field, 2013). Therefore, histograms and Q-Q plots, skew and kurtosis values, and outliers were also examined. A visual inspection of the histograms and Q-Q plots for all the variables indicated that bullying victimization, substance use, and sexual risk taking were not normally distributed. Substance use and sexual risk taking, but not bullying victimization, had skewness values that exceeded +2 and -2 , kurtosis values that exceeded +3 and -3 , and all three variables had outliers based on raw values with $z$ scores greater than $|3.29|$ (Tabachnick \& Fidell, 2013). However, considering that all of these variables tend to be lower in frequency within the emerging adult population (e.g., people are more likely to not experience bullying), positive skew and outliers were expected. Potential outliers were included in the analysis for these variables except sexual risk taking because it reflected responses toward the higher end of bullying victimization and substance use, which were of interest and because responses for these variables were within acceptable limits (i.e., each of them did not exceed their respective point scales). Furthermore, considering that self-report data on sexual behaviour may be underreported or exaggerated (Morrison-Beedy, Carey, \& Tu, 2006), positive skew and outliers were expected for the sexual risk taking variable. To reduce 
the impact of the outliers, extreme values were winsorized by replacing them with the next highest (raw) value that was not an outlier (i.e., a raw value with a $z$ score below the cut-off of $|3.29|$ (Field, 2013). As a result, this reduced the skew and kurtosis of the sexual risk taking variable, which improved the distribution. Transformations were not applied to the variables because transformed variables can make the data difficult to interpret (Field 2013; Tabachnick \& Fidell, 2013).

\section{Multivariate assumptions.}

Path analysis. I screened the data for multivariate assumptions of multicollinearity, multivariate normality (together with outliers, linearity, and homoscedasticity), independence of observations, and an adequate sample size. First, I screened the data for multicollinearity. Initially, a correlational matrix was examined for multicollinearity. No variables had correlations greater than .80 suggesting there was no multicollinearity (Field, 2013). Furthermore, the variance inflation factor (VIF) for all variables was less than 10 indicating no multicollinearity between variables (Bowerman \& O’Connell, 2000). In addition, tolerance values for all variables were greater than 0.2 suggesting the absence of multicollinearity (Menard, 1995).

Next, I assessed multivariate normality. Visual inspection of the histograms and P-P plots indicated that multivariate normality was violated for both substance use and sexual risk taking. To identify multivariate outliers, I examined Mahalanobis distances, Cook's distances, and leverage values. Values for Cook's distance were less than 1 and no values were three times greater than the average leverage value, indicating there were no influential cases for both variables (Field, 2013). However, six Mahalanobis distances were greater than the chi square critical value (set at an alpha of .001), indicating 
potential outliers. Analyses conducted with and without these six Mahalanobis distances did not improve the pattern of results so they were not removed from the study. To assess linearity and homoscedasticity, a visual inspection of bivariate scatterplots indicated that the assumption of linearity was met, and a visual inspection of the residual scatterplots indicated that the assumption of homoscedasticity was not met for both substance use and sexual risk taking. Despite the fact that the data failed to meet the assumptions of multivariate normality and homoscedasticity, bootstrapping with bias-corrected confidence intervals using 5,000 samples was conducted for subsequent analyses, as this robust procedure does not rely on assumptions of multivariate normality and homoscedasticity and is often preferred over transforming variables if assumptions are violated (Field, 2013; Shrout \& Bolger, 2002).

For the assumption of independence of observations, random sampling was part of the design and the data set was inspected to ensure the same participant did not complete the study more than once (e.g., checking names and IP addresses for duplicates). As such, independence of observations can be assumed. Finally, the sample size consisted of 515 participants. Kline (2016) recommends a minimum sample size of 200 participants. Thus, the sample size appeared to be adequate.

Logistic regression. I screened the data for multivariate assumptions including the dependent variables measured on a dichotomous scale, independence of observations, and linearity between any continuous predictors and the logit of the dependent variables. First, both dependent variables were dichotomized. Substance use was dichotomized into yes (i.e., has used cannabis and/or alcohol at least one or more times) and no (i.e., has not used cannabis and/or alcohol). Sexual risk taking was dichotomized into yes (i.e., has 
engaged in sexual risk taking at least one or more times) and no (i.e., has not engaged in sexual risk taking). Independence of observations was met as discussed above. Finally, I assessed the linear relationships between the independent variables and the logit of the dependent variables using the Box-Tidwell procedure. None of the interactions were significant, indicating that the linearity of the logit for all variables was met.

\section{Correlations}

Effect sizes of correlations were small to large (see Table 1 for descriptive statistics and Table 2 for correlations). Identifying as a man was significantly correlated with substance use $\left(r_{s}=-.12, p=.008\right)$ and lower self-esteem $(r=-.19, p<.001)$. Identifying as a woman was significantly correlated with depressive symptoms $(r=.13, p$ $=.003)$ and anxiety symptoms $(r=.18, p<.001)$. Childhood physical abuse was significantly positively correlated with childhood sexual abuse $(r=.11, p=.02)$, bullying victimization $(r=.14, p=.003)$, substance use $\left(r_{s}=.14, p=.009\right)$, depressive symptoms $(r=.17, p<.001)$, and anxiety symptoms $(r=.13, p=.002)$. Childhood sexual abuse was significantly positively correlated with bullying victimization $(r=.20, p<.001)$, substance use $\left(r_{s}=.11, p=.03\right)$, and sexual risk taking $\left(r_{s}=.16, p<.001\right)$. Bullying victimization was significantly positively correlated with substance use $\left(r_{s}=.20, p<\right.$ $.001)$, sexual risk taking $\left(r_{s}=.20, p<.001\right)$, depressive symptoms $(r=.36, p<.001)$, and anxiety symptoms $(r=.30, p<.001)$. Bullying victimization was significantly negatively correlated with self-esteem $(r=-.28, p<.001)$. Substance use was significantly positively correlated with sexual risk taking $\left(r_{s}=.47, p<.001\right)$, depressive symptoms $\left(r_{s}=.18, p<\right.$ $.001)$, and anxiety symptoms $\left(r_{s}=.10, p=.03\right)$. Sexual risk taking was significantly positively correlated with depressive symptoms $\left(r_{s}=.12, p=.008\right)$. Self-esteem was 
significantly negatively correlated with depressive symptoms $(r=-.57, p<.001)$ and anxiety symptoms $(r=-.73, p<.001)$ and significantly positively correlated with impression management $(r=.13, p=.003)$. Depressive symptoms were significantly positively correlated with anxiety symptoms $(r=.71, p<.001)$. Finally, anxiety symptoms were significantly negatively correlated with impression management $(r=$ $.12, p=.007)$. 
Table 1

Descriptive Statistics for Key Variables

\begin{tabular}{|c|c|c|c|c|c|c|c|c|}
\hline \multirow[b]{2}{*}{ Variable } & \multicolumn{4}{|c|}{ Bullying victimization $(n=456)$} & \multicolumn{4}{|c|}{ None $(n=59)$} \\
\hline & $n$ & $\%$ & $M$ & $S D$ & $n$ & $\%$ & $M$ & $S D$ \\
\hline CPA & 130 & 28.51 & - & - & 12 & 20.34 & - & - \\
\hline CSA & 30 & 6.58 & - & - & 1 & 1.69 & - & - \\
\hline Substance use & 379 & 83.11 & 8.00 & 6.78 & 50 & 84.75 & 5.58 & 5.29 \\
\hline Sexual risk taking & 272 & 59.65 & 5.59 & 7.96 & 35 & 59.32 & 2.48 & 3.45 \\
\hline Self-esteem & 278 & 60.96 & 27.25 & 5.01 & 20 & 33.89 & 31.53 & 5.15 \\
\hline Depressive symptoms & 342 & 75.00 & 23.51 & 8.74 & 32 & 54.24 & 17.28 & 4.33 \\
\hline Anxiety symptoms & 306 & 67.11 & 45.41 & 10.76 & 22 & 37.29 & 38.64 & 8.65 \\
\hline
\end{tabular}

Note. CPA $=$ Childhood Physical Abuse; CSA $=$ Childhood Sexual Abuse. 
Table 2

Correlations for All Study Variables

\begin{tabular}{|c|c|c|c|c|c|c|c|c|c|c|}
\hline Variable & 1 & 2 & 3 & 4 & 5 & 6 & 7 & 8 & 9 & 10 \\
\hline 1. Gender & - & -.06 & .04 & .05 & $-.12 * *$ & -.05 & $-.19 * * *$ & $.13 * *$ & $.18 * * *$ & -.02 \\
\hline 2. CPA & & - & $.11 * * *$ & $.14 * *$ & $.12 * *$ & -.01 & -.07 & $.17 * * *$ & $.13 * * *$ & -.05 \\
\hline 3. CSA & & & - & $.20 * * *$ & $.11 *$ & $.16^{* * *}$ & -.05 & .07 & .06 & -.07 \\
\hline 4. Bullying & & & & - & $.20 * * *$ & $.20 * * *$ & $-.28 * * *$ & $.36 * * *$ & $.30 * * *$ & .09 \\
\hline 5. $\mathrm{SU}^{\mathrm{a}}$ & & & & & - & $.47 * * *$ & -.03 & $.18^{* * *}$ & $.10^{*}$ & -.05 \\
\hline 6. $\mathrm{SR}^{\mathrm{a}}$ & & & & & & - & -.02 & $.12 * *$ & .03 & -.04 \\
\hline 7. SE & & & & & & & - & $-.57 * * *$ & $-.73 * * *$ & $.13 * *$ \\
\hline 8. Depression & & & & & & & & - & $-.71 * * *$ & -.05 \\
\hline 9. Anxiety & & & & & & & & & - & $-.12 * *$ \\
\hline 10. IM & & & & & & & & & & - \\
\hline
\end{tabular}

Note. $\mathrm{CPA}=$ Childhood Physical Abuse; $\mathrm{CSA}=$ Childhood Sexual Abuse; Bullying = Bullying Victimization; SU = Substance Use; $\mathrm{SR}=$ Sexual Risk Taking; SE = Self-esteem; Depression = Depressive Symptoms; Anxiety = Anxiety Symptoms; IM = Impression Management.

Gender coded as $0=$ Man, $1=$ Woman.

aSpearman correlations.

$* p<.05 . * * p<.01 . * * * p<.001$. 


\section{Primary Analyses}

A path analysis was conducted using MPlus version 7.4 (Muthén \& Muthén, 1998-2017) to test for significant direct effects of bullying victimization on substance use and sexual risk taking, and the indirect effects of bullying victimization through lower self-esteem, depressive symptoms, and anxiety symptoms simultaneously. Although sex differences in coping strategies may be decreasing over time (Matud, 2004), men are still more likely to engage in the externalizing behaviours that were analyzed in the current study (e.g., Chen \& Jacobson, 2012; Puente et al., 2013). Therefore, I controlled for gender. Furthermore, additional forms of victimization such as childhood physical and sexual abuse were also controlled for given its association with substance use and sexual risk taking (e.g., Abajobir et al., 2017; Lo \& Cheng, 2007). All paths were estimated and error terms were correlated resulting in a just-identified (saturated) model with fit indices that were not informative (Kline, 2016; Pearl, 2012). Most mediation models tend to be just-identified (Hayes, 2013; Hayes, Montoya, \& Rockwood, 2017) and previous theory and empirical research on bullying victimization, negative mental health outcomes, and substance use and sexual risk taking suggest that all paths should be included in the model. Furthermore, although a good fitting model is important, what is just as (or even more) important are the estimates of the effects of one variable on another variable and the conclusions made about relationships between variables included in the model that support or do not support hypotheses of interest (Hayes et al., 2017). Parameters for direct effects were estimated using Maximum Likelihood Robust to correct for nonnormal distributions of variables. To test for indirect effects, $95 \%$ bias-corrected confidence intervals with 5,000 bootstrapped samples were estimated using Maximum 
Likelihood, and any confidence interval that did not cross zero was considered a significant indirect effect (Shrout \& Bolger, 2002).

Consistent with hypothesis 1 , bullying victimization had significant direct effects on substance use $(\beta=.14, S E=.05, p=.008)$ and sexual risk taking $(\beta=.11, S E=.05, p$ $=.030$; see Table 3 and Figure 1 for direct path coefficients). In support of hypothesis 2, there were significant indirect effects of bullying victimization on substance use through lower self-esteem $(B=-0.20, S E=.10, \beta=-.03,95 \% \mathrm{BCa} C \mathrm{CI}[-0.50,-0.001])$ and depressive symptoms $(B=0.52, S E=.21, \beta=.10,95 \% \mathrm{BCa} C \mathrm{C}[0.03,0.12])$. Furthermore, consistent with hypothesis 3, there were also significant indirect effects of bullying victimization on sexual risk taking through lower self-esteem $(B=-0.40, S E=$ $.19, \beta=-.05,95 \% \mathrm{BCa} C \mathrm{C}[-0.10,-0.02])$ and anxiety symptoms $(B=0.36, S E=.18, \beta=$ $.04,95 \%$ BCa CI $[0.01,0.10])$. 
Table 3

Direct Paths among Bullying Victimization, Mental Health Outcomes, and Health Risk Behaviours

\begin{tabular}{|c|c|c|c|c|c|c|c|c|c|c|}
\hline \multirow[b]{2}{*}{ Variable } & \multicolumn{2}{|l|}{ Self-esteem } & \multicolumn{2}{|c|}{ Depressive symptoms } & \multicolumn{2}{|c|}{ Anxiety symptoms } & \multicolumn{2}{|l|}{ Substance use } & \multicolumn{2}{|c|}{ Sexual risk taking } \\
\hline & $B(S E)$ & $\beta(\mathrm{SE})$ & $B(S E)$ & $\beta(S E)$ & $B(S E)$ & $\beta(S E)$ & $B(S E)$ & $\beta(S E)$ & $B(S E)$ & $\beta(S E)$ \\
\hline Gender $^{\mathrm{a}}$ & $-1.92(.53)^{* * *}$ & $-.16(.04)^{* * *}$ & $1.86(.73)^{*}$ & $.11(.04)^{* *}$ & $1.42(.88)^{* *}$ & $.14(.04)^{* * *}$ & $-1.22(.48)^{*}$ & $-.12(.05)^{*}$ & $-0.55(.61)$ & $-.05(.05)$ \\
\hline $\mathrm{CPA}$ & $-0.88(.64)$ & $-.07(.05)$ & $1.89(.82)^{*}$ & $.10(.04)^{*}$ & $-0.46(1.13)$ & $-.01(.05)$ & $0.92(.65)$ & $.08(.05)$ & $-0.88(.64)$ & $-.05(.04)$ \\
\hline CSA & $0.86(1.01)$ & $.04(.04)$ & $-0.22(1.76)$ & $-.01(.05)$ & $-0.60(2.19)$ & $-.01(.05)$ & $0.27(1.14)$ & $.01(.06)$ & $2.69(1.59)$ & $.11(.07)$ \\
\hline BV & $-1.80(.40)^{* * *}$ & $-.22(.05)^{* * *}$ & $3.92(.56)^{* * *}$ & $.32(.05)^{* * *}$ & $4.12(.72)^{* * *}$ & $.24(.05)^{* * *}$ & $1.00(.39)^{*}$ & $.14(.05)^{* *}$ & $1.00(.48)^{*}$ & $.11(.05)^{*}$ \\
\hline SE & - & - & - & - & - & - & $0.10(.05)$ & $.11(.05)^{*}$ & $0.22(.09)^{*}$ & $.21(.07)^{* *}$ \\
\hline DEP & - & - & - & - & - & - & $0.13(.04)^{* *}$ & $.23(.08)^{* *}$ & $0.01(.04)$ & $.02(.05)$ \\
\hline ANX & - & - & - & - & - & - & $0.01(.02)$ & $.04(.07)$ & $0.05(.02)$ & $.17(.07)^{*}$ \\
\hline$R^{2}$ & .08 & & .13 & & .10 & & .10 & & .04 & \\
\hline
\end{tabular}

Note. CPA = Childhood Physical Abuse; $\mathrm{CSA}=$ Childhood Sexual Abuse; BV = Bullying Victimization; $\mathrm{SE}=\mathrm{Self}-\mathrm{esteem}$; DEP = Depressive Symptoms; ANX = Anxiety Symptoms.

Gender coded as $0=$ Man, $1=$ Woman.

$B=$ unstandardized path coefficients; $\beta=$ standardized path coefficients.

$* p<.05 . * * p<.01 . * * * p<.001$. 


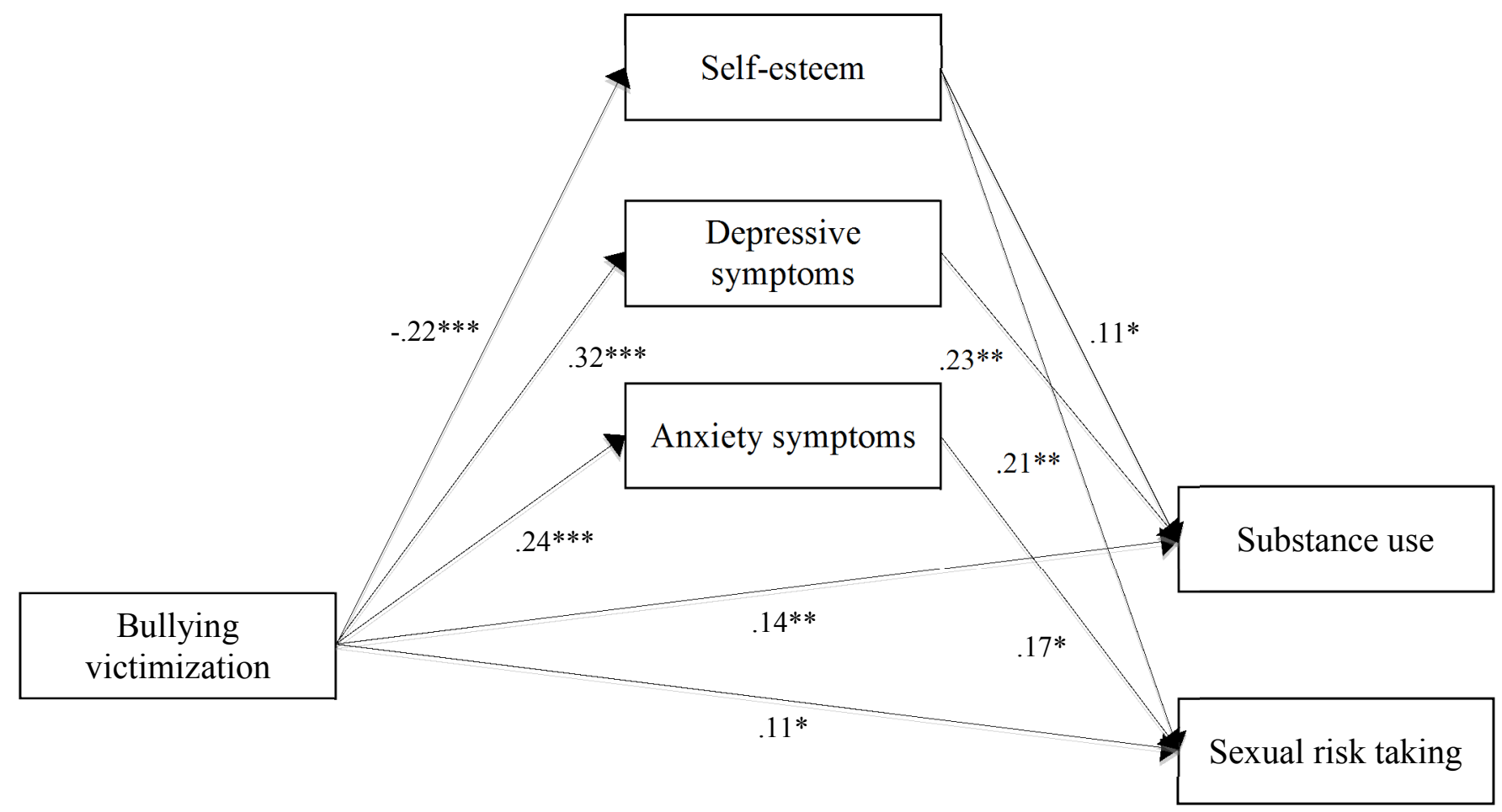

Figure 1. Significant direct paths for the overall model. All paths, covariances, and disturbances were estimated, but only significant paths are displayed for ease of presentation; No line indicates no significant path. Standardized path coefficients are presented for direct paths; see in text for indirect path coefficients and confidence intervals.

${ }^{*} p<.05 . * * p<.01 . * * * p<.001$. 


\section{Secondary Analyses}

Two logistic regression analyses were conducted using SPSS 24 to determine whether or not youth with a history of both bullying victimization and childhood maltreatment (i.e., polyvictimization) were more likely to engage in health risk behaviours such as substance use and sexual risk taking. Two dummy variables were created. The first variable included participants who were only bullied $(0=$ no history of bullying victimization and $1=$ a least one or more incidents of bullying victimization). The second variable included participants who were both bullied and maltreated $(0=$ no history of polyvictimization and $1=$ a least one or more incidents of polyvictimization). Variables were entered hierarchically into logistic regression models with gender in step one and bullying victimization and polyvictimization in step two for both substance use and sexual risk taking dependent variables.

Substance use. The addition of gender in the first step revealed a good model fit for substance use as indicated through Hosmer and Lemeshow's test, $\chi^{2}(1)=1.06, p=$ .303 , Cox and Snell $R^{2}=.014$, and Nagelkerke $R^{2}=.018$. However, comparison of loglikelihood ratios for models with and without gender showed no significant improvement with the addition of this variable, $\chi^{2}(1)=1.35, p=.246$. The model correctly classified $56.3 \%$ of cases. The addition of bullying victimization and polyvictimization in the second step revealed a good model fit for substance use as indicated through Hosmer and Lemeshow's test, $\chi^{2}(3)=2.58, p=.461$, Cox and Snell $R^{2}=.024$, and Nagelkerke $R^{2}=$ .032. Comparison of log-likelihood ratios for models with and without bullying victimization and polyvictimization showed significant improvement with the addition of these variables, $\chi^{2}(3)=8.04, p=.041$. The model correctly classified $57.7 \%$ of cases 
with the addition of bullying victimization and polyvictimization. Results of the logistic regression revealed that bullying victimization was a significant predictor of substance use, $B=0.82, S E=.40$, Wald $\chi^{2}(1)=4.11, p=.043$. Odds ratio suggested that youth with a history of bullying victimization were $2.26(95 \% \mathrm{CI}[1.02,4.97])$ times more likely to engage in substance use. Furthermore, polyvictimization was also a significant predictor of substance use, $B=1.00, S E=.42$, Wald $\chi^{2}(1)=5.14, p=.023$. Odds ratio suggested that youth with a history of polyvictimization were $2.61(95 \% \mathrm{CI}[1.13,6.00])$ times more likely to engage in substance use.

Sexual risk taking. The addition of gender in the first step revealed a good model fit for sexual risk taking as indicated through Hosmer and Lemeshow's test, $\chi^{2}(1)$ $=0.02, p=.899$, Cox and Snell $R^{2}=.016$, and Nagelkerke $R^{2}=.024$. However, comparison of log-likelihood ratios for models with and without gender showed no significant improvement with the addition of this variable, $\chi^{2}(1)=0.10, p=.814$. The model correctly classified $79.0 \%$ of cases. The addition of bullying victimization and polyvictimization in the second step revealed a good model fit for sexual risk taking as indicated through Hosmer and Lemeshow's test, $\chi^{2}(3)=0.83, p=.842$, Cox and Snell $R^{2}$ $=.032$, and Nagelkerke $R^{2}=.051$. Comparison of log-likelihood ratios for models with and without bullying victimization and polyvictimization showed significant improvement with the addition of these variables, $\chi^{2}(3)=9.40, p=.024$. The model correctly classified $79.4 \%$ of cases with the addition of bullying victimization and polyvictimization. Results of the logistic regression revealed that bullying victimization was a significant predictor of sexual risk taking, $B=1.21, S E=.40$, Wald $\chi^{2}(1)=9.04, p$ $=.003$. Odds ratio suggested that youth with a history of bullying victimization were 3.35 
(95\% CI $[1.52,7.38])$ times more likely to engage in sexual risk taking. Furthermore, polyvictimization was also a significant predictor of sexual risk taking, $B=1.32, S E=$ .49 , Wald $\chi^{2}(1)=9.06, p=.003$. Odds ratio suggested that youth with a history of polyvictimization were 3.74 (95\% CI $[1.58,8.81])$ times more likely to engage in sexual risk taking. A summary of the study's hypotheses, data analyses, and results are presented in Table 4. 
Table 4

Summary of Hypotheses, Data Analyses, and Results

\begin{tabular}{|c|c|c|c|c|c|c|}
\hline Hypothesis & $\begin{array}{l}\text { Exogenous/ } \\
\text { Independent } \\
\text { variable(s) }\end{array}$ & Mediators & $\begin{array}{l}\text { Endogenous/ } \\
\text { Dependent } \\
\text { variable(s) }\end{array}$ & Prediction & Analysis & Results \\
\hline 1 & $\begin{array}{l}\text { Bullying } \\
\text { victimization }\end{array}$ & - & $\begin{array}{l}\text { Substance use and } \\
\text { sexual risk taking }\end{array}$ & $\begin{array}{l}\text { Bullying victimization will have } \\
\text { significant direct effects on substance } \\
\text { use and sexual risk taking }\end{array}$ & Path analysis & $\begin{array}{l}\text { Direct effects of bullying } \\
\text { victimization on substance } \\
\text { use and sexual risk taking }\end{array}$ \\
\hline 2 & $\begin{array}{l}\text { Bullying } \\
\text { victimization }\end{array}$ & $\begin{array}{l}\text { Self-esteem, depressive } \\
\text { symptoms, and anxiety } \\
\text { symptoms }\end{array}$ & $\begin{array}{l}\text { Substance use and } \\
\text { sexual risk taking }\end{array}$ & $\begin{array}{l}\text { Bullying victimization will have } \\
\text { significant indirect effects on } \\
\text { substance use through lower self- } \\
\text { esteem, depressive symptoms, and } \\
\text { anxiety symptoms }\end{array}$ & Path analysis & $\begin{array}{l}\text { Indirect effects of bullying } \\
\text { victimization on substance } \\
\text { use through lower self- } \\
\text { esteem and depressive } \\
\text { symptoms, but not anxiety } \\
\text { symptoms }\end{array}$ \\
\hline 3 & $\begin{array}{l}\text { Bullying } \\
\text { victimization }\end{array}$ & $\begin{array}{l}\text { Self-esteem, depressive } \\
\text { symptoms, and anxiety } \\
\text { symptoms }\end{array}$ & $\begin{array}{l}\text { Substance use and } \\
\text { sexual risk taking }\end{array}$ & $\begin{array}{l}\text { Bullying victimization will have } \\
\text { significant indirect effects on sexual } \\
\text { risk taking through lower self-esteem, } \\
\text { depressive symptoms, and anxiety } \\
\text { symptoms }\end{array}$ & Path analysis & $\begin{array}{l}\text { Indirect effects of bullying } \\
\text { victimization on sexual risk } \\
\text { taking through lower self- } \\
\text { esteem and anxiety } \\
\text { symptoms, but not } \\
\text { depressive symptoms }\end{array}$ \\
\hline $\begin{array}{l}\text { No a priori } \\
\text { hypothesis }\end{array}$ & $\begin{array}{l}\text { Bullying } \\
\text { victimization and } \\
\text { polyvictimization }\end{array}$ & - & $\begin{array}{l}\text { Substance use and } \\
\text { sexual risk taking }\end{array}$ & - & $\begin{array}{l}\text { Logistic } \\
\text { regression }\end{array}$ & $\begin{array}{l}\text { Bullying victimization and } \\
\text { polyvictimization predicted } \\
\text { substance use and sexual } \\
\text { risk taking }\end{array}$ \\
\hline
\end{tabular}




\section{CHAPTER 5}

\section{DISCUSSION}

The main purpose of the current study was to explore the association between bullying victimization and two common health risk behaviours (e.g., substance use and sexual risk taking) among emerging adults. Bullying victimization can be conceptualized as a chronic stressor (La Greca \& Landoll, 2011) that youth may attempt to cope with in unhealthy ways. Although previous research has examined the relationship between bullying and coping (e.g., Newman et al., 2011; Topper et al., 2011), the current study addressed a gap in the literature by focusing on mental health mediators that may serve as developmental pathways linking bullying victimization and two health risk behaviours as potential maladaptive coping strategies. Results offered mixed support for hypotheses. Bullying victimization had significant direct effects on substance use and sexual risk taking. In addition, bullying victimization had significant indirect effects on substance use through lower self-esteem and depressive symptoms and significant indirect effects on sexual risk taking through lower self-esteem and anxiety symptoms. These findings are consistent with previous research (e.g., Luk et al., 2010; Zapolski et al., 2018), but also extend the literature by highlighting additional psychosocial problems (e.g., selfesteem, anxiety) that may function as developmental pathways linking bullying victimization with both substance use and sexual risk taking. Direct and indirect effects among bullying victimization, negative mental health outcomes, and health risk behaviours are discussed in further detail below.

The secondary purpose of the current study was to investigate the relationship between polyvictimization and health risk behaviours such as substance use and sexual 
risk taking. Previous research has often focused on the effects of polyvictimization and the cumulative effects of multiple forms of victimization on mental health outcomes among youth (e.g., Finkelhor et al., 2007; Finkelhor et al., 2009; Lereya et al., 2015; Margolin et al., 2010). However, research is sparse on the links between polyvictimization and substance use and sexual risk taking outcomes (e.g., Alexander, Amerigo, \& Harrelson, 2018; Wright, Fagan, \& Pinchevsky, 2013), particularly when one type of the victimization includes bullying (e.g., Lereya et al., 2015). Despite no a priori hypotheses, youth with a history of polyvictimization were more likely to engage in substance use and sexual risking taking than those with only a history of bullying victimization. These findings provide support for the idea that polyvictimization may lead to more adverse outcomes for victims (Finkelhor et al., 2007, 2011) and contribute to the literature by focusing on behavioural health outcomes such as substance and sexual risk taking that are often neglected in favour of psychological adjustment problems (Wright et al., 2013). The associations between polyvictimization and health risk behaviours are discussed in further detail below.

\section{Direct Effects}

Substance use. In the current study, bullying victimization had a significant direct effect on substance use. This finding is consistent with previous research as victims of both traditional bullying (e.g., physical, relational) and cyberbullying were more likely to use substances such as alcohol and cannabis compared to uninvolved youth (Copeland et al., 2013; Goebert et al., 2011; Kim et al., 2011; Kritsotakis et al., 2017; Luk et al., 2010; Mitchell et al., 2007; Radliff et al., 2012; Rospenda et al., 2013; Sánchez et al., 2017). Although experimenting with alcohol and cannabis is normative during emerging 
adulthood (Arnett, 2000), victims of bullying may be more likely to engage in substance use in riskier ways (i.e., earlier or heavier use) that influence the development of substance use problems (Sullivan, Farrell, \& Kliewer, 2006). Bullying victimization may initiate frequent substance use if youth lack alternative coping skills and support for effectively managing the experience of victimization (Goebert et al., 2011). The link between bullying victimization and substance use provides support for self-medication models of substance use in which occasional or heavy substance use and their psychotropic effects act as a coping mechanism for specific stressors (Khantzian, 1997).

In addition, Houbre and colleagues (2006) suggest that engaging in substance use may improve one's social image within a peer group. Considering that bullies tend to target out-group peers such as those who are perceived to be submissive (Schwartz et al., 1998) and physically weak (Hodges \& Perry, 1999), have no friends (Veenstra, Lindenberg, Munniksma, \& Dijkstra, 2010), and/or have lower status in the peer group (Hodges \& Perry, 1999), substances may be used in an attempt to alter peer perceptions and reduce bullying (Houbre, Tarquinio, Thuillier, \& Hergott, 2006). Consistent with this expectation, the Partnership Attitude Tracking Study (2008) reported that $65 \%$ of adolescents say they use drugs to "look cool." Self-worth depends on gaining (or not gaining) the approval of others, and the desire to be socially accepted by peers can lead youth to engage in health risk behaviours (e.g., substance use) despite the harmful consequences (Houbre et al., 2006). Therefore, the reasons for engaging in substance use may be twofold. First, substances are used as a maladaptive coping strategy to selfmedicate due to the stressors associated with being bullied. Second, substance use may function as an alternative, but still maladaptive, coping strategy to reduce bullying 
victimization directly by attempting to increase peer acceptance and signal to others one's in-group membership. Overall, bullying victimization serves as an independent risk factor for substance use.

Sexual risk taking. Bullying victimization also had a significant direct effect on sexual risk taking. This finding is consistent with a growing body of literature showing that youth who report being bullied are at an elevated risk for engaging in sexual risk taking behaviours (e.g., Bouffard \& Koeppel, 2017; Kritsotakis et al., 2017; Li, DiStefano et al., 2014; Robinson \& Espelage, 2013; Russell et al., 2011). Similar to substance use, sexual behaviour is normative during emerging adulthood (Arnett, 2000), but individuals with a history of bullying victimization may be prone to engaging in sexual behaviour in riskier ways (e.g., not using contraceptives) that harm one's health (contracting a STI, unplanned pregnancy; Brody, 2010; Diamond \& Huebner, 2012; Malhotra, 2008). For instance, bullying victimization may lead to risky decisions when it comes to negotiating contraceptive use during sexual interactions. Negotiating contraceptive use can sometimes be confrontational especially if a partner is adamant about not using contraceptives (Kritsotakis et al., 2017). Victims of bullying often feel powerless, perceive the harm against them to be beyond their control, and look to avoid creating further conflict. This perceived lack of control and conflict avoidance in their peer interactions may translate to their romantic interactions whereby the inability of victims to take control of decisions that involve them, and others, jeopardize safe sexual practices (Kritsotakis et al., 2017).

Furthermore, victims of bullying are less likely to be in dating relationships (Arnocky \& Vaillancourt, 2012), and a lack of sexual experience in university is not 
consistent with current societal ideals (Kritsotakis et al., 2017). As mentioned previously, victims are often targeted because they are perceived to be submissive, physically weak, and/or unpopular (Hodges \& Perry, 1999; Schwartz et al., 1998), which are traits that are less likely to lead to sexual opportunities (de Bruyn, Cillessen, \& Weisfeld, 2012; Mayeux, Sandstrom, \& Cillessen, 2008; Prinstein, Meade \& Cohen, 2003). However, risky sexual activity may provide easier access to engaging in sexual behaviour (e.g., activity with uncommitted partners). Individuals who feel isolated or lonely as a result of being bullied may engage in risky sexual activity as a means to achieve affection and intimacy, despite the health risks (Torres \& Gore-Felton, 2007; Wilson \& Widom, 2008). Thus, similar to the self-medication models of substance use, sexual risk taking also appears to serve as a maladaptive coping mechanism when exposed to distress with bullying victimization as an independent risk factor for sexual risk taking. Taken together, youth many engage in health risk behaviours such as substance use and sexual risking as maladaptive ways of coping with past histories of bullying victimization.

Despite the fact that approach coping strategies (e.g., social support, problem solving) allow for appropriate responses to distress (Roth \& Cohen, 1986), an approach orientation is typically used when the distress is perceived to be within an individual's control (Hampel et al., 2009). However, bullying victimization involves harm directed toward another person of which the affected person has no control over. Thus, avoidance rather than approach strategies may be used to minimize the distress associated with being victimized. Although avoidance coping can alleviate distress to some degree through distancing or distraction, it ultimately serves as a maladaptive means for regulating emotional experiences (Fuendeling, 1998) and may increase the likelihood of 
engaging in high risk behaviours such as substance use or risky sexual activity (Wills \& Hirky, 1996). Coping theory (Lazarus \& Folkman, 1984) proposes that youth may engage in high risk behaviours in response to increased psychological distress resulting from exposure to bullying victimization, but it is unclear what types of distress in particular may influence the likelihood of some individuals to engage in substance use and sexual risk taking. Results of the path analysis lend some insight into which negative mental health outcomes explain the links between bullying victimization and substance use and sexual risk taking.

\section{Indirect Effects}

Substance use. In the current study, bullying victimization had a significant indirect effect on substance use through depressive symptoms. This finding is in line with previous research exploring depression as a mediator between bullying victimization and substance use in adolescent samples (e.g., Luk et al., 2010; Zapolski et al., 2018). The evidence is strong that bullying victimization is positively associated with depression in both cross-sectional and longitudinal samples (e.g., Bowes et al., 2016; Holt et al., 2014; Klomek et al., 2007; Lereya et al., 2015; Menesini et al., 2009; Russell et al., 2011; Schwartz et al., 2015; Ttofi et al., 2011; Reid et al., 2016; Turner et al., 2013). Victims involved in both traditional bullying and cyberbullying are at an elevated risk for depression (Luk et al., 2010; Schenk \& Fremouw, 2012). Similarly, Menesini and colleagues (2009) reported that compared to bullies and uninvolved individuals, victims were more likely to experience depressive symptoms. Taken together, research thus far suggests victimization is related to depression across various forms of bullying among both male and female youth. 
Studies have also shown that depression is a consistently unique predictor of substance use (Hussong et al., 2017; Maslowsky et al., 2014; Pesola et al., 2015; Mason, Hitch, \& Spoth, 2009; Mason, Hitchings, \& Spoth, 2007; Needham, 2007; Sung, Erkanli, Angold, \& Costello 2004). Sihvola and colleagues (2008) found that depressive disorders were associated with multiple substance use outcomes including frequent alcohol and cannabis use three years later. Similarly, Fleming and colleagues (2008) found that elevated levels of depressive symptoms were predictive of alcohol and cannabis use for girls and cannabis use for boys. Consistent with previous studies, depressive symptoms were significantly related to substance use in the current study. Given the link between bullying victimization and depression and the link between depression and substance use, the significant indirect effect was not surprising. Victims of bullying may experience depressive symptoms, which in turn predict substance use. Turning to substance use may be an attempt to lift one's mood or escape from feelings of hopelessness. This is consistent with Khantzian's (1997) self-medication hypothesis whereby people often consume substances as a short-term regulation strategy to reduce or manage or negative emotional states that are particularly problematic or painful. In other words, some substances can effectively, but temporarily, regulate emotions by promoting positive affect and reducing negative affect (Kober, 2014). The pleasure-inducing effects of some substances may be appealing to youth with depressive symptoms seeking a means to cope (Prosek, Giordano, Woehler, Price, \& McCullough, 2018). Therefore, depressive symptoms appear to be one pathway through which individuals with a history of bullying victimization engage in substance use. 
Similarly, bullying victimization had a significant indirect effect on substance use through lower self-esteem. The literature regarding bullying and self-esteem consistently finds that victims of bullying tend to have lower self-esteem than those not involved in bullying (e.g., Brighi et al., 2012; Brighi et al., 2012; Egan \& Perry, 1998; Hawker \& Boulton, 2000; Jones et al., 2014; Kowalski \& Limber, 2013; Olweus, 1993; Overbeek et al., 2010; Russell et al., 2011). A recent meta-analysis (Tsaousis, 2016) found that selfesteem was negatively associated with both peer victimization and bullying perpetration. Moreover, Patchin and Hinduja (2010) explored the relationship between cyberbullying and self-esteem, and found that victims of cyberbullying, when compared to youth uninvolved in bullying, showed lower levels of self-esteem. Taken together, research thus far suggests different forms of bullying victimization is related to lower self-esteem among both male and female youth.

In recent years, researchers have found lower self-esteem to be antecedent of substance use. Cross-sectional studies have provided evidence for the association between lower self-esteem and substance use (e.g., Bartsch et al., 2017; Bitancourt, Tissot, Fidalgo, Galduróz, \& da Silveira Filho, 2016; Fisher, Zapolski, Sheehan, \& Barnes-Najor, 2017; McKay et al., 2012). Building on the cross-sectional data, one longitudinal study examined the relation between self-esteem and substance use over six years and found that although there was a strong relationship between self-esteem and alcohol and cannabis use during adolescence, these relationships became weaker once participants reached young adulthood (Lee, Seo, Torabi, Lohrmann, \& Song, 2017). Moreover, Oshri and colleagues (2017) examined links between self-esteem growth during adolescence and substance use in young adulthood. They found that declining 
self-esteem was associated with greater alcohol and cannabis abuse. In line with empirical findings suggesting relations between bullying victimization, self-esteem, and substance use, a significant indirect effect was expected. In other words, individuals who had been bullied had lower self-esteem, which in turn predicted substance use.

Substance use appears to escalate when youth with lower levels of self-esteem cannot find a more positive way to cope with distress (McCormack, Laybold, DickermanNelson, \& Budd, 1993). As a result, lower self-esteem may influence behaviour because individuals are likely to modify how they act and behave to either maintain or increase their self-esteem (Longmore, Manning, Giordano, \& Rudolph, 2004) such as using substances to cope with negative feeling related to lower self-esteem (e.g., low self-worth and assertiveness, helplessness, and powerlessness) and increase positive affective states (Park \& Yang, 2017). Moreover, some substances can produce feelings of relaxation and tension reduction, which may be appealing to individuals with lower self-esteem (Pullen, 1994). Much like depression, the link among bullying victimization, lower self-esteem, and substance use seems to adhere to the self-mediation hypothesis (Khantzian, 1997). In addition to the self-medication model, lower self-esteem as a mental health mediator may be comparable to depressive symptoms as a mental health mediator given the clinical relationship between them. For instance, lower self-esteem is an associated feature of various clinical disorders, particularly depression (Erol \& Orth, 2011), and it plays an important etiological role in several classic and contemporary theories/models of depression (Abramson, Seligman, \& Teasdale, 1978; Blatt, D’Afflitti, \& Quinlan, 1976; Evraire \& Dozois, 2011; Morley \& Moran, 2011). Considering that bullying victimization had a significant indirect effect on substance through depressive symptoms, 
as discussed above, it may be expected that examining a construct strongly related to depression would produce a similar result. As such, lower self-esteem served as a pathway linking bullying victimization to substance use as a maladaptive coping mechanism.

Conversely, bullying victimization did not have a significant indirect effect on substance use through anxiety symptoms. An extensive body of research has established exposure to bullying victimization as a significant predictor of anxiety (Copeland et al., 2013; Espelage et al., 2016; Holt et al., 2014; Jones et al., 2017; Kowalski \& Limber, 2013; Lereya et al., 2015; Reid et al., 2016; Schenk \& Fremouw, 2012; Sourander et al., 2007; Stapinski et al., 2014). Longitudinal studies highlight the long-term impact of bullying on mental health. For example, previous research has demonstrated that victims of bullying in childhood and adolescence still suffer adverse mental health outcomes (e.g., anxiety, depression) several years later in young adulthood (Östberg, Modin, \& Låftman, 2018; Wolke \& Lereya, 2015). Furthermore, a recent systematic review and meta-analysis identifying health and psychosocial concerns linked with bullying victimization (all direct and indirect forms of bullying including cyberbullying) found the evidence was strongest for causal relationships between bullying victimization and mental health problems such as anxiety and depression (Moore et al., 2017). Taken together, men and women may experience anxiety as a consequence of bullying victimization.

In addition to the link between bullying victimization and anxiety, a link between anxiety and substance use has been found in both cross-sectional and longitudinal studies (Buckner et al., 2008; Buckner, Bonn-Miller, Zvolensky, \& Schmidt, 2007; Marmorstein 
et al., 2010; Sung et al., 2004; Wolitzky-Taylor, Bobova, Zinbard, Mineka, \& Craske, 2012). However, compared to depression, the support is weaker for a positive association between anxiety and substance use, with as many results suggesting that anxiety may be a protective factor as well as a risk factor for future substance use (Hussong et al., 2017). Despite mixed findings, the current study found a weak correlation between anxiety symptoms and substance use (but a null finding in the path analysis), which is in line with the self-medication model of substance use (Khantzian, 1997), to help cope with anxious thoughts and feelings and reinforce the use of substances by increasing their frequency and quantity (Marmorstein et al., 2010). However, the lack of a significant indirect effect suggests that substance use may not function as a coping mechanism for anxiety symptoms generated by a history of bullying victimization. One reason may be because of the complex relationship between anxiety and substance use, particularly cannabis. On the one hand, cannabis is often used to relax the body and mind and promote feelings of calmness. On the other hand, studies have linked cannabis to heightened levels of anxiety symptoms and panic attacks (Bonn-Miller, Zvolensky, Leen-Feldner, Feldner, \& Yartz, 2005; Zvolensky et al., 2008). Using cannabis can produce acute changes in physical (e.g., increased heart rate; Hall \& Degenhardt, 2009) and cognitive (e.g., limited or impaired attention; Crean, Crane, \& Mason, 2011) states that may feel beyond the control of the individual and promote anxiety (Chorpita \& Balow, 1998). Thus, some individuals may be deterred from engaging in substance as a coping a mechanism if it increases anxiety and instead engage in other adaptive or maladaptive coping strategies.

Another reason for the lack of a significant indirect effect may be because of the general elevation in anxiety among emerging adults during the university years, which is 
the most common mental health problem experienced by students (Center for Collegiate Mental Health, 2018). Given the prevalence of anxiety among university students, the level of distress may be too overwhelming (e.g., history of bullying victimization, worrying about academics) for substance use as a coping strategy that youth may engage in other maladaptive coping strategies to manage or reduce anxiety symptoms. In sum, substance use represents one mechanism for coping with depressive symptoms and lower self-esteem, but another health risk behaviour often co-occurring with substance use is sexual risk taking. Sexual risk taking may represent an alternative mechanism for coping with psychosocial distress.

Sexual risk taking. Bullying victimization had a significant indirect effect on sexual risk taking through lower self-esteem. As mentioned previously, the evidence is strong for the link between bullying victimization and lower self-esteem. However, there has been considerably less research exploring the link between self-esteem and sexual risk taking. Paul and Colleagues (2000) found that university students with lower levels of self-esteem were more likely to engage in a sexual experience (either coital or noncoital) with a stranger or brief acquaintance. Similarly, Bersamin and colleagues (2014) found that self-esteem was negatively related to casual sex (i.e., having sex with someone they knew for less than a week) in a sample of university students. Men and women often report feelings of sexual regret after casual sex encounters (Fisher et al., 2012), and these feelings have been linked to lower self-esteem (Grello, Welsh, \& Harper, 2006). However, diminished self-esteem may also precede casual sex encounters or sexual risk taking more broadly. Engaging in risky sexual behaviour may function as a coping mechanism for those experiencing poor psychological outcomes (Sikkema et al., 
2009). Individuals with lower self-esteem often lack confidence in themselves and doubt their own worth (Enejoh et al., 2016). These qualities may increase the likelihood of being pressured into engaging in risky sexual activity (Enejoh et al., 2016). Initiating sexual behaviour may allow individuals to feel better about themselves and provide a feeling of intimacy (Enejoh et al., 2016). Additionally, youth with low self-esteem, as well as those who are bullied, generally have less friends and social support and may have the propensity to respond to stress through unhealthy behaviours (Dumont \& Provost, 1999; Veenstra et al., 2010) such as sexual risk taking. Sexual risk taking appears to be a maladaptive coping strategy for individuals dealing with negative feelings about the self. Thus, bullying victimization may be one stressor that generates lower selfesteem, which in turn makes it more likely that youth will engage in sexual risk taking as a way to cope.

Similar to self-esteem, bullying victimization also had a significant indirect effect on sexual risk taking through anxiety symptoms. As mentioned previously, the positive association between bullying victimization and anxiety is well established. However, the association between anxiety and sexual risk taking has received little research attention. In cross-sectional studies, higher levels of anxiety symptoms predicted increased risky sexual behaviours (e.g., earlier sexual debut, having multiple sexual partners, using alcohol or drugs during sex, and having unprotected sex; Mustanski, 2007; Wagner, 2001; Wong et al., 2017). Furthermore, compared to individuals without psychiatric disorders, individuals with anxiety disorders were more likely to report sexually transmitted infections (Ramrakha, Caspi, Dickson, Moffitt, \& Paul, 2000). These previous findings are consistent with the significant positive association between anxiety 
symptoms and sexual risk taking found in the current study. The arousal component associated with anxiety may share features related to sexual arousal (Mustanski, 2007). Excitation transfer theory hypothesizes the influence of residual arousal from a previous emotional experience on subsequent emotional responses (Zillmann, 1983). The residual arousal evoked from preceding, but unrelated, emotional reactions can be misattributed or "transferred" to feelings of sexual arousal (Cantor, Zillmann, \& Bryant, 1975; Zillmann, 1983), which could increase the willingness to engage in sexual risk taking (Mustanski, 2007). Despite the fear aspects of anxiety that may lead to the avoidance of sexual behaviour, feeling "jittery" and "keyed up" may be linked to feelings of excitement that increase the willingness to engage in risky sexual activity (Zillmann, 1983). Although sexual risk taking may be maladaptive, it appears to be a coping strategy for youth who are feeling anxious. Therefore, youth with a history of bullying victimization may engage in sexual risking to alleviate symptoms of anxiety.

In contrast to self-esteem and anxiety symptoms, bullying victimization had no significant indirect effect on sexual risk taking through depressive symptoms. As mentioned previously, past data clearly highlight the link between bullying victimization and depression. Furthermore, research has begun to suggest links between depressive symptoms and sexual risk taking (e.g., Khan et al., 2009; Kosunen, Kaltiala-Heino, Rimpelä, \& Laippala, 2003; Langille, Asbridge, Kisely, \& Wilson, 2012; Lehrer et al., 2006; Paxton \& Robinson, 2008; Wilson, Asbridge, Kisley, \& Langille, 2010). Although sexual risk taking is a risk factor for depression (Hallfors, Waller, Bauer, Ford \& Halpern, 2005; Shrier, Harris, Sternberg, \& Beardslee, 2002; Waller et al., 2006), individuals who are depressed may be vulnerable to sexual risk taking. For example, in a 
nationally representative longitudinal sample, youth with recent or chronic depression during adolescence were more likely to have multiple sexual partners than those without depression six years later even after controlling for demographic, socioeconomic, and adolescent STI risk and substance use variables (Khan et al., 2009). Furthermore, higher depressive symptoms were associated with not using condoms and birth control and using substances during the last sexual episode for boys, whereas moderate depressive symptoms were associated with substance use during the last sexual episode for girls (Lehrer et al., 2006). Depression may impair cognitive function and memory (Rock, Roiser, Riedel \& Blackwell, 2014), decrease impulse control and motivation (Lejoyeux, Arbaretaz, McLoughlin, \& Ades, 2002; Rao, 2006), and increase feelings of hopelessness, worthlessness, and disregard for self (Abramson et al., 1989; American Psychiatric Association, 2013; Testa \& Steinberg, 2010). These depression-related effects may make it less likely that individuals tend to their physical health by inhibiting the ability to avoid sexual risk taking behaviour in attempt to treat their depression (Alvy et al., 2011; Khan et al., 2009; Ramrakha et al., 2000).

However, the current study found no significant relationship between depressive symptoms and sexual risk taking. In addition, the lack of a significant indirect effect suggests that sexual risk taking may not be a coping strategy for reducing depressive symptoms generated by a history of bullying victimization. In retrospect, this finding is not surprising. Depression is often characterized by diminished interest or pleasure and loss of energy (American Psychiatric Association, 2013). Furthermore, social withdrawal and irritability may decrease an individual's desire or impair the ability to form relationships (Baldwin, 2001). Depressed youth are less likely to engage in the 
exploration and experimentation associated with sexual behaviour (Sandberg-Thoma \& Dush, 2014), and their behaviour and affect increase the probability of rejection (Coyne, 1976). This collection of symptoms may be expected to produce difficulties in sexual behaviour and may explain why depression is sometimes not a significant predictor of sexual risk taking (e.g., Bachanas et al., 2002a, 2002b; Lavan \& Johnson, 2002). Therefore, youth who have experienced bullying in the past may use other maladaptive coping strategies to minimize depressive symptoms.

\section{Polyvictimization and Health Risk Behaviours}

Youth with only a history of bullying showed an increased risk of engaging in substance use and sexual risk taking. However, youth with a history of polyvictimization (i.e., bullying and childhood maltreatment) were at an even greater risk of engaging in substance use and sexual risk taking. These results are line with a few studies suggesting links between polyvictimization and health risk behaviours. However, these studies have either not included bullying as part of polyvictimization or used a specific sample with limited generalizability (e.g., college-aged women; Alexander et al., 2018; Wright et al., 2013). The current study addressed these concerns by including a specific measure of bullying victimization when taking into account polyvictimization and using a sample with greater generalizability. When victimization occurs across multiple domains of an individual's life, the number of "safe havens" to which they can turn to for help, relief, or coping are restricted (Holt, Buckley, \& Whelan, 2008; Margolin et al., 2009; Mrug, Loosier, \& Windle, 2008). Thus, youth who do not have very many places to go to escape or avoid exposure from victimization may be at even higher risk for negative outcomes (Wright et al., 2013). For instance, youth who are bullied at school by their peers may be 
able to seek help or support at home from their parents (Wright et al., 2013). Parental support has often been found to be a protective factor against bullying victimization (Baldry \& Farrington, 2005; Reid, Holt, Bowman, Espelage, \& Green, 2016). However, youth who have been maltreated by their parents are not likely to turn to them for help or support for the bullying at school (Wright et al., 2013). Furthermore, Finkelhor and colleagues (2007) have also suggested that youth may have a certain "threshold" for being resilient to victimization over time or across multiple domains, but the accumulation of different victimizations may exceed this threshold, become too burdensome to overcome, and ultimately lead to outcomes such as substance use and sexual risk taking.

Similar to the direct effects of bullying victimization on substance use and sexual risk taking discussed above, these health risk behaviours may also function as maladaptive coping mechanisms for youth with a history of polyvictimization. Exposure to victimization across multiple contexts may be perceived as more intense or severe, which in turn may increase the likelihood of some youth engaging in maladaptive coping behaviours above and beyond those who experience only one form of victimization (Agnew, 2006). The theoretical and practical implications for individuals with a history of bullying victimization and polyvictimization are discussed below.

\section{Implications}

Theory. The findings from the current study have several important theoretical implications for the consequences of bullying victimization and polyvictimization among emerging adults. Previous research on bullying has used theoretical frameworks such as social information processing (e.g., Crick \& Dodge, 1994), social-ecological models 
(e.g., Swearer \& Espelage, 2004), and evolutionary perspectives (e.g., Volk, Camilleri, Dane, \& Marini, 2012) to identify individual and environmental factors that contribute and are related to bullying. However, when investigating the ways victims deal with the psychosocial problems associated with bullying victimization, using a coping theoretical framework may be the most appropriate (e.g., Lazarus \& Folkman, 1984; Roth \& Cohen, 1986). Coping theories emphasize different strategies (each with their own trade-offs) for dealing with the source of a stressor. Findings from the coping literature suggest that approach strategies (e.g., confronting the source of the stressor) tend to predict more positive outcomes than avoidance strategies (e.g., managing cognitive or emotional reactions; Roth \& Cohen, 1986). In the case of bullying victimization, an extremely stressful event, youth may use less mature forms of coping (e.g., avoidance; Wadsworth, 2015). The repeated use of less mature forms of coping, limited availability of healthy alternatives, or constant exposure to a stressor may establish a maladaptive coping pattern (Wadsworth, 2015). Furthermore, when stressors are perceived to be outside of one's control and not modifiable, avoidance coping patterns are likely to be used (Folkman, Lazarus, Dunkel-Schetter, DeLongis, \& Gruen, 1986).

Considering that bullying is defined as a repeated act of aggression against another individual with less power, it can often be difficult for some youth to cope adaptively because the bullying experience is beyond their control (Donoghue et al., 2014; Ttofi et al., 2016). Due to the uncontrollable nature of being bullied, youth may engage in avoidance coping to reduce distress associated with their bullying experiences (Hunter et al., 2004; Ttofi et al., 2016). Results from the current study provide support for substance use and sexual risk taking as maladaptive means for regulating the emotional 
experiences of those who have been bullied. For youth exposed to both bullying victimization and childhood maltreatment, they may be at an even greater risk for engaging in substance use and sexual risk taking. This is not surprising when considering that polyvictims are dealing with stressors across multiple domains compared to youth who are only bullied or only maltreated. Similar to bullying victimization, substance use and sexual risk taking may also be used as coping mechanisms, especially if youth are experiencing polyvictimization. Although previous research has examined these health risk behaviours within the context of bullying, only a small number of studies have used the approach-avoidance coping model (Roth \& Cohen, 1986) to conceptualize how youth may cope with being bullied.

Current results also suggest that negative mental health outcomes such as lower self-esteem, depressive symptoms, and anxiety symptoms may serve as a developmental pathway linking bullying victimization to both substance use and sexual risk taking. In other words, bullying victimization among emerging adults may generate lower selfesteem and elevated depressive and anxiety symptoms, which in turn results in substance use and sexual risk taking. In addition to providing knowledge about how youth cope with the bullying victimization, the current study also highlights why youth may be engaging in certain maladaptive coping behaviours. However, not all indirect effects were significant. Bullying victimization did not have significant indirect effects on substance use through anxiety symptoms and sexual risk taking through depressive symptoms. This suggests that some youth may engage in other maladaptive coping strategies to deal with these specific mental health problems or that different mental health problems may serve as developmental pathways linking bullying victimization 
with these specific health risk behaviours.

Practice. To go along with the theoretical implications, the findings from this study may also help to inform the development of psychosocial interventions for youth with a history of bullying victimization and polyvictimization. Although the first step may be to prevent or reduce bullying from occurring in schools, meta-analyses suggest that the effectiveness of school-based anti-bullying programs vary considerably across programs (Langford et al., 2015; Merrell, Gueldner, Ross, \& Isava, 2008; Ttofi \& Farrington, 2011). For instance, Farrington and Ttofi's (2009) meta-analysis concluded that anti-bullying programs are often effective, reducing the prevalence of bullying and being bullied by an average of 20 to $23 \%$ in experimental schools compared to control schools. However, these programs are less effective when they are evaluated with more sophisticated study designs such as randomized controlled trials (Langford et al., 2015; Ttofi \& Farrington, 2011). As a result, some programs do not produce positive effects, some have never been evaluated, and some are so poorly evaluated that it is difficult to draw valid conclusions regarding their effects (Evans, Fraser, \& Cotter, 2014; Menesini \& Salmivalli, 2017). These anti-bullying programs may produce little positive effects because many implement zero-tolerance policies or empathy training, which focuses on punishment, improving cognitive/social skills, or using a "one-size-fits-all" approach that treats bullying as homogeneous behaviour (Anderson \& Kincaid, 2005; Ellis et al., 2012; Merrell et al., 2008; Volk et al., 2012).

Despite mixed evidence for the effects of anti-bullying programs, the majority of youth are still being bullied. As a mentioned previously, bullying victimization is a risk factor for psychological maladjustment (and physical health problems; Copeland et al., 
2014) even later in life after the bullying has stopped. Therefore, if reducing bullying in schools is still a complex issue needing to be resolved, then bullying psychosocial interventions that involve helping youth who may be experiencing a variety of mental health problems as a result of being bullied are worth considering. Unfortunately, only one study has been conducted that involves manualized psychosocial treatment for victims of school bullying. Berry and Hunt (2009) implemented a cognitive behavioural group intervention program with adolescent boys that included cognitive behaviouralbased anxiety management strategies, improving social skills and self-esteem, and teaching adaptive coping strategies in bullying situations. The intervention was effective in significantly reducing victims' experiences of bullying, anxiety, depression, and distress with gains maintained three months later (Berry \& Hunt, 2009). However, the intervention was not effective in improving self-esteem or modifying aggressive or avoidant responses to bullying situations (Berry \& Hunt, 2009). Building on Berry and Hunt's (2009) manualized treatment program, results of the current study emphasize the importance of continuing to develop and refine psychosocial interventions using evidence-based psychotherapies (e.g., cognitive behavioural therapy) to address psychological maladjustment among emerging adults who are victims of bullying to prevent the risk for subsequent substance use and sexual risk taking in both men and women. In addition, psychosocial interventions should help victims develop positive coping skills and limit the use of negative coping skills when dealing with bullying victimization or the negative emotions associated with bullying victimization (Wadsworth, 2015). Previous research has suggested that more active, problem-solving coping approaches reduce the likelihood of substance use and sexual risk behaviours 
(Brady, Tschann, Pasch, Flores, \& Ozer, 2009; Teva, Bermúdez, \& Buela-Casal, 2010).

Besides the direct and indirect effects of bullying victimization on health risk behaviours, the results of the current study also suggest that youth with a history of polyvictimization (i.e., bullying and child maltreatment) may be at even greater risk for engaging in substance use and sexual risk taking. Current prevention and intervention programs to help victimized youth are fragmented because they are often tailored toward single forms of victimization (Turner et al., 2010). Researchers need to acknowledge that failing to consider exposure to multiple forms of victimization is likely to underestimate the severity of adverse outcomes (Turner et al., 2010). Instead, adequate prevention and intervention programs may require a multidisciplinary and transdiagnostic approach that involves incorporating and integrating expertise from various research fields to target polyvictimization early in life (Cyr et al., 2013) in order increase positive coping skills and reduce the risk for engaging in substance use and sexual risk taking.

\section{Limitations and Future Directions for Research}

In line with my findings and implications, there are some limitations to the current study. First, self-report measures were used to collect the data, which may be susceptible to social desirability bias. Self-report data on bullying victimization, child maltreatment, and health risk behaviours may be inconsistent or underreported (Rigby \& Johnson, 2006; Hardt \& Rutter, 2004; Harris, Griffin, McCaffrey, \& Morra, 2008; Morrison-Beedy et al., 2006). However, the inclusion of the BIDR to identify participants who may have been inclined to respond in socially desirable ways and assuring participants that their responses would be kept confidential appeared to reduce respondents' concerns and to improve response quality to sensitive questions (Krumpal, 2013). Furthermore, 
participants filled out the questionnaires online, which can create a social situation where participants feel a sense of disinhibition and reduce social desirability effects (BoothKewley, Larson, \& Miyoshi 2007). Another concern with self-report measures is that participants were asked to recall experiences (e.g., bullying victimization, childhood maltreatment) that may have occurred several years ago. Retrospective self-report may be subject to recall error and memory instability, which compromises internal validity (Cammack \& Hogue, 2017; Hardt \& Rutter, 2004). However, recent research has established that retrospective reports are reliable and valid even for traumatic events such as experiences of victimization (Brewin, Andrews, \& Gotlib, 1993; Hardt \& Rutter, 2004). Taken together, previous studies have found using self-report measures for bullying (e.g., Olweus, 2013), childhood maltreatment (Hardt \& Rutter, 2004), substance use (e.g., Buchan, Dennis, Tims, \& Diamon, 2002; Del Boca \& Darkes, 2003), and sexual behaviour (e.g., Brener, Billy, \& Grady, 2003) tend to demonstrate modest to good validity for capturing these behaviours. Future studies using multiple informants or sources to gather data would offer more reliability and validity.

Another limitation was that the study was cross-sectional making it difficult to derive causal relationships among the variables. For example, given that all variables were measured concurrently, the results do not indicate whether negative mental health outcomes are a cause or outcome of bullying victimization or if avoidance coping behaviours are a cause or outcome of poor mental health. For instance, although some research suggests bullying victimization is a consequence of psychosocial problems (e.g., Boulton et al., 2010; Kaltiala-Heino \& Fröjd, 2011; Siegel et al., 2009), the majority of studies on bullying and mental health indicate that bullying is a predictor of psychosocial 
problems. Therefore, despite the cross-sectional nature of the results, the temporal order of the variables was consistent with previous research and theory. Future longitudinal studies may be able to establish causal relations among the variables (MacKinnon, 2008).

Third, the sample consisted of primarily heterosexual emerging adults collected from a psychology participant pool, lending some caution to the generalizability of the results to younger samples (e.g., children and adolescents), community samples, and LGBTQ samples. Although emerging adults may use maladaptive coping behaviours such as substance use and sexual risk taking to deal with the psychosocial distress from being bullied, children may use different maladaptive coping behaviours that are more developmentally appropriate. For instance, children may deal with the stress of peer conflict by engaging in aggressive behaviour (e.g., yelling, hitting; Kochenderfer-Ladd, 2004; Marsh et al., 2011), blaming themselves for being bullied (Tenenbaum, Varjas, Meyers, \& Parris, 2012), or distancing (e.g., ignoring or pretending nothing happened; Andreou, 2001; Mahady Wilton, Craig, \& Pepler, 2000). Furthermore, despite the value of conducting social science research with student samples, these samples tend to be more homogenous than community samples, which raise concerns regarding the representativeness and generalizability of the findings to nonstudents (Murray, Rugeley, Mitchell, \& Mondak, 2013). Finally, the scope of the current study was not geared toward sexual minority youth despite these individuals being at a higher risk for bullying victimization and poor mental health outcomes compared to heterosexual youth (Coulter, Herrick, Friedman, \& Stall, 2016; King et al., 2008; McLaughlin, Hatzenbuehler, Xuan, \& Conron, 2012; Schuster et al., 2015). The sample in the current study was mostly heterosexual making it difficult to conduct analyses with the small LGBTQ sample so the 
theoretical and practical implications of the findings should be limited to heterosexual youth. Future research should conduct studies with younger and more diverse samples to determine the nature of the relationships among bullying victimization, mental health, and coping and increase external validity.

The current study examined the most common negative mental health outcomes associated with bullying victimization. However, previous research has found that bullying victimization is an antecedent to a variety of adverse, but less common, mental health outcomes such as posttraumatic stress disorder, eating disorders, and suicidality (e.g., Copeland et al., 2015, Idsoe, Dyregrov, \& Idsoe, 2012; Klomek et al., 2009). These, among other psychosocial problems, should be explored in future research as potential developmental pathways linking bullying victimization to health risk behaviours. Moreover, the current study examined substance use and sexual risk taking as two maladaptive coping behaviours that youth may employ to manage psychosocial distress. However, it was beyond the scope of the current study to examine under which internal (e.g., individual differences) and external (e.g., environmental contexts) factors youth are more likely to turn to substance use than sexual risk taking or vice versa. In addition, there are other maladaptive coping behaviours (e.g., self-blame, denial), as well as adaptive coping behaviours (e.g., using emotional support, positive reframing), that were not examined but are behaviours that some youth may be willing to employ (Carver, 1997). Future research should explore how internal and external factors may influence youth to engage in one health risk behaviour over the other and explore other maladaptive and adaptive coping behaviours to gain a more comprehensive understanding of the strategies youth may use to manage psychosocial distress from a history of bullying 
victimization.

Finally, polyvictimization consisted of bullying and child maltreatment. However, youth may be exposed to a broad range of victimizations that were not analyzed in the current study. For instance, in addition to peer victimization and childhood maltreatment, youth may also be exposed to indirect victimization (e.g., witnessing domestic violence), sexual victimization (e.g., rape), or conventional crime (e.g., robbing, kidnapping; Finkelhor, Omrod, Turner, \& Hamby, 2005b). Future studies may benefit from taking into account these different forms of victimization to create a more comprehensive polyvictimization variable to determine its influence on substance use and sexual risk taking.

\section{Conclusion}

Despite the limitations, the results of the current study suggest that bullying victimization can have important direct and indirect effects on both mental health and health risk behaviours. Some youth may use maladaptive coping strategies such as substance use and sexual risk taking as a result of being bullied. Furthermore, certain psychosocial problems such as lower self-esteem, depressive symptoms, and anxiety symptoms may serve as developmental pathways linking bullying victimization with both substance use and sexual risk taking. In other words, bullying victimization predicts adverse mental health outcomes, which in turn may contribute to the onset of health risk behaviours as ways to cope with these negative outcomes. However, bullying victimization as a risk factor for adverse physical and mental health outcomes is not the only concern. Youth with a history of bullying victimization may have also experienced additional victimizations, particularly childhood maltreatment. Polyvictimization may 
place youth at even greater risk for engaging in substance use and sexual risk taking.

Therefore, interventions that focus on bullying may also need to take into account other forms of victimization in order to adequately address substance use and sexual risk taking associated with a history of polyvictimization. 


\section{REFERENCES}

Abajobir, A. A., Kisely, S., Maravilla, J. C., Williams, G., \& Najman, J. M. (2017). Gender differences in the association between childhood sexual abuse and risky sexual behaviours: A systematic review and meta-analysis. Child Abuse \& Neglect, 63, 249-260. doi:10.1016/j.chiabu.2016.11.023

Abramson, L. Y., Metalsky, G. I., \& Alloy, L. B. (1989). Hopelessness depression: A theory-based subtype of depression. Psychological Review, 96, 358-372.

Abramson, L. Y., Seligman, M. E. P., \& Teasdale, J. D. (1978). Learned helplessness in humans: Critique and reformulation. Journal of Abnormal Psychology, 87, 49-74. doi:10.1037/0021-843X.87.1.49

Adamson, S. J., Kay-Lambkin, F. J., Baker, A. L., Lewin, T. J., Thornton, L., Kelly, B. J., \& Sellman, J. D. (2010). An improved brief measure of cannabis misuse: the Cannabis Use Disorders Identification Test-Revised (CUDIT-R). Drug and Alcohol Dependence, 110, 137-143. doi:10.1016/j.drugalcdep.2010.02.017

Agnew, R. (2006). Pressured into crime: An overview of general strain theory. Cary, NC: Roxbury Publishing Company.

Alexander, A. A., Amerigo, L. S., \& Harrelson, M. E. (2018). Polyvictimization and sexual risk behaviours in college-aged women. Criminal Justice Review, 43, 1-15. doi:10.1177/0734016818767727

Allison, P. D. (2001). Missing Data. Thousand Oaks, CA: Sage Publishing.

Alvy, L. M., McKirnan, D. J., Mansergh, G., Koblin, B., Colfax, G. N., Flores, S. A., ... \& Project MIX Study Group. (2011). Depression is associated with sexual risk among men who have sex with men, but is mediated by cognitive escape and selfefficacy. AIDS and Behavior, 15, 1171-1179. doi:10.1007/s10461-010-9678- 
Anderson, C. M., \& Kincaid, D. (2005). Applying behavior analysis to school violence and discipline problems: Schoolwide positive behavior support. The Behavior Analyst, 28, 49-63. doi:10.1007/BF03392103

Andreou, E. (2001). Bully/victim problems and their association with coping behaviour in conflictual peer interactions among school-age children. Educational Psychology, 21, 59-66. doi:10.1080/01443410125042

Annaheim, B. (2013). Who is smoking pot for fun and who is not? An overview of instruments to screen for cannabis-related problems in general population surveys. Addiction Research \& Theory, 21, 410-428. doi:10.3109/16066359.2012. 735295

Arnocky, S., \& Vaillancourt, T. (2012). A multi-informant longitudinal study on the relationship between aggression, peer victimization, and dating status in adolescence. Evolutionary Psychology, 10, 253-270. doi:10.1177/147470491201 000207

Arnett, J. J. (2000). Emerging adulthood: A theory of development from the late teens through the twenties. American Psychologist, 55, 469-480. doi:10.1037/0003066X.55.5.469

Arnett, J. J. (2004). Emerging adulthood: The winding road from the late teens through the twenties. New York, NY: Oxford University Press.

Arnett, J. J. (2007). Socialization in emerging adulthood: From the family to the wider world, from socialization to self-socialization. In J. E. Gruesec \& P. D. Hastings (Eds.), Handbook of socialization: Theory and research (pp. 208-231). New 
York, NY: Guilford Press.

Arseneault, L., Bowes, L., \& Shakoor, S. (2010). Bullying victimization in youths and mental health problems: 'Much ado about nothing'?. Psychological Medicine, 40, 717-729. doi:10.1017/S003 329170

Bachanas, P. J., Morris, M. K., Lewis-Gess, J. K., Sarett-Cuasay, E. J., Sirl, K., Ries, J. K., \& Sawyer, M. K. (2002). Predictors of risky sexual behavior in African American adolescent girls: Implications for prevention interventions. Journal of Pediatric Psychology, 27, 519-530. doi:10.1093/jpepsy/27.6.519

Bachanas, P. J., Morris, M. K., Lewis-Gess, J. K., Sarett-Cuasay, E. J., Flores, A. L., Sirl, K. S., \& Sawyer, M. K. (2002). Psychological adjustment, substance use, HIV knowledge, and risky sexual behavior in at-risk minority females: Developmental differences during adolescence. Journal of Pediatric Psychology, 27, 373-384. doi:10.1093/jpepsy/27.4.373

Baldry, A. C. \& Farrington, D. P. (2005). Protective factors as moderators of risk factors in adolescence bullying. Social Psychology of Education, 8, 263-284. doi:10.1007 /s11218-005-5866-5

Baldwin, D. S. (2001). Depression and sexual dysfunction. British Medical Bulletin, 57, 81-99. doi:10.1093/bmb/57.1.81

Bancroft, J., Janssen, E., Strong, D., Carnes, L., Vukadinovic, Z., \& Long, J. S. (2003). Sexual risk-taking in gay men: The relevance of sexual arousability, mood, and sensation seeking. Archives of Sexual Behavior, 32, 555-572. doi:10.1023/A:102 604162836

Bartsch, L. A., King, K. A., Vidourek, R. A., \& Merianos, A. L. (2017). Self-Esteem and Alcohol Use Among Youths. Journal of Child \& Adolescent Substance Abuse, 1- 
11. doi:10.1080/1067828X.2017.1322018

Berry, K., \& Hunt, C. J. (2009). Evaluation of an intervention program for anxious adolescent boys who are bullied at school. Journal of Adolescent Health, 45, 376-382. doi:10.1016/j.jadohealth.2009.04.023

Bersamin, M. M., Zamboanga, B. L., Schwartz, S. J., Donnellan, M. B., Hudson, M., Weisskirch, R. S., ...Caraway, S. J. (2014). Risky business: Is there an association between casual sex and mental health among emerging adults?. Journal of Sex Research, 51, 43-51. doi:10.1080/00224499.2013.772088

Birmaher, B. \& Brent, D. (2007). Practice parameter for the assessment and treatment of children and adolescents with depressive disorders. Journal of the American Academy of Child \& Adolescent Psychiatry, 46, 1503-1526. doi:10.1097/chi.0b013e318145ae1c

Bitancourt, T., Tissot, M. C. R. G., Fidalgo, T. M., Galduróz, J. C. F., \& da Silveira Filho, D. X. (2016). Factors associated with illicit drugs' lifetime and frequent/heavy use among students results from a population survey. Psychiatry Research, 237, 290-295. doi:10.1016/j.psychres.2016.01.026

Blatt, S. J., D’Afflitti, J. P., \& Quinlan, D. M. (1976). Experiences of depression in normal young adults. Journal of Abnormal Psychology, 85, 383-389. doi:10.1037/ 0021-843X.85.4.383

Bonn-Miller, M. O., Zvolensky, M. J., Leen-Feldner, E. W., Feldner, M. T., \& Yartz, A. R. (2005). Marijuana use among daily tobacco smokers: Relationship to anxietyrelated factors. Journal of Psychopathology and Behavioral Assessment, 27, 279-289. doi:10.1007/s10862-005-2408-6

Booth-Kewley, S., Larson, G. E., \& Miyoshi, D. K. (2007). Social desirability effects on 
computerized and paper-and-pencil questionnaires. Computers in Human Behavior, 23, 463-477. doi:10.1016/j.chb.2004.10.020

Boroughs, M.S., Safren, S.A., \& O’Cleirigh, C. (2016, July). Collaborative Development of Integrated Treatment Platforms for Emerging Adults with a History of Being Bullied. Paper presented at the International School Psychology Association 2016 Conference, Amsterdam, Netherlands.

Bouffard, L. A., \& Koeppel, M. D. (2017). Sex differences in the health risk behavior outcomes of childhood bullying victimization. Victims \& Offenders, 12, 549-565. doi:10.1080/15564886.2015.1118420

Boulton, M. J., Smith, P. K., \& Cowie, H. (2010). Short-term longitudinal relationships Between children's peer victimization/bullying experiences and self-perceptions evidence for reciprocity. School Psychology International, 31, 296-311. doi:10.11 $77 / 0143034310362329$

Boulton, M. J., Trueman, M., \& Murray, L. (2008). Associations between peer victimization, fear of future victimization and disrupted concentration on class work among junior school pupils. British Journal of Educational Psychology, 78, 473-489. doi:10.1348/000709908X320471

Bowes, L., Arseneault, L., Maughan, B., Taylor, A., Caspi, A., \& Moffitt, T. E. (2009). School, neighborhood, and family factors are associated with children's bullying involvement: A nationally representative longitudinal study. Journal of the American Academy of Child \& Adolescent Psychiatry, 48, 545-553. doi:10.1097/ CHI.0b013e31819cb017

Bowes, L., Joinson, C., Wolke, D., \& Lewis, G. (2016). Peer victimisation during 
adolescence and its impact on depression in early adulthood: prospective cohort study in the United Kingdom. British Medical Journal, 50, 176-183. doi:10.1136/ /bjsports-2015-h2469rep

Bowerman, B. L., \& O'connell, R. T. (2000). Linear statistical models: An applied approach (2nd ed.). Duxbury Press.

Brady, S. S., Tschann, J. M., Pasch, L. A., Flores, E., \& Ozer, E. J. (2008). Cognitive coping moderates the association between violent victimization by peers and substance use among adolescents. Journal of Pediatric Psychology, 34, 304-310. doi:10.1093/jpepsy/jsn076

Brener, N. D., Billy, J. O., \& Grady, W. R. (2003). Assessment of factors affecting the validity of self-reported health-risk behavior among adolescents: evidence from the scientific literature. Journal of Adolescent Health, 33, 436-457. doi:10.1016/S 1054-139X(03)00052-1

Brewin, C. R., Andrews, B., \& Gotlib, I. H. (1993). Psychopathology and early experience: a reappraisal of retrospective reports. Psychological Bulletin, 113, $82-98$.

Briere, J. \& Runtz, M. (1993). Childhood sexual abuse: Long-term sequelae and implications for psychological assessment. Journal of Interpersonal Violence, 8, 312-330.

Brighi, A., Guarini, A., Melotti, G., Galli, S., \& Genta, M. L. (2012). Predictors of victimisation across direct bullying, indirect bullying and cyberbullying. Emotional and Behavioural Difficulties, 17, 375-388. doi:10.1080/13632752.2012 .704684 
Brighi, A., Melotti ,G., Guarini, A., Genta, M.L., Ortega, R., Mora-Merchan, J., \& Thompson, F. (2012). Self-esteem and loneliness in relation to cyberbullying in three European countries. In Q. Li, D. Cross, \& P. K. Smith (Eds.), Cyberbullying in the global playground: re-search from international perspectives (pp. 32-56). Hoboken, NJ: Wiley-Blackwell.

Brody, S. (2010). The relative health benefits of different sexual activities. The Journal of Sexual Medicine, 7, 1336-1361. doi:10.1111/j.1743-6109.2009.01677.x

Brown, B. B. (2004). Adolescents' relationship with peers. In R. M. Lerner \& L. Steinberg (Eds.), Handbook of Adolescent Psychology, $2^{\text {nd }}$ Edition (pp. 363-394). Hoboken, NJ: Wiley-Blackwell.

Browne, A., \& Finkelhor, D. (1986). Impact of child sexual abuse: A review of the research. Psychological Bulletin, 99, 66-77.

Buchan, B. J., L. Dennis, M., Tims, F. M., \& Diamond, G. S. (2002). Cannabis use: consistency and validity of self-report, on-site urine testing and laboratory testing. Addiction, 97, 98-108. doi.org/10.1046/j.1360-0443.97.s01.1.x

Buckner, J. D., Bonn-Miller, M. O., Zvolensky, M. J., \& Schmidt, N. B. (2007). Marijuana use motives and social anxiety among marijuana-using young adults. Addictive Behaviors, 32, 2238-2252. doi:10.1016/j.addbeh.2007.04.004

Buckner, J. D., Schmidt, N. B., Lang, A. R., Small, J. W., Schlauch, R. C., \& Lewinsohn, P. M. (2008). Specificity of social anxiety disorder as a risk factor for alcohol and cannabis dependence. Journal of Psychiatric Research, 42, 230-239. doi:10.1016/ j.jpsychires. 2007.01.002

Cammack, A. L., \& Hogue, C. J. (2017). Retrospectively self-reported age of childhood abuse onset in a United States nationally representative sample. Injury 
Epidemiology, 4, 1-6. doi:10.1186/s40621-017-0103-1

Cantor, J. R., Zillmann, D., \& Bryant, J. (1975). Enhancement of experienced sexual arousal in response to erotic stimuli through misattribution of unrelated residual excitation. Journal of Personality and Social Psychology, 32, 69-75. doi:10.1037/ h0076784

Carver, C. S. (1997). You want to measure coping but your protocol too long: Consider the brief cope. International journal of Behavioral Medicine, 4, 92-100. doi:10.12 07/s15327558ijbm0401_6

Casey-Cannon, S., Hayward, C., \& Gowen, K. (2001). Middle-school girls' reports of Peer victimization: Concerns, consequences, and implications. Professional School Counseling, 5, 138-148

Center for Collegiate Mental Health. (2018, January). 2017 Annual Report (Publication No. STA 18-166). Retrieved from https://sites.psu.edu/ccmh/files/2018/02/2017_CCMH_Report-1r4m88x.pdf Cerutti, R., Manca, M., Presaghi, F., \& Gratz, K. L. (2011). Prevalence and clinical correlates of deliberate self-harm among a community sample of Italian adolescents. Journal of Adolescence, 34, 337-347. doi:10/10.1016/j.adolescence.2 010.04 .004

Chen, H., Cohen, P., \& Chen, S. (2010). How big is a big odds ratio? Interpreting the magnitudes of odds ratios in epidemiological studies. Communications in Statistics-Simulation and Computation, 39, 860-864. doi:10.1080/036109110036 50383

Chen, P., \& Jacobson, K. C. (2012). Developmental trajectories of substance use from 
early adolescence to young adulthood: Gender and racial/ethnic differences. Journal of Adolescent Health, 50, 154-163. doi:10.1016/j.jadohealth.2011.05.013

Chester, K. L., Callaghan, M., Cosma, A., Donnelly, P., Craig, W., Walsh, S., \& Molcho, M. (2015). Cross-national time trends in bullying victimization in 33 countries among children aged 11, 13 and 15 from 2002 to 2010. The European Journal of Public Health, 25, 61-64. doi:10.1093/eurpub/ckv029

Cicchetti, D. (2016). Socioemotional, personality, and biological development: Illustrations from a multilevel developmental psychopathology perspective on child maltreatment. Annual Review of Psychology, 67, 187-211. doi:10.1146/annu rev-psych-122414-033259

Chorpita, B. F., \& Barlow, D. H. (1998). The development of anxiety: the role of control in the early environment. Psychological Bulletin, 124, 3-21. doi:10.1037/0033-29 09.124 .1 .3

Comeau, N., Stewart, S. H., \& Loba, P. (2001). The relations of trait anxiety, anxiety sensitivity, and sensation seeking to adolescents' motivations for alcohol, cigarette, and cannabis use. Addictive Behaviors, 26, 803-825. doi:10.1016/S0306 $-4603(01) 00238-6$

Copeland, W. E., Bulik, C. M., Zucker, N., Wolke, D., Lereya, S. T., \& Costello, E. J. (2015). Does childhood bullying predict eating disorder symptoms? A prospective, longitudinal analysis. International Journal of Eating Disorders, 48, 1141-1149. doi:10.1002/eat.22459

Copeland, W. E., Wolke, D., Angold, A., \& Costello, E. J. (2013). Adult psychiatric outcomes of bullying and being bullied by peers in childhood and adolescence. 
Journal of the American Medical Association, 70, 419-426. doi:10.1001/jama psychiatry.2013.504

Copeland, W. E., Wolke, D., Lereya, S. T., Shanahan, L., Worthman, C., \& Costello, E. J. (2014). Childhood bullying involvement predicts low-grade systemic inflammation into adulthood. Proceedings of the National Academy of Sciences, 111, 7570-7575. doi:10.1073/pnas.1323641111

Costello, E. J., Egger, H. L., \& Angold, A. (2005). The developmental epidemiology of anxiety disorders: phenomenology, prevalence, and comorbidity. Child and Adolescent Psychiatric Clinics of North America, 14, 631-648. doi:10.1016/j.chc. 2005.06 .003

Coulter, R. W., Herrick, A. L., Friedman, M. R., \& Stall, R. D. (2016). Sexual-orientation differences in positive youth development: The mediational role of bullying victimization. American Journal of Public Health, 106, 691-697. doi:10.2105/AJP H.2015.303005

Coyne, J. C. (1976). Toward an interactional description of depression. Psychiatry, 39, 28-40. doi:10.1080/00332747.1976.11023874

Craig, W., Harel-Fisch, Y., Fogel-Grinvald, H., Dostaler, S., Hetland, J., Simons-Morton, B., ...Pickett, W. (2009). A cross-national profile of bullying and victimization among adolescents in 40 countries. International Journal of Public Health, 54, 216-224. doi:10.1007/s00038-009-5413-9

Crean, R. D., Crane, N. A., \& Mason, B. J. (2011). An evidence based review of acute and long-term effects of cannabis use on executive cognitive functions. Journal of Addiction Medicine, 5, 1-8. doi:10.1097/ADM.0b013e31820c23fa 
Crick, N. R., \& Dodge, K. A. (1994). A review and reformulation of social informationprocessing mechanisms in children's social adjustment. Psychological Bulletin, $115,74-101$.

Cyr, K., Chamberland, C., Clément, M. Ė., Lessard, G., Wemmers, J. A., Collin-Vézina, D., \& Damant, D. (2013). Polyvictimization and victimization of children and youth: Results from a populational survey. Child Abuse \& Neglect, 37, 814820. doi:10.1016/j.chiabu.2013.03.009

Darke, S., Hall, W., Heather, N., Ward, J., \& Wodak, A. (1991). The reliability and validity of a scale to measure HIV risk-taking behaviour among intravenous drug users. AIDS, 5, 181-185. doi:10.1097/00002030-199102000-00008

de Bruyn, E. H., Cillessen, A. H., \& Weisfeld, G. E. (2012). Dominance-popularity status, behavior, and the emergence of sexual activity in young adolescents. Evolutionary Psychology, 10, 296-319. doi:10.1177/147470491201000209

Del Boca, F. K., \& Darkes, J. (2003). The validity of self-reports of alcohol consumption: state of the science and challenges for research. Addiction, 98, 1-12. doi:10.1046/ j.1359-6357.2003.00586.x

Diamond, L. M., \& Huebner, D. M. (2012). Is good sex good for you? Rethinking sexuality and health. Social and Personality Psychology Compass, 6, 54-69. doi:1 $0.1111 / j .1751-9004.2011 .00408 . x$

Dohrenwend, B. P., Levav, I., Shrout, P. E., Schwartz, S., Naveh, G., Link, B. G., ...Stueve, A. (1992). Socioeconomic status and psychiatric disorders: the causation-selection issue. Science, 255, 946-952.

Donoghue, C., Almeida, A., Brandwein, D., Rocha, G., \& Callahan, I. (2014). Coping 
With Verbal and Social Bullying in Middle School. International Journal of Emotional Education, 6, 40-53.

Due, P., Holstein, B. E., Lynch, J., Diderichsen, F., Gabhain, S. N., Scheidt, P., \& Currie, C. (2005). Bullying and symptoms among school-aged children: international comparative cross sectional study in 28 countries. European Journal of Public Health, 15, 128-132. doi:10.1093/eurpub/cki105

Dumont, M., \& Provost, M. A. (1999). Resilience in adolescents: Protective role of social support, coping strategies, self-esteem, and social activities on experience of stress and depression. Journal of Youth and Adolescence, 28, 343-363. doi:10.102 3/A:1021637011732

Duncan, R. D. (1999). Maltreatment by parents and peers: The relationship between child abuse, bully victimization, and psychological distress. Child Maltreatment, 4 , 45-55. doi:10.1177/1077559599004001005

Duncan, R. D. (2004). The impact of family relationships on school bullies and their victims. In D. L. Espelage \& S. M. Swearer (Eds.), Bullying in American schools (pp. 227-244). Mahwah, NJ: Lawrence Erlbaum Associates.

Dussich, J. P., \& Maekoya, C. (2007). Physical child harm and bullying-related behaviors: A comparative study in Japan, South Africa, and the United States. International Journal of Offender Therapy and Comparative Criminology, 51, 495-509. doi:10.1177/0306624X06298463

Earnshaw, V. A., Elliott, M. N., Reisner, S. L., Mrug, S., Windle, M., Emery, S. T., ...Schuster, M. A. (2017). Peer Victimization, Depressive Symptoms, and Substance Use: A Longitudinal Analysis. Pediatrics, 139(6), 1-8. doi:10.1542/pe 
ds.2016-3426

Eaton W. W., Muntaner, C., Smith, C., Tien, A., \& Ybarra, M. Center for Epidemiologic Studies Depression Scale: Review and Revision (CESD and CESD-R). (2004) In M.E. Maruish (Ed.), The Use of Psychological Testing for Treatment Planning and Outcomes Assessment (pp. 363-377). Mahwah, NJ: Lawrence Erlbaum Associates.

Eaton, N. R., Thompson Jr, R. G., Hu, M. C., Goldstein, R. B., Saha, T. D., \& Hasin, D. S. (2015). Regularly drinking alcohol before sexual activity in a nationally representative sample: prevalence, sociodemographics, and associations with psychiatric and substance use disorders. American Journal of Public Health, 105, 1387-1393. doi:10.2105/AJPH.2015.302556

Egan, S. K. \& Perry, D. G. (1998). Does low self-regard invite victimization?. Developmental Psychology, 34, 299-309. doi:10.1037/0012-1649.34.2.299

Ellis, B. J., Del Giudice, M., Dishion, T. J., Figueredo, A. J., Gray, P., Griskevicius, V., ...Wilson, D. S. (2012). The evolutionary basis of risky adolescent behavior: implications for science, policy, and practice. Developmental Psychology, 48, 598-623. doi:10.1037/a0026220

Enders, C. K., \& Bandalos, D. L. (2001). The relative performance of full information maximum likelihood estimation for missing data in structural equation models. Structural Equation Modeling, 8, 430-457. doi:10.1207/S15328007SEM 0803_5

Enejoh, V., Pharr, J., Mavegam, B. O., Olutola, A., Karick, H., \& Ezeanolue, E. E. (2016). Impact of self esteem on risky sexual behaviors among Nigerian 
adolescents. AIDS Care, 28, 672-676. doi:10.1080/09540121.2015.1120853

Epstein, M., Bailey, J. A., Manhart, L. E., Hill, K. G., \& Hawkins, J. D. (2014). Sexual risk behavior in young adulthood: broadening the scope beyond early sexual initiation. The Journal of Sex Research, 51, 721-730. doi:10.1016/j.jadohealth. 2013.09.016

Erol, R. Y. \& Orth, U. (2011). Self-esteem development from age 14 to 30 years: A longitudinal study. Journal of Personality and Social Psychology, 101, 607-619. doi:10.1037/a0024299

Espelage, D. L., Hong, J. S., \& Mebane, S. (2016). Recollections of childhood bullying and multiple forms of victimization: correlates with psychological functioning among college students. Social Psychology of Education, 4, 715-728. doi:10.1007 /s11218-016-9352-z

Evans, C. B., Fraser, M. W., \& Cotter, K. L. (2014). The effectiveness of school-based bullying prevention programs: A systematic review. Aggression and Violent Behavior, 19, 532-544. doi:10.1016/j.avb.2014.07.004

Evans, C. B., Smokowski, P. R., \& Cotter, K. L. (2014). Cumulative bullying victimization: An investigation of the dose-response relationship between victimization and the associated mental health outcomes, social supports, and school experiences of rural adolescents. Children and Youth Services Review, 44, 256-264. doi:10.1016/j.childyouth.2014.06.021

Evraire, L. E., \& Dozois, D. J. A. (2011). An integrative model of excessive reassurance seeking and negative feedback seeking in the development and maintenance of depression. Clinical Psychology Review, 31, 1291-1303. doi:10/1016/j.cpr.2011. 07.014 
Farrington, D. P., \& Ttofi, M. M. (2009). How to reduce school bullying. Victims and Offenders, 4, 321-326. doi:10.1080/15564880903227255

Faul, F., Erdfelder, E., Lang, A.G., \& Buchner, A. (2007). G*Power 3: A flexible statistical power analysis program for the social, behavioral, and biomedical sciences. Behavior Research Methods, 39, 175-191. doi:10.3758/BF03193146

Fennell, M. J. (1997). Low self-esteem: A cognitive perspective. Behavioural and Cognitive Psychotherapy, 25, 1-26. doi:10.1017/S1352465800015368

Fergusson, D. M., McLeod, G. F., \& Horwood, L. J. (2013). Childhood sexual abuse and adult developmental outcomes: Findings from a 30-year longitudinal study in New Zealand. Child Abuse \& Neglect, 37, 664-674. doi:10.1016/j.chiabu.2013.03. 013

Field, A. (2013). Discovering statistics using IBM SPSS statistics (4th ed.). London: Sage Publishing.

Finkelhor, D., Ormrod, R. K., \& Turner, H. A. (2007). Poly-victimization: A neglected component in child victimization. Child Abuse \& Neglect, 31, 7-26. doi:10.1016/ j.chia bu. 2006.06 .008

Finkelhor, D., Ormrod, R. K., \& Turner, H. A. (2009). Lifetime assessment of polyvictimization in a national sample of children and youth. Child Abuse \& Neglect, 33, 403-411. doi:10.1016/j.chiabu.2008.09.012

Finkelhor, D., Ormrod, R., Turner, H., \& Hamby, S. L. (2005a). The victimization of children and youth: A comprehensive, national survey. Child Maltreatment, 10, 5-25. doi:10.1177/1077559504271287

Finkelhor, D., Ormrod, R., Turner, H., \& Hamby, S. L. (2005b). Measuring poly- 
victimization using the Juvenile Victimization Questionnaire. Child Abuse \& Neglect, 29, 1297-1312. doi:10.1016/j.chiabu.2005.06.005

Finkelhor, D., Turner, H. A., \& Hamby, S. L. (2012). Let's prevent peer victimization, not just bullying. Child Abuse \& Neglect, 36, 271-274. doi:10.1016/j.chiabu.2 011.12 .001

Finkelhor, D., Turner, H., Hamby, S. L., \& Ormrod, R. (2011). Polyvictimization: Children's Exposure to Multiple Types of Violence, Crime, and Abuse. OJJDP Juvenile Justice Bulletin (pp. 1-12). Washington, DC: US Government Printing Office.

Finkelhor, D., Turner, H., Ormrod, R., \& Kracke, K. (2009). Children's Exposure to Violence: A Comprehensive National Survey. OJJDP Juvenile Justice Bulletin (pp. 1-12). Washington, DC: US Government Printing Office.

Fisher, S., Zapolski, T. C., Sheehan, C., \& Barnes-Najor, J. (2017). Pathway of protection: Ethnic identity, self-esteem, and substance use among multiracial youth. Addictive Behaviors, 72, 27-32. doi:10.1016/j.addbeh.2017.03.003

Fleming, C. B., Mason, W. A., Mazza, J. J., Abbott, R. D., \& Catalano, R. F. (2008). Latent growth modeling of the relationship between depressive symptoms and substance use during adolescence. Psychology of Addictive Behaviours, 22, 186-197. doi:10.1037/0893-164X.22.2.186

Folkman, S., Lazarus, R. S., Dunkel-Schetter, C., DeLongis, A., \& Gruen, R. J. (1986). Dynamics of a stressful encounter: cognitive appraisal, coping, and encounter outcomes. Journal of Personality and Social Psychology, 50, 992-1003. doi:10.10 37/0022-3514.50.5.992 
Folkman, S. \& Moskowitz, J. T. (2004). Coping: Pitfalls and promise. Annual Review of Psychology, 55, 745-774. doi:10.1146/annurev.psych.55.090902.141456

Fredstrom, B. K., Adams, R. E., \& Gilman, R. (2011). Electronic and school-based victimization: Unique contexts for adjustment difficulties during adolescence. Journal of Youth and Adolescence, 40, 405-415. doi:10.1007/s10964-010-9569-7

Fuendeling, J. M. (1998). Affect regulation as a stylistic process within adult attachment. Journal of Social and Personal Relationships, 15, 291-322. doi:10.1177/0265407 598153001

George, W. H., Zawacki, T. M., Simoni, J. M., Stephens, K. A., \& Lindgren, K. P. (2005). Assessment of sexually risky behaviors. In D. M. Donovan \& A. G. Marlatt (Eds.), Assessment of addictive behaviors (pp. 425-444). New York, NY: Guilford Press.

Gibb, B. E. \& Alloy, L. B. (2006). A prospective test of the hopelessness theory of depression in children. Journal of Clinical Child and Adolescent Psychology, 35, 264-274. doi:10.1207/s15374424jccp3502_10

Goebert, D., Else, I., Matsu, C., Chung-Do, J., \& Chang, J. Y. (2011). The impact of cyberbullying on substance use and mental health in a multiethnic sample. Maternal and Child Health Journal, 15, 1282-1286. doi:10.1007/s10995-010-067 2-x

Grant, D. M., Beck, J. G., Farrow, S. M., \& Davila, J. (2007). Do interpersonal features of social anxiety influence the development of depressive symptoms? Cognition and Emotion, 21, 646-663. doi:10.1080/02699930600713036

Gray-Little, B., Williams, V. S., \& Hancock, T. D. (1997). An item response theory 
analysis of the Rosenberg Self-Esteem Scale. Personality and Social Psychology Bulletin, 23, 443-451. doi; 10.1177/0146167297235001

Grello, C. M., Welsh, D. P., \& Harper, M. S. (2006). No strings attached: The nature of casual sex in college students. Journal of Sex Research, 43, 255-267. doi:10.1080/ 00224490609552324

Grills, A. E. \& Ollendick, T. H. (2002). Peer victimization, global self-worth, and anxiety in middle school children. Journal of Clinical Child and Adolescent Psychology, $31,59-68$.

Hallfors, D. D., Waller, M. W., Bauer, D., Ford, C. A., \& Halpern, C. T. (2005). Which comes first in adolescence-sex and drugs or depression?. American Journal of Preventive Medicine, 29, 163-170. doi:10.1016/j.amepre.2005.06.002

Hall, W., \& Degenhardt, L. (2009). Adverse health effects of non-medical cannabis use. The Lancet, 374, 1383-1391. doi:10.1016/S0140-6736(09)61037-0

Hallam, R. (1992). Counselling for anxiety problems. London: Sage Publishing. Hammen, C. (1999). The emergence of an interpersonal approach to depression. In T. Joiner \& J. C. Coyne (Eds.), The interactional nature of depression: Advances in interpersonal approaches (pp. 21-36). Washington, DC: American Psychological Association.

Hampel, P., Manhal, S., \& Hayer, T. (2009). Direct and relational bullying among children and adolescents: Coping and psychological adjustment. School Psychology International, 30, 474-490.

Hardt, J., \& Rutter, M. (2004). Validity of adult retrospective reports of adverse childhood experiences: review of the evidence. Journal of Child Psychology and Psychiatry, 45, 260-273. doi:10.1111/j.1469-7610.2004.00218.x 
Harter, S. (1999). The Construction of the Self: A Developmental Perspective. Guilford New York, NY: Guilford Press.

Hartung, C. M., Little, C. S., Allen, E. K., \& Page, M. C. (2011). A psychometric comparison of two self-report measures of bullying and victimization: Differences by sex and grade. School Mental Health, 3, 44-57. doi:10.1007/s12310-0109046-1

Hawker, D. S. \& Boulton, M. J. (2000). Twenty years' research on peer victimization and psychosocial maladjustment: A meta-analytic review of cross-sectional studies. Journal of Child Psychology and Psychiatry, 41, 441-455. doi:10.1111/14697610.00629

Hayes, A. F. (2013). Introduction to Mediation, Moderation, and Conditional Process Analysis: A Regression-Based Approach. New York, NY: Guilford Press.

Hayes, A. F., Montoya, A. K., \& Rockwood, N. J. (2017). The analysis of mechanisms and their contingencies: PROCESS versus structural equation modeling. Australasian Marketing Journal, 25, 76-81. doi:10.1016/j.ausmj.2017.02.001

Hays, R. D., Merz, J. F., \& Nicholas, R. (1995). Response burden, reliability, and validity of the CAGE, Short MAST, and AUDIT alcohol screening measures. Behavior Research Methods, Instruments, \& Computers, 27, 277-280. doi:10.3758/BF032 04745

Huebner, A. J., \& Howell, L. W. (2003). Examining the relationship between adolescent sexual risk-taking and perceptions of monitoring, communication, and parenting styles. Journal of Adolescent Health, 33, 71-78. doi:10.1016/S1054-139X(03) $00141-1$ 
Hodges, E. V. \& Perry, D. G. (1999). Personal and interpersonal antecedents and consequences of victimization by peers. Journal of Personality and Social Psychology, 76, 677-685. doi:10.1037/0022-3514.76.4.677

Holt, S., Buckley, H., \& Whelan, S. (2008). The impact of exposure to domestic violence on children and young people: A review of the literature. Child Abuse \& Neglect, 32, 797-810. doi:10.1016/j.chiabu.2008.02.004

Holt, M. K., Greif Green, J., Reid, G., DiMeo, A., Espelage, D. L., Felix, E. D., ...Sharkey, J. D. (2014). Associations between past bullying experiences and psychosocial and academic functioning among college students. Journal of American College Health, 62, 552-560. doi:10.1080/07448481.2014.947990

Holt, M. K., Green, J. G., Tsay-Vogel, M., Davidson, J., \& Brown, C. (2016). Multidisciplinary Approaches to Research on Bullying in Adolescence. Adolescent Research Review, 2, 1-10. doi:10.1007/s40894-016-0041-0

Hong, J. S., Davis, J. P., Sterzing, P. R., Yoon, J., Choi, S., \& Smith, D. C. (2014). A conceptual framework for understanding the association between school bullying victimization and substance misuse. American Journal of Orthopsychiatry, 84, 696-710. doi:10.1037/ort0000036

Hong, J. S., Espelage, D. L., Grogan-Kaylor, A., \& Allen-Meares, P. (2012). Identifying potential mediators and moderators of the association between child maltreatment and bullying perpetration and victimization in school. Educational Psychology Review, 24, 167-186. doi:10.1007/s10648-011-9185-4

Houbre, B., Tarquinio, C., Thuillier, I., \& Hergott, E. (2006). Bullying among students and its consequences on health. European Journal of Psychology of 
Education, 21, 183-208. doi:10.1007/BF03173576

Hunter, S. C., Mora-Merchan, J., \& Ortega, R. (2004). The long-term effects of coping strategy use in victims of bullying. The Spanish Journal of Psychology, 7, 312. doi:10.1017/S1138741600004704

Hussong, A. M., Ennett, S. T., Cox, M. J., \& Haroon, M. (2017). A systematic review of the unique prospective association of negative affect symptoms and adolescent substance use controlling for externalizing symptoms. Psychology of Addictive Behaviors, 31, 137-147. doi:10.1037/adb0000247

Idsoe, T., Dyregrov, A., \& Idsoe, E. C. (2012). Bullying and PTSD symptoms. Journal of Abnormal Child Psychology, 40, 901-911. doi:10.1007/s10802-012-9620-0

Irish, L., Kobayashi, I., \& Delahanty, D. L. (2009). Long-term physical health consequences of childhood sexual abuse: A meta-analytic review. Journal of Pediatric Psychology, 35, 450-461. doi:10.1093/jpepsy/jsp118

Jones, H. A., Bilge-Johnson, S., Rabinovitch, A. E., \& Fishel, H. (2014). Self-reported peer victimization and suicidal ideation in adolescent psychiatric inpatients: The mediating role of negative self-esteem. Clinical Child Psychology and Psychiatry, 19, 606-616. doi:10.1177/1359104513492747

Jones, A., Robinson, E., Oginni, O., Rahman, Q., \& Rimes, K. A. (2017). Anxiety disorders, gender nonconformity, bullying and self-esteem in sexual minority adolescents: prospective birth cohort study. Journal of Child Psychology and Psychiatry, 58, 1201-1209. doi:10.1111/jcpp.12757

Juvonen, J. \& Graham, S. (2014). Bullying in schools: The power of bullies and the plight of victims. Annual Review of Psychology, 65, 159-185. doi:10.1146/annure 
V-psych-010213-115030

Kaltiala-Heino, R. \& Fröjd, S. (2011). Correlation between bullying and clinical depression in adolescent patients. Adolescent Health, Medicine and Therapeutics, 2, 37-34. doi:10.2147/AHMT.S11554

Kaltiala-Heino, R., Fröjd, S., \& Marttunen, M. (2010). Involvement in bullying and depression in a 2-year follow-up in middle adolescence. European Child \& Adolescent Psychiatry, 19, 45-55. doi:10.1007/s00787-009-0039-2

Kaltiala-Heino, R., Rimpelä, M., Marttunen, M., Rimpelä, A., \& Rantanen, P. (1999). Bullying, depression, and suicidal ideation in Finnish adolescents: school survey. British Medical Journal, 319, 348-351. doi:10.1136/bmj.319.7206.348

Kassel, J. D., Bornovalova, M., \& Mehta, N. (2007). Generalized expectancies for negative mood regulation predict change in anxiety and depression among college students. Behaviour Research and Therapy, 45, 939-950. doi:10.1016/j.brat.2006. 07.014

Kays, K., Gathercoal, K., \& Buhrow, W. (2012). Does survey format influence selfdisclosure on sensitive question items?. Computers in Human Behavior, 28, 251-256. doi:10.1016/j.chb.2011.09.007

Kelly, E. V., Newton, N. C., Stapinski, L. A., Slade, T., Barrett, E. L., Conrod, P. J., \& Teesson, M. (2015). Suicidality, internalizing problems and externalizing problems among adolescent bullies, victims and bully-victims. Preventive Medicine, 73, 100-105. doi:10.1016/j.ypmed.2015.01.020

Khan, M. R., Kaufman, J. S., Pence, B. W., Gaynes, B. N., Adimora, A. A., Weir, S. S., \& Miller, W. C. (2009). Depression, sexually transmitted infection, and sexual 
risk behavior among young adults in the United States. Archives of Pediatrics \& Adolescent Medicine, 163, 644-652. doi:10.1001/archpediatrics.2009.95

Khantzian, E. J. (1997). The self-medication hypothesis of substance use disorders: a reconsideration and recent applications. Harvard Review of Psychiatry, 4, 231244.

Kianpoor, M. \& Bakhshani, N. M. (2012). Trauma, dissociation, and high-risk behaviors. International Journal of High Risk Behaviors and Addiction, 1, 9-13. doi:10.5812/ ijhrba.4624

Kilpatrick, A.C. (1992). Long-Range Effects of Child and Adolescent Sexual Experiences. Hillsdale, NJ: Lawrence Erlbaum Associates.

Kim, M. J., Catalano, R. F., Haggerty, K. P., \& Abbott, R. D. (2011). Bullying at elementary school and problem behaviour in young adulthood: A study of bullying, violence and substance use from age 11 to age 21. Criminal Behaviour and Mental Health, 21, 136-144. doi:10.1002/cbm.804

King, K. M., Nguyen, H. V., Kosterman, R., Bailey, J. A., \& Hawkins, J. D. (2012). Cooccurrence of sexual risk behaviors and substance use across emerging adulthood: evidence for state-and trait-level associations. Addiction, 107, 1288-1296. doi:10. $1111 / j .1360-0443.2012 .03792 . x$

King, M., Semlyen, J., Tai, S. S., Killaspy, H., Osborn, D., Popelyuk, D., \& Nazareth, I. (2008). A systematic review of mental disorder, suicide, and deliberate self harm in lesbian, gay and bisexual people. BMC Psychiatry, 8, 1-17. doi:10.1186/1471244X-8-70

Kline, R. B. (2016). Principles and practice of structural equational modeling (4th ed.). New York, NY: Guilford Press. 
Klomek, A. B., Marrocco, F., Kleinman, M., Schonfeld, I. S., \& Gould, M. S. (2007). Bullying, depression, and suicidality in adolescents. Journal of the American Academy of Child \& Adolescent Psychiatry, 46, 40-49. doi:10.1097/01chi.00 00242237.84925 .18

Klomek, A. B., Sourander, A., Niemelä, S., Kumpulainen, K., Piha, J., Tamminen, T., ...Gould, M. S. (2009). Childhood bullying behaviors as a risk for suicide attempts and completed suicides: a population-based birth cohort study. Journal of the American Academy of Child \& Adolescent Psychiatry, 48, 254-261. doi: 10.1097/CHI.0b013e318196b91f

Kober, H. (2014). Emotion regulation in substance use disorders. In J. J. Gross (Ed.), Handbook of emotion regulation (pp. 428-446). New York, NY: Guilford Press.

Kochenderfer-Ladd, B. (2004). Peer victimization: The role of emotions in adaptive and maladaptive coping. Social Development, 13, 329-349. doi:10.1111/j.1467-9507.2 004.00271.x

Kochenderfer-Ladd, B. \& Skinner, K. (2002). Children's coping strategies: Moderators of the effects of peer victimization?. Developmental Psychology, 38, 267-278. doi:10 $.1037 / 0012-1649.38 .2 .267$

Kosunen, E., Kaltiala-Heino, R., Rimpelä, M., \& Laippala, P. (2003). Risk-taking sexual behaviour and self-reported depression in middle adolescence-a school-based survey. Child: Care, Health and Development, 29, 337-344. doi:10.1046/j.1365-2 214.2003.00357.x

Kowalski, R. M. \& Limber, S. P. (2013). Psychological, physical, and academic 
correlates of cyberbullying and traditional bullying. Journal of Adolescent Health, 53, S13-S20. doi:10.1016/j.jadohealth.2012.09.018

Kritsotakis, G., Papanikolaou, M., Androulakis, E., \& Philalithis, A. E. (2017). Associations of Bullying and Cyberbullying With Substance Use and Sexual Risk Taking in Young Adults. Journal of Nursing Scholarship, 49, 360-370. doi:10.11 11/jnu.12299

Krumpal, I. (2013). Determinants of social desirability bias in sensitive surveys: a literature review. Quality \& Quantity, 47, 2025-2047. doi:10.1007/s11135-011-96 40-9.

Kumpulainen, K., Räsänen, E., \& Puura, K. (2001). Psychiatric disorders and the use of mental health services among children involved in bullying. Aggressive Behavior, 27, 102-110. doi:10.1002/ab.3

La Greca, A. M. \& Harrison, H. M. (2005). Adolescent peer relations, friendships, and romantic relationships: Do they predict social anxiety and depression?. Journal of Clinical Child and Adolescent Psychology, 34, 49-61. doi:10.1207/s15374424 jecp3401_5

La Greca, A. M. \& Landoll, R. R. (2011). Peer influences. In W. K. Silverman \& A. Field (Eds.), Anxiety Disorders in Children and Adolescents, Second edition (pp. 323-346). Cambridge University Press.

Langford, R., Bonell, C., Jones, H., Pouliou, T., Murphy, S., Waters, E., ...Campbell, R. (2015). The World Health Organization's Health Promoting Schools framework: a Cochrane systematic review and meta-analysis. BMC Public Health, 15, 1-5. doi:10.1186/s12889-015-1360-y 
Langille, D., Asbridge, M., Kisely, S., \& Wilson, K. (2012). Risk of depression and multiple sexual risk-taking behaviours in adolescents in Nova Scotia, Canada. Sexual Health, 9, 254-260. doi:10.1071/SH11029

Laugharne, J., Lillee, A., \& Janca, A. (2010). Role of psychological trauma in the cause and treatment of anxiety and depressive disorders. Current Opinion in Psychiatry, 23, 25-29. doi:10.1097/YCO.0b013e3283345dc5

Lavan, H., \& Johnson, J. G. (2002). The association between axis I and II psychiatric symptoms and high-risk sexual behavior during adolescence. Journal of Personality Disorders, 16, 73-94. doi:10.1521/pedi.16.1.73.22559

Lanyon, R. I. \& Carle, A. C. (2007). Internal and external validity of scores on the Balanced Inventory of Desirable Responding and the Paulhus Deception Scale. Educational and Psychological Measurement, 67, 859-876. doi:10.1177/0013164 406299104

Lazarus, R. S. \& Folkman, S. (1984). Stress, appraisal, and coping. New York, NY: Springer.

Leary, M. R. (1999). Making sense of self-esteem. Current directions in Psychological Science, 8, 32-35. doi:10.1111/1467-8721.00008

Leary, M. R. (2005). Sociometer theory and the pursuit of relational value: Getting to the root of self-esteem. European Review of Social Psychology, 16, 75-111. doi:10.10 $80 / 10463280540000007$

Lee, C. G., Seo, D. C., Torabi, M. R., Lohrmann, D. K., \& Song, T. M. (2018). Longitudinal Trajectory of the Relationship Between Self-Esteem and Substance Use From Adolescence to Young Adulthood. Journal of School Health, 88, 9-14. 
doi:10.1111/josh. 12574

Lehrer, J. A., Shrier, L. A., Gortmaker, S., \& Buka, S. (2006). Depressive symptoms as a longitudinal predictor of sexual risk behaviors among US middle and high school students. Pediatrics, 118, 189-200. doi:10.1542/peds.2005-1320

Lejoyeux, M., Arbaretaz, M., McLoughlin, M., \& Ades, J. (2002). Impulse control disorders and depression. The Journal of Nervous and Mental Disease, 190, 310-314.

Lereya, S. T., Copeland, W. E., Costello, E. J., \& Wolke, D. (2015). Adult mental health consequences of peer bullying and maltreatment in childhood: two cohorts in two countries. The Lancet Psychiatry, 2, 524-531. doi:10.1016/S2215-0366(15)001650

Leserman, J. (2005). Sexual abuse history: Prevalence, health effects, mediators, and psychological treatment. Psychosomatic Medicine, 67, 906-915. doi:10.1097/01.p sy.0000188405.54425.20

Li, A., \& Bagger, J. (2007). The Balanced inventory of desirable responding (BIDR) a reliability generalization study. Educational and Psychological Measurement, 67, 525-544. doi:10.1177/0013164406292087

Li, M. J., DiStefano, A., Mouttapa, M., \& Gill, J. K. (2014). Bias-motivated bullying and psychosocial problems: Implications for HIV risk behaviors among young men who have sex with men. AIDS Care, 26, 246-256. doi:10.1080/09540121.201 3.811219

Lo, C. C., \& Cheng, T. C. (2007). The impact of childhood maltreatment on young adults' substance abuse. The American Journal of Drug and Alcohol Abuse, 33, 139-146. 
doi:10.1080/00952990601091119

Lodge, J. \& Feldman, S. S. (2007). Avoidant coping as a mediator between appearance related victimization and self-esteem in young Australian adolescents. British Journal of Developmental Psychology, 25, 633-642. doi:10.1348/026151007X18 5310

Longmore, M. A., Manning, W. D., Giordano, P. C., \& Rudolph, J. L. (2004). Selfesteem, depressive symptoms, and adolescents' sexual onset. Social Psychology Quarterly, 67, 279-295. doi:10.1177/019027250406700304

Lopez, C. \& DuBois, D. L. (2005). Peer victimization and rejection: Investigation of an integrative model of effects on emotional, behavioral, and academic adjustment in early adolescence. Journal of Clinical Child and Adolescent Psychology, 34, 25-36. doi:10.1207/s15374424jccp3401_3

López-Pelayo, H., Batalla, A., Balcells, M. M., Colom, J., \& Gual, A. (2015). Assessment of cannabis use disorders: a systematic review of screening and diagnostic instruments. Psychological Medicine, 45, 1121-1133. doi:10.1017/S00 33291714002463

Luk, J. W., Wang, J., \& Simons-Morton, B. G. (2010). Bullying victimization and substance use among US adolescents: Mediation by depression. Prevention Science, 11, 355-359. doi:10.1007/s11121-010-0179-0

Lund, E. M., \& Ross, S. W. (2016). Bullying perpetration, victimization, and demographic differences in college students: a review of the literature. Trauma, Violence, \& Abuse, 18, 348-360. doi: 10.1177/1524838015620818 MacKinnon, D. (2008). Introduction to Statistical Mediation Analysis. New York, NY: Lawrence Erlbaum Associates. 
Mahady Wilton, M. M., Craig, W. M., \& Pepler, D. J. (2000). Emotional regulation and display in classroom victims of bullying: Characteristic expressions of affect, coping styles and relevant contextual factors. Social Development, 9, 226-245. doi:10.1111/1467-950700121

Malhotra, S. (2008). Impact of the sexual revolution: consequences of risky sexual behaviors. Journal of American Physicians and Surgeons, 13, 88-90.

Margolin, G., Vickerman, K. A., Oliver, P. H., \& Gordis, E. B. (2010). Violence exposure in multiple interpersonal domains: Cumulative and differential effects. Journal of Adolescent Health, 47, 198-205. doi:10.1016/j.jadohealth.201 0.01 .020

Margolin, G., Vickerman, K. A., Ramos, M. C., Serrano, S. D., Gordis, E. B., Iturralde, E., ... \& Spies, L. A. (2009). Youth exposed to violence: Stability, co-occurrence, and context. Clinical Child and Family Psychology Review, 12, 39-54. doi:10.100 7/s10567-009-0040-9

Marmorstein, N. R., White, H. R., Loeber, R., \& Stouthamer-Loeber, M. (2010). Anxiety as a predictor of age at first use of substances and progression to substance use problems among boys. Journal of Abnormal Child Psychology, 38, 211-224. doi:10.1007/s10802-009-9360-y

Marsh, H. W., Nagengast, B., Morin, A. J., Parada, R. H., Craven, R. G., \& Hamilton, L. R. (2011). Construct validity of the multidimensional structure of bullying and victimization: An application of exploratory structural equation modelling Journal of Educational Psychology, 103, 701-732. doi:10.1037/a0024122

Martino, S.C., Ellickson, P.L., \& McCaffery, D.F. (2008) Developmental Trajectories of 
Substance Use From Early to Late Adolescence: A Comparison of Rural and Urban Youth. Journal of Studies on Alcohol and Drugs, 69, 430-440. doi:10.152 88/jsad.2008.69.430

Maslowsky, J., Schulenberg, J. E., O'Malley, P. M., \& Kloska, D. D. (2014). Depressive symptoms, conduct problems, and risk for polysubstance use among adolescents: Results from US national surveys. Mental Health and Substance Use, 7, 157-169. doi: $10.1080 / 17523281.2013 .786750$

Mason, W. A., Hitch, J. E., \& Spoth, R. L. (2009). Longitudinal relations among negative affect, substance use, and peer deviance during the transition from middle to late adolescence. Substance Use \& Misuse, 44, 1142-1159. doi:10.1080/10826080802 495211

Mason, W. A., Hitchings, J. E., \& Spoth, R. L. (2007). Emergence of delinquency and depressed mood throughout adolescence as predictors of late adolescent problem substance use Psychology of Addictive Behaviors, 21, 13-24. doi:10.1037/0893-16 $4 X .21 .1 .13$

Matud, M. P. (2004). Gender differences in stress and coping styles. Personality and individual differences, 37, 1401-1415. doi.org/10.1016/j.paid.2004.01.010

Mayeux, L., Sandstrom, M. J., \& Cillessen, A. H. (2008). Is being popular a risky proposition?. Journal of Research on Adolescence, 18, 49-74. doi:10.1111/j.1532 $-7795.2008 .0550 . x$

Menard, S. (1995). Applied Logistic Regression Analysis. Thousand Oaks, CA: Sage Publishing.

Meneses-Gaya, C. D., Zuardi, A. W., Loureiro, S. R., \& Crippa, J. A. S. (2009). Alcohol Use Disorders Identification Test (AUDIT): an updated systematic review of 
psychometric properties. Psychology \& Neuroscience, 2, 83-97. doi:10.3922/j.psn s.2009.1.12

Merrell, K. W., Gueldner, B. A., Ross, S. W., \& Isava, D. M. (2008). How effective are school bullying intervention programs? A meta-analysis of intervention research. School Psychology Quarterly, 23, 26-42. doi:10.1037/1045-3830.23.1.2

6

McCormack, A. S., Laybold, A. M., Dickerman-Nelson, J., \& Budd, C. F. (1993). Stress, and substance use: Student attitudes toward alcohol, marijuana and cocaine. College Student Journal, 27, 215-222.

McKay, M. T., Sumnall, H. R., Cole, J. C., \& Percy, A. (2012). Self-esteem and selfefficacy: Associations with alcohol consumption in a sample of adolescents in Northern Ireland. Drugs: Education, Prevention and Policy, 19, 72-80. doi:10.31 09/09687637.2011.579 585

McKinney, C. M., Harris, T. R., \& Caetano, R. (2009). Reliability of self-reported childhood physical abuse by adults and factors predictive of inconsistent reporting. Violence and Victims, 24, 653-668. doi:10.1891/0886-6708.24.5.653

McLaughlin, K. A., Hatzenbuehler, M. L., Xuan, Z., \& Conron, K. J. (2012).

Disproportionate exposure to early-life adversity and sexual orientation disparities in psychiatric morbidity. Child Abuse \& Neglect, 36, 645-655. doi:10.1016/j.chiab u.2012.07.004

Menesini, E., Modena, M., \& Tani, F. (2009). Bullying and victimization in adolescence: Concurrent and stable roles and psychological health symptoms. The Journal of Genetic Psychology, 170, 115-134. doi:10.3200/GNTP.170.2.115-134

Menesini, E., \& Salmivalli, C. (2017). Bullying in schools: the state of knowledge and 
effective interventions. Psychology, Health \& Medicine, 22, 240-253. doi:10.1080 /13548506.2017.1279740

Messman-Moore, T. L., Walsh, K. L., \& DiLillo, D. (2010). Emotion dysregulation and risky sexual behavior in revictimization. Child Abuse \& Neglect, 34, 967-976. doi:10.1016/j.chiabu.2010.06.004

Mitchell, K. J., Ybarra, M., \& Finkelhor, D. (2007). The relative importance of online victimization in understanding depression, delinquency, and substance use. Child Maltreatment, 12, 314-324. doi:10.1177/1077559507305996

Mohr, A. (2006). Family variables associated with peer victimization: Does family violence enhance the probability of being victimized by peers?. Swiss Journal of Psychology, 65, 107-116. doi:10.1024/1421-0185.65.2.107

Moore, S. E., Norman, R. E., Suetani, S., Thomas, H. J., Sly, P. D., \& Scott, J. G. (2017). Consequences of bullying victimization in childhood and adolescence: A systematic review and meta-analysis. World journal of Psychiatry, 7, 60-76. doi:1 0.5498/wjp.v7.i1.60

Morley, T. E., \& Moran, G. (2011). The origins of cognitive vulnerability in early childhood: Mechanisms linking early attachment to later depression. Clinical Psychology Review, 31, 1071-1082. doi:10.1016/ j.cpr.2011.06.006

Morrison-Beedy, D., Carey, M. P., \& Tu, X. (2006). Accuracy of audio computerassisted self-interviewing (ACASI) and self-administered questionnaires for the assessment of sexual behavior. AIDS and Behavior, 10, 541-552. doi:10.1007/s 10 461-006-9081-y

Mrug, S., Loosier, P. S., \& Windle, M. (2008). Violence exposure across multiple 
contexts: Individual and joint effects on adjustment. American Journal of Orthopsychiatry, 78, 70-84. doi:10.1037/0002-9432.78.1.70

Murray, G. R., Rugeley, C. R., Mitchell, D. G., \& Mondak, J. J. (2013). Convenient yet not a convenience sample: Jury pools as experimental subject pools. Social Science Research, 42, 246-253. doi.org/10.1016/j.ssresearch.2012.06.002

Mustanski, B. (2007). The influence of state and trait affect on HIV risk behaviors: A daily diary study of MSM. Health Psychology, 26, 618-626. doi:10.1037/0278-61 33.26.5.618

Muthén, L., \& Muthén, B. O. (1998-2017). Mplus. User's guide. Los Angeles, CA: Muthén \& Muthén.

Nansel, T. R., Overpeck, M., Pilla, R. S., Ruan, W. J., Simons-Morton, B., \& Scheidt, P. (2001). Bullying behaviors among US youth: Prevalence and association with psychosocial adjustment. Journal of the American Medical Association, 285, 2094-2100. doi:10.1001/jama.285.16.2094

Needham, B. L. (2007). Gender differences in trajectories of depressive symptomatology and substance use during the transition from adolescence to young adulthood. Social Science \& Medicine, 65, 1166-1179. doi:10.1016/j.socsimed.2007.04.037

Nelson, D. B., Zhao, H., Corrado, R., Mastrogiannnis, D. M., \& Lepore, S. J. (2017). Preventing unintended pregnancy among young sexually active women: recognizing the role of violence, self-esteem, and depressive symptoms on use of contraception. Journal of Women's Health, 26, 352-360. doi:10.1089/jwh.2016.57 53

Newbury, J. B., Arseneault, L., Moffitt, T. E., Caspi, A., Danese, A., Baldwin, J. R., \& 
Fisher, H. L. (2018). Measuring childhood maltreatment to predict early-adult psychopathology: Comparison of prospective informant-reports and retrospective self-reports. Journal of Psychiatric Research, 96, 57-64. doi:10.1016/j.jpsychires. 2017.09.020

Newman, M. L., Holden, G. W., \& Delville, Y. (2011). Coping with the stress of being bullied: Consequences of coping strategies among college students. Social Psychological and Personality Science, 2, 205-211. doi:10.1177/19485506103 86388

Norman, R. E., Byambaa, M., De, R., Butchart, A., Scott, J., \& Vos, T. (2012). The longterm health consequences of child physical abuse, emotional abuse, and neglect: a systematic review and meta-analysis. PLOS Medicine, 9, e1001349. doi:10.1371/ journal.pmed.1001349

Olsen, J. P., Parra, G. R., \& Bennett, S. A. (2010). Predicting violence in romantic relationships during adolescence and emerging adulthood: A critical review of the mechanisms by which familial and peer influences operate. Clinical Psychology Review, 30, 411-422. doi:10.1016/j.cpr.2010.02.002

Olweus, D. (1993a). Victimization by peers: Antecedents and long-term outcomes. In K. H. Rubin \& J. B. Asendorpf (Eds.), Social Withdrawal, Inhibition, and Shyness in Childhood (pp. 315-341). Hillsdale, NJ: Lawrence Erlbaum Associates.

Olweus, D. (1993b). Bullying at school: What we know and what we can do. Oxford, UK and Cambridge, MA: Wiley-Blackwell.

Olweus, D. (1996). The Revised Olweus Bully/Victim Questionnaire. University of Bergen, Research Center for Health Promotion.

Olweus, D. (2010). Foundations for understanding bullying. In S. R. Jimerson, S. M. 
Swearer, \& D. L. Espelage (Eds.), The handbook of bullying in schools: An international perspective (pp. 9-33). New York, NY: Routledge.

Olweus, D. (2013). School bullying: Development and some important challenges. Annual Review of Clinical Psychology, 9, 751-780. doi:10.1146/annurev-clinpsy$050212-185516$

Oshri, A., Carlson, M. W., Kwon, J. A., Zeichner, A., \& Wickrama, K. K. (2017). Developmental growth trajectories of self-esteem in adolescence: associations with child neglect and drug use and abuse in young adulthood. Journal of Youth and Adolescence, 46, 151-164. doi:10.1007/s10964-016-0483-5

Östberg, V., Modin, B., \& Låftman, S. B. (2018). Exposure to school bullying and psychological health in young adulthood: A prospective 10-year follow-up study. Journal of School Violence, 17, 194-209. doi:10.1080/15388220.2017.1296 770

Overbeek, G., Zeevalkink, H., Vermulst, A., \& Scholte, R. H. (2010). Peer Victimization, Self-esteem, and Ego Resilience Types in Adolescents: A Prospective Analysis of Person- context Interactions. Social Development, 19, 270-284. doi:10.1111/j.146 7-9507.2008.00535.x

Park, K., \& Yang, T. C. (2017). The Long-term Effects of Self-Esteem on Depression: The Roles of Alcohol and Substance Use During Young Adulthood. The Sociological Quarterly, 58, 429-446. doi:10.1080/00380253.2017.1331718

Partnership Attitude Tracking Study (2008, August). Retrieved from https://rugfree.org/wp-content/uploads/2011/04/PATS-Teens-2007-FullReport.pdf 
Patchin, J. W., \& Hinduja, S. (2010). Cyberbullying and self-esteem. Journal of School Health, 80, 614-621. doi:10.1111/j.1746-1561.2010.00548.x

Paul, E. L., McManus, B., \& Hayes, A. (2000). “Hookups”: Characteristics and correlates of college students' spontaneous and anonymous sexual experiences. Journal of Sex Research, 37, 76-88. doi:10.1080/00224490009552023

Paulhus, D. L. (1986). Self-deception and impression management in test responses. In A. Angleitner \& J. S. Wiggins (Eds.), Personality assessment via questionnaire (pp. 143-165). New York, NY: Springer.

Paulhus, D. L. (1991). Measurement and control of response bias. In J. P. Robinson, P. R. Shaver, \& L. S. Wrightsman (Eds.), Measures of personality and social psychological attitudes (pp. 17-59). San Diego, CA: Academic Press.

Paxton, K. C., \& Robinson, W. L. (2008). Depressive symptoms, gender, and sexual risk behavior among African-American adolescents: Implications for prevention and intervention. Journal of Prevention \& Intervention in the Community, 35, 49-62. doi: $10.1300 / \mathrm{J} 005 \mathrm{v} 35 \mathrm{n} 02 \_05$

Pearl, J. (2012). The causal foundations of structural equational modeling. In R. R. Hoyle (Ed.), Handbook of Structural Equational Modeling (68-91). New York, NY: Guilford Press.

Pesola, F., Shelton, K. H., Heron, J., Munafò, M., Maughan, B., Hickman, M., \& van den Bree, M. B. (2015). The mediating role of deviant peers on the link between depressed mood and harmful drinking. Journal of Adolescent Health, 56, 153159. doi:10.1016/j.adohealth.2014.10.268

Pituch, K. A. \& Stevens, J. P. (2015). Applied Multivariate Statistics for the Social 
Sciences (6th ed.). New York, NY: Routledge.

Polusny, M. A., \& Follette, V. M. (1995). Long-term correlates of child sexual abuse:

Theory and review of the empirical literature. Applied and Preventive Psychology, 4, 143-166. doi:10.1016/S0962-1849(05)80055-1

Prinstein, M. J., Meade, C. S., \& Cohen, G. L. (2003). Adolescent oral sex, peer popularity, and perceptions of best friends' sexual behavior. Journal of Pediatric Psychology, 28, 243-249. doi:10.1093/jpepsy/jsg012

Prosek, E. A., Giordano, A. L., Woehler, E. S., Price, E., \& McCullough, R. (2018). Differences in emotion dysregulation and symptoms of depression and anxiety among illicit substance users and nonusers. Substance Use \& Misuse, 1-4. doi:10. $1080 / 10826084.2018 .1436563$

Puente, D., Zabaleta, E., Rodríguez-Blanco, T., Cabanas, M., Monteagudo, M., Pueyo, M. J., ...Bolíbar, B. (2011). Gender differences in sexual risk behaviour among adolescents in Catalonia, Spain. Gaceta Sanitaria, 25, 13-19. doi:

10.1016/j.gaceta.2010.07.012

Pullen, L. M. (1994). The relationships among alcohol abuse in college students and selected psychological/demographic variables. Journal of Alcohol and Drug Education. 40, 36-50.

Radliff, K. M., Wheaton, J. E., Robinson, K., \& Morris, J. (2012). Illuminating the relationship between bullying and substance use among middle and high school youth. Addictive Behaviors, 37, 569-572. doi:10.1016/j.addbeh.2012.01.001

Ramrakha, S., Caspi, A., Dickson, N., Moffitt, T. E., \& Paul, C. (2000). Psychiatric disorders and risky sexual behaviour in young adulthood: cross sectional study in 
birth cohort. British Medical Journal, 321, 263-266. doi:10.1136/bmj.321.7256.2 63

Rao, U. (2006). Links between depression and substance abuse in adolescents: neurobiological mechanisms. American Journal of Preventive Medicine, 31, 161-174. doi:10.1016/j.amepre.2006.07.002

Reid, G. M., Holt, M. K., Bowman, C. E., Espelage, D. L., \& Green, J. G. (2016). Perceived social support and mental health among first-year college students with histories of bullying victimization. Journal of Child and Family Studies, 11, 3331-3341. doi:10.1007/s10826-016-0477-7

Rigby, K. \& Johnson, B. (2006). Expressed readiness of Australian schoolchildren to act as bystanders in support of children who are being bullied. Educational Psychology, 26, 425-440. doi:10.1080/01443410500342047

Ritchwood, T. D., Ford, H., DeCoster, J., Sutton, M., \& Lochman, J. E. (2015). Risky sexual behavior and substance use among adolescents: A meta-analysis. Children and Youth Services Review, 52, 74-88. doi:10.1016/j.childyouth.2015.03.005

Robinson, J. P., \& Espelage, D. L. (2013). Peer victimization and sexual risk differences between lesbian, gay, bisexual, transgender, or questioning and nontransgender heterosexual youths in grades 7-12. American Journal of Public Health, 103, 1810-1819. doi:10.2105/AJPH.2013.301387

Rock, P. L., Roiser, J. P., Riedel, W. J., \& Blackwell, A. D. (2014). Cognitive impairment in depression: a systematic review and meta-analysis. Psychological Medicine, 44, 2029-2040. doi:10.1017/S0033291713002535

Rosenberg M. (1965). Society and the Adolescent Self-Image. Princeton, NJ: Princeton 
University Press.

Rosenberg, M. (1979). Conceiving the Self. New York, NY: Basic Books.

Rosenberg, M., Schooler, C., Schoenbach, C., \& Rosenberg, F. (1995). Global self-

esteem and specific self-esteem: Different concepts, different outcomes. American Sociological Review, 60, 141-156.

Rospenda, K. M., Richman, J. A., Wolff, J. M., \& Burke, L. A. (2013). Bullying victimization among college students: Negative consequences for alcohol use. Journal of Addictive Diseases, 32, 325-342. doi:10.1080/10550887.2013.8499 71

Roth, S. \& Cohen, L. J. (1986). Approach, avoidance, and coping with stress. American Psychologist, 41, 813-819.

Roth, D. A., Coles, M. E., \& Heimberg, R. G. (2002). The relationship between memories for childhood teasing and anxiety and depression in adulthood. Journal of Anxiety Disorders, 16, 149-164. doi:10.1016/S0887-6185(01)00096-2

Rusby, J. C., Forrester, K. K., Biglan, A., \& Metzler, C. W. (2005). Relationships between peer harassment and adolescent problem behaviors. The Journal of Early Adolescence, 25, 453-477. doi:10.1177/0272431605279837

Russell, S. T., Ryan, C., Toomey, R. B., Diaz, R. M., \& Sanchez, J. (2011). Lesbian, gay, bisexual, and transgender adolescent school victimization: Implications for young adult health and adjustment. Journal of School Health, 81, 223-230. doi: 10.1111/j.1746-1561.2011.00583.x

Saewyc, E. M., Magee, L. L., \& Pettingell, S. E. (2004). Teenage Pregnancy and Associated Risk Behaviors Among Sexually Abused Adolescents. Perspectives 
on Sex and Reproductive Health, 36, 98-105. doi:10.1363/psrh.36.98.04.

Salmivalli, C., Kaukiainen, A., Kaistaniemi, L., \& Lagerspetz, K. M. (1999). Selfevaluated self-esteem, peer-evaluated self-esteem, and defensive egotism as predictors of adolescents' participation in bullying situations. Personality and Social Psychology Bulletin, 25, 1268-1278. doi:10.1177/0146167299258008

Salmon, G., James, A., Cassidy, E. L., \& Javaloyes, M. A. (2000). Bullying a review: Presentations to an adolescent psychiatric service and within a school for emotionally and behaviourally disturbed children. Clinical Child Psychology and Psychiatry, 5, 563-579. doi:10.1177/1359104500005004010

Sánchez, F. C., Navarro-Zaragoza, J., Ruiz-Cabello, A. L., Romero, M. F., \& Maldonado, A. L. (2017). Association between bullying victimization and substance use among college students in Spain. Adicciones, 29. 22-32. doi:10.20882/adicciones. 827

Sandberg-Thoma, S. E., \& Kamp Dush, C. M. (2014). Indicators of adolescent depression and relationship progression in emerging adulthood. Journal of Marriage and Family, 76, 191-206. doi:10.1111/jomf.12081

Saunders, J. B., Aasland, O. G., Babor, T. F., De la Fuente, J. R., \& Grant, M. (1993). Development of the alcohol use disorders identification test (AUDIT): WHO collaborative project on early detection of persons with harmful alcohol consumption-II. Addiction, 88, 791-804. doi:10.1111/j.1360-0443.1993.tb02 093.x

Schafer, J. L., \& Graham, J. W. (2002). Missing data: Our view of the state of the art. Psychological Methods, 7, 147-177. doi:10.1037//1082-989X.7.2.147 
Scharfstein, L., Alfano, C., Beidel, D., \& Wong, N. (2011). Children with generalized anxiety disorder do not have peer problems, just fewer friends. Child Psychiatry \& Human Development, 42, 712-723. doi:10.1007/s10578-011-0245-2

Schenk, A. M., \& Fremouw, W. J. (2012). Prevalence, psychological impact, and coping of cyberbully victims among college students. Journal of School Violence, 11, 21-37. doi:10.1080/15388220.2011.630310

Schmitt, D. P., \& Allik, J. (2005). Simultaneous Administration of the Rosenberg SelfEsteem Scale in 53 Nations: Exploring the Universal and Culture-Specific Features of Global Self-Esteem. Journal of Personality and Social Psychology, 89, 623-642. doi:10.1037/0022-3514.89.4.623

Schuster, M. A., Bogart, L. M., Klein, D. J., Feng, J. Y., Tortolero, S. R., Mrug, S., ...Elliott, M. N. (2015). A longitudinal study of bullying of sexual-minority youth. New England Journal of Medicine, 372, 1872-1874. doi:10.1056/NEJ Mc1413064

Schwartz, D., Dodge, K. A., \& Coie, J. D. (1993). The emergence of chronic peer victimization in boys' play groups. Child Development, 64, 1755-1772. doi:10.111 1/j.1467-8624.1993.tb04211.x

Schwartz, D., Dodge, K. A., Coie, J. D., Hubbard, J. A., Cillessen, A. H., Lemerise, E. A., \& Bateman, H. (1998). Social-cognitive and behavioral correlates of aggression and victimization in boys' play groups. Journal of Abnormal Child Psychology, 26, 431-440. doi:10.1023/A:102269560

Schwartz, D., Lansford, J. E., Dodge, K. A., Pettit, G. S., \& Bates, J. E. (2015). Peer victimization during middle childhood as a lead indicator of internalizing problems and diagnostic outcomes in late adolescence. Journal of Clinical Child 
\& Adolescent Psychology, 44, 393-404. doi:10.1080/15374416.2014.881293

Senn, T. E., Carey, M. P., \& Vanable, P. A. (2008). Childhood and adolescent sexual abuse and subsequent sexual risk behavior: Evidence from controlled studies, methodological critique, and suggestions for research. Clinical Psychology Review, 28, 711-735. doi:10.1016/j.cpr.2007.10.002

Senn, T. E., Carey, M. P., Vanable, P. A., Coury-Doniger, P., \& Urban, M. (2007). Characteristics of sexual abuse in childhood and adolescence influence sexual risk behavior in adulthood. Archives of Sexual Behavior, 36, 637-645. doi:10.1007/s10 508-006-9109-4

Sentse, M., Kretschmer, T., \& Salmivalli, C. (2015). The longitudinal interplay between bullying, victimization, and social status: Age-related and gender differences. Social Development, 24, 659-677. doi:10.1111/sode.12115

Shields, A., \& Cicchetti, D. (2001). Parental maltreatment and emotion dysregulation as risk factors for bullying and victimization in middle childhood. Journal of Clinical Child Psychology, 30, 349-363. doi:10.1207/S15374424JCCP3003_7

Shrier, L. A., Harris, S. K., \& Beardslee, W. R. (2002). Temporal associations between depressive symptoms and self-reported sexually transmitted disease among adolescents. Archives of Pediatrics \& Adolescent Medicine, 156, 599-606. doi:10. 1001/archpedi.156.6.599

Shrout, P. E., \& Bolger, N. (2002). Mediation in experimental and nonexperimental studies: new procedures and recommendations. Psychological Methods, 7, 422445. doi:10.1037//1082-989X.7.4.422

Sihvola, E., Rose, R. J., Dick, D. M., Pulkkinen, L., Marttunen, M., \& Kaprio, J. (2008). 
Early-onset depressive disorders predict the use of addictive substances in adolescence: a prospective study of adolescent Finnish twins. Addiction, 103, 2045-2053. doi:10.1111/j.1360-0443.2008.02363.x

Siegel, R. S., La Greca, A. M., \& Harrison, H. M. (2009). Peer victimization and social anxiety in adolescents: Prospective and reciprocal relationships. Journal of Youth and Adolescence, 38, 1096-1109. doi:10.1007/s10964-009-9392-1

Sikkema, K. J., Hansen, N. B., Meade, C. S., Kochman, A., \& Fox, A. M. (2009). Psychosocial predictors of sexual HIV transmission risk behavior among HIVpositive adults with a sexual abuse history in childhood. Archives of Sexual Behavior, 38, 121-134. doi:10.1007/s10508-007-9238-4

Simantov, E., Schoen, C., \& Klein, J. D. (2000). Health-compromising behaviors: why do adolescents smoke or drink?: identifying underlying risk and protective factors. Archives of Pediatrics \& Adolescent Medicine, 154, 1025-1033. doi:10.1001/arch pedi. 154.10 .1025

Sinclair, K. R., Cole, D. A., Dukewich, T., Felton, J., Weitlauf, A. S., Maxwell, M. A., ...Jacky, A. (2012). Impact of physical and relational peer victimization on depressive cognitions in children and adolescents. Journal of Clinical Child \& Adolescent Psychology, 41, 570-583. doi:10.1080/15374416.2012.704841

Sinha, R. (2008). Chronic stress, drug use, and vulnerability to addiction. Annals of the New York Academy of Sciences, 1141, 105-130. doi:10.1196/annals.1441.030

Skinner, E. A., Edge, K., Altman, J., \& Sherwood, H. (2003). Searching for the structure of coping: a review and critique of category systems for classifying ways of coping. Psychological Bulletin, 129, 216-269. doi:10.1037/0033- 
2909.129.2.216

Smart-Richman, L. \& Leary, M. R. (2009). Reactions to discrimination, stigmatization, ostracism, and other forms of interpersonal rejection: a multimotive model. Psychological Review, 116, 365. doi:10.1037/a0015250

Smith, D. W., Davis, J. L., \& Fricker-Elhai, A. E. (2004). How does trauma beget trauma? Cognitions about risk in women with abuse histories. Child Maltreatment, 9, 292-303. doi:10.1177/1077559504266524

Smith, P. K., del Barrio, C., \& Tokunaga, R. S. (2013). Definitions of bullying and cyberbullying: How useful are the terms. In S. Bauman, D. Cross, \& J. Walker (Eds.), Principles of cyberbullying research: Definitions, measures, and methodology (pp. 26-40). New York, NY: Routledge.

Solberg, M. E., \& Olweus, D. (2003). Prevalence estimation of school bullying with the Olweus Bully/Victim Questionnaire. Aggressive Behavior, 29, 239-268. doi:10.10 $02 / a b .10047$

Solberg, M. E., Olweus, D., \& Endresen, I. M. (2007). Bullies and victims at school: Are they the same pupils?. British Journal of Educational Psychology, 77, 441-464. doi:10.1348/000709906X105689

Sourander, A., Jensen, P., Rönning, J. A., Niemelä, S., Helenius, H., Sillanmäki, L., ...Almqvist, F. (2007). What is the early adulthood outcome of boys who bully or are bullied in childhood? The Finnish "From a Boy to a Man" study. Pediatrics, 120, 397-404. doi:10.1542/peds.2006-2704

Sowislo, J. F., \& Orth, U. (2013). Does low self-esteem predict depression and anxiety? A meta-analysis of longitudinal studies. Psychological Bulletin, 139, 213-240. 
doi:10.1037/a0028931

Spielberger, C. D. (1989). State-Trait Anxiety Inventory: A comprehensive bibliography. Palo Alto, CA: Consulting Psychologists Press.

Spielberger, C. D., Gorsuch, R. L., Lushene, R., Vagg, P. R., \& Jacobs, G. A. (1983). Manual for the State-Trait Anxiety Inventory STAI (Form Y). Palo Alto, CA: Consulting Psychologists Press.

Spirito, A., Stark, L. J., Grace, N., \& Stamoulis, D. (1991). Common problems and coping strategies reported in childhood and early adolescence. Journal of Youth and Adolescence, 20, 531-544. doi:10.1007/BF01540636

Springer, K. W., Sheridan, J., Kuo, D., \& Carnes, M. (2007). Long-term physical and mental health consequences of childhood physical abuse: Results from a large population-based sample of men and women. Child Abuse \& Neglect, 31, 517530. doi:10.1016/j.chiabu.2007.01.003

Stapinski, L. A., Bowes, L., Wolke, D., Pearson, R. M., Mahedy, L., Button, K. S., Lewis, B., \& Araya, R. (2014). Peer victimization during adolescence and risk for anxiety disorders in adulthood: a prospective cohort study. Depression and Anxiety, 31, 574-582. doi:10.1002/da.22270

Steinberg, L., \& Monahan, K. C. (2007). Age differences in resistance to peer influence. Developmental Psychology, 43, 1531-1543. doi:10.1037/0012-1649.43.6.1531

Storch, E. A., Masia-Warner, C., Crisp, H., \& Klein, R. G. (2005). Peer victimization and social anxiety in adolescence: A prospective study. Aggressive Behavior, 31, 437-452. doi:10.1002/ab.20093

Sullivan, T. N., Farrell, A. D., \& Kliewer, W. (2006). Peer victimization in early 
adolescence: Association between physical and relational victimization and drug use, aggression, and delinquent behaviors among urban middle school students. Development and Psychopathology, 18, 119-137. doi:10.1017/S09545794060600 $7 X$

Sung, M., Erkanli, A., Angold, A., \& Costello, E. J. (2004). Effects of age at first substance use and psychiatric comorbidity on the development of substance use disorders. Drug and Alcohol Dependence, 75, 287-299. doi:10.1016/j.drugalcd ep.2004.03.013

Swearer, S. M., \& Espelage, D. L. (2004). A social-ecological framework of bullying among youth. In D. L. Espelage \& S. M. Swearer (Eds.), Bullying in American schools: A social-ecological perspective on prevention and intervention (pp. 112). Mahwah, NJ: Erlbaum.

Swenson, L. M., Nordstrom, A., \& Hiester, M. (2008). The role of peer relationships in adjustment to college. Journal of College Student Development, 49, 551-567. doi:10.1353/csd.0.0038

Tabachnick, B. G., \& Fidell, L. S. (2013). Using Multivariate Statistics (6th ed.). Upper Saddle River, NJ: Pearson.

Telzer, E. H., Fuligni, A. J., Lieberman, M. D., Miernicki, M. E., \& Galván, A. (2015). The quality of adolescents' peer relationships modulates neural sensitivity to risk taking. Social Cognitive and Affective Neuroscience, 10, 389-398. doi:10.1093/sc an/nsu064

Tenenbaum, L. S., Varjas, K., Meyers, J., \& Parris, L. (2011). Coping strategies and perceived effectiveness in fourth through eighth grade victims of bullying. School 
Psychology International, 32, 263-287. doi:10.1177/0143034311402309

Testa, C. R., \& Steinberg, L. (2010). Depressive symptoms and health-related risk-taking in adolescence. Suicide and Life-Threatening Behavior, 40, 298-305. doi:10.1521/ suli.2010.40.3.298.

Teva, I., Bermúdez, M. P., \& Buela-Casal, G. (2010). Sexual sensation seeking, social stress, and coping styles as predictors of HIV/STD risk behaviors in adolescents. Youth \& Society, 42, 255-277. doi.org/10.1177/0044118X09353572

Tillfors, M., Persson, S., Willén, M., \& Burk, W. J. (2012). Prospective links between social anxiety and adolescent peer relations. Journal of Adolescence, 35, 12551263. doi:10.1016/j.adolescence.2012.04.008

Topper, L. R., Castellanos-Ryan, N., Mackie, C., \& Conrod, P. J. (2011). Adolescent bullying victimisation and alcohol-related problem behaviour mediated by coping drinking motives over a 12month period. Addictive Behaviors, 36, 6-13. doi:10.10 16/j.addbeh.2010.08.016

Torres, H. L., \& Gore-Felton, C. (2007). Compulsivity, substance use, and loneliness: The loneliness and sexual risk model (LSRM). Sexual Addiction \& Compulsivity, 14, 63-75. doi:10.1080/10720160601150147

Tsaousis, I. (2016). The relationship of self-esteem to bullying perpetration and peer victimization among schoolchildren and adolescents: A meta-analytic review. Aggression and Violent Behavior, 31, 186-199. doi:10.1016/j.avb.2016.09.005

Ttofi, M. M., Farrington, D. P., Lösel, F., Crago, R. V., \& Theodorakis, N. (2016). School bullying and drug use later in life: A meta-analytic investigation. School Psychology Quarterly, 31, 8-27. doi:10.1037/spq0000120 
Ttofi, M. M. \& Farrington, D. P. (2011). Effectiveness of school-based programs to reduce bullying: A systematic and meta-analytic review. Journal of Experimental Criminology, 7, 27-56. doi:10.1007/s11292-010-9109-1

Ttofi, M. M., Farrington, D. P., Lösel, F., \& Loeber, R. (2011). Do the victims of school bullies tend to become depressed later in life? A systematic review and metaanalysis of longitudinal studies. Journal of Aggression, Conflict and Peace Research, 3, 63-73. doi:10.1108/17596591111132873

Turchik, J. A., \& Garske, J. P. (2009). Measurement of sexual risk taking among college students. Archives of Sexual Behavior, 38, 936-948. doi:10.1007/s10508-008-938 $8-\mathrm{z}$

Turner, M. G., Exum, M. L., Brame, R., \& Holt, T. J. (2013). Bullying victimization and adolescent mental health: General and typological effects across sex. Journal of Criminal Justice, 41, 53-59. doi:10.1016/j.jcrimjus.2012.12.005

Turner, H. A., Finkelhor, D., \& Ormrod, R. (2010). Poly-victimization in a national sample of children and youth. American Journal of Preventive Medicine, 38, 323-330. doi:10.1016/j.amepre.2009.11.012

Turner, H. A., Shattuck, A., Finkelhor, D., \& Hamby, S. (2016). Polyvictimization and youth violence exposure across contexts. Journal of Adolescent Health, 58, 208214. doi:10.1016/j.jadohealth.2015.09.021

Valkenburg, P. M., Peter, J., \& Schouten, A. P. (2006). Friend networking sites and their relationship to adolescents' well-being and social self-esteem. CyberPsychology \& Behavior, 9, 584-590. doi:10.1089/cpb.2006.9.584

Van Dam, N. T., \& Earleywine, M. (2011). Validation of the Center for Epidemiologic Studies Depression Scale-Revised (CESD-R): Pragmatic depression assessment 
in the general population. Psychiatry Research, 186, 128-132. doi:10.1016/j.ps ychres.2010.08.018

Veenstra, R., Lindenberg, S., Munniksma, A., \& Dijkstra, J. K. (2010). The complex relation between bullying, victimization, acceptance, and rejection: Giving special attention to status, affection, and sex differences. Child Development, 81, 480486. doi:10.1111/j.1467-8624.2009.01411.x

Vispoel, W. P. \& Tao, S. (2013). A generalizability analysis of score consistency for the Balanced Inventory of Desirable Responding. Psychological Assessment, 25, 94-104. doi:10.1037/a0029061

Volk, A. A., Camilleri, J. A., Dane, A. V., \& Marini, Z. A. (2012). Is adolescent bullying an evolutionary adaptation?. Aggressive Behavior, 38, 222-238. doi:10.1002/ab.2 1418

Volk, A., Craig, W., Boyce, W., \& King, M. (2006). Adolescent risk correlates of bullying and different types of victimization. International Journal of Adolescent Medicine and Health, 18, 575-586. doi:10.1515/IJAMH.2006.18.4.575

Wadsworth, M. E. (2015). Development of maladaptive coping: A functional adaptation to chronic, uncontrollable stress. Child Development Perspectives, 9, 96-100. doi:10.1111/cdep.12112

Wagner, M. K. (2001). Behavioral characteristics related to substance abuse and risktaking, sensation-seeking, anxiety sensitivity, and self reinforcement. Addictive Behaviors, 26, 115-120. doi:10.1016/S0306-4603(00)00071-X

Wagner, E. F., Myers, M. G., \& McIninch, J. L. (1999). Stress-coping and temptationcoping as predictors of adolescent substance use. Addictive Behaviors, 24, 769- 
779. doi:10.1016/S0306-4603(99)00058-1

Waller, M. W., Hallfors, D. D., Halpern, C. T., Iritani, B. J., Ford, C. A., \& Guo, G. (2006). Gender differences in associations between depressive symptoms and patterns of substance use and risky sexual behavior among a nationally representative sample of US adolescents. Archives of Women's Mental Health, 9, 139-150. doi:10.1007/s00737-006-0121-4

Wells, A., \& Carter, K. (2002). Further tests of a cognitive model of generalized anxiety disorder: Metacognitions and worry in GAD, panic disorder, social phobia, depression, and nonpatients. Behavior Therapy, 32, 85-102. doi:10.1016/S00057894(01)80045-9

White, H. R., McMorris, B. J., Catalano, R. F., Fleming, C. B., Haggerty, K. P., \& Abbott, R. D. (2006). Increases in alcohol and cannabis use during the transition out of high school into emerging adulthood: The effects of leaving home, going to college, and high school protective factors. Journal of Studies on Alcohol, 67, 810-822. doi:10.15288/jsa.2006.67.810

Wills, T. A., \& Cleary, S. D. (1995). Stress-coping model for alcohol-tobacco interactions in adolescence. In J. B. Fertig \& J. P. Allen (Eds.), Alcohol and tobacco: From basic science to clinical practice (pp. 107-128). National Institutes of Health: Bethesda, MD.

Wills, T.A. \& Hirky, A.E. (1996) Coping and substance abuse: A theoretical model and review of the evidence. In M. Zeichnec \& N.S. Eudler (Eds.), Handbook of coping: Theory, research, and applications (pp. 279-302). New York, NY: Wiley-Blackwell. 
Wills, T. A., Vaccaro, D., \& Benson, G. (1995). Coping and competence in adolescent alcohol and drug use. In J. L. Wallander \& L. J. Siegel (Eds.), Adolescent health problems: behavioral perspectives (pp. 160-178). New York, NY: Guilford Press.

Wilson, K., Asbridge, M., Kisely, S., \& Langille, D. (2010). Associations of risk of depression with sexual risk taking among adolescents in Nova Scotia high schools. The Canadian Journal of Psychiatry, 55, 577-585. doi:10.1177/0706743 71005500906

Wilson, H. W., \& Widom, C. S. (2008). An examination of risky sexual behavior and HIV in victims of child abuse and neglect: a 30-year follow-up. Health Psychology, 27, 149-158. doi:10.1037/0278-6133.27.2.149

Wolitzky-Taylor, K., Bobova, L., Zinbarg, R. E., Mineka, S., \& Craske, M. G. (2012). Longitudinal investigation of the impact of anxiety and mood disorders in adolescence on subsequent substance use disorder onset and vice versa. Addictive Behaviors, 37, 982-985. doi:10.1016/j.addbeh.2012.03.026

Wolke, D., \& Lereya, S. T. (2015). Long-term effects of bullying. Archives of Disease in Childhood, 100, 879-885. doi:10.1136/archdischild-2014-306667

Wong, J. Y. H., Choi, E. P. H., Chan, C. K. Y., \& Fong, D. Y. T. (2017). Controlling Anxiety Mediates the Influence of Childhood Adversities on Risky Sexual Behaviors Among Emerging Adults. The Journal of Sex Research, 54, 1-8. doi:10.1080/00224499.2017.1278 569

Wright, E. M., Fagan, A. A., \& Pinchevsky, G. M. (2013). The effects of exposure to violence and victimization across life domains on adolescent substance use. Child 
Abuse \& Neglect, 37, 899-909. doi:10.1016/j.chiabu.2013.04.010

Zapolski, T. C., Rowe, A. T., Fisher, S., Hensel, D. J., \& Barnes-Najor, J. (2018). Peer victimization and substance use: Understanding the indirect effect of depressive symptomatology across gender. Addictive Behaviors, 84, 160-166. doi:10.1016/j.a ddbeh. 2018.04.010

Zillmann, D. (1983). Treatment of excitation in emotional behavior. In J. T. Cacioppo \& R. E. Petty (Eds.), Social psychophysiology: A sourcebook (pp. 215-240). New York, NY: Guilford Press.

Zisook, S., Lesser, I., Stewart, J. W., Wisniewski, S. R., Balasubramani, G. K., Fava, M., ...Trivedi, M. H. (2007). Effect of age at onset on the course of major depressive disorder. American Journal of Psychiatry, 164, 1539-1546. doi:10.1176/appi.ajp. 2007.06101757

Zvolensky, M. J., Lewinsohn, P., Bernstein, A., Schmidt, N. B., Buckner, J. D., Seeley, J., \& Bonn-Miller, M. O. (2008). Prospective associations between cannabis use, abuse, and dependence and panic attacks and disorder. Journal of Psychiatric Research, 42, 1017-1023. doi:10.1016/j.jpsychires.2007.10.012

Zwierzynska, K., Wolke, D., \& Lereya, T. S. (2013). Peer victimization in childhood and internalizing problems in adolescence: a prospective longitudinal study. Journal of Abnormal Child Psychology, 41, 309-323. doi:10.1007/s10802-012-9678-8 


\section{APPENDICES}

Appendix A: Demographics Questionnaire

1. How old are you?

I am __ years old.

2. With which gender do you most identify?

$\square$ Male

$\square$ Female

$\square$ Transgender

$\square$ Intersex

$\square$ Other (please specify):

3. Which of the following best describes your sexual orientation/identity:

$\square$ Heterosexual or straight

$\square$ Mostly heterosexual or straight

$\square$ Bisexual

$\square$ Gay

$\square$ Lesbian

$\square$ Pansexual

$\square$ Asexual

$\square$ Other (please specify):

4. Ethnicity (Check all that apply):

$\square$ Aboriginal (e.g., Inuit, Metis, North American Indian)

$\square$ Arab/West Asian (e.g., Armenian, Egyptian, Iranian, Lebanese, Moroccan)

$\square$ East Asian (e.g., Chinese, Filipino, Korean, Japanese)

$\square$ Black (e.g., African, Haitian, Jamaican, Somali)

$\square$ Latin American

$\square$ South Asian (e.g., Indian, Afghan, Punjabi, Bengali)

$\square$ White (Caucasian)

$\square$ Other (please specify)

5. Compared to the average Canadian, do you think your family is (circle one):

$\square$ A lot less wealthy

$\square$ Less wealthy

$\square$ About the same

$\square$ More wealthy

$\square$ A lot more wealthy

6. Year of study:

$\square 1^{\text {st }}$ year

$\square 2^{\text {nd }}$ year

$\square 3^{\text {rd }}$ year 

$\square 4^{\text {th }}$ year
$\square 5^{\text {th }}$ year or more
7. Program of study: 
Appendix B: Revised Olweus Bully/Victim Questionnaire

Here are some questions about being bullied by others. First we explain what bullying is. We say a person is being bullied when another person or several persons:

- Say mean or hurtful things, or make fun of them, or call them mean and hurtful names

- Completely ignore of exclude them from his group of friends or leave them out of things on purpose

- Hit, kick, push, shove around, spit on, throw objects at, or lock them inside a room

- Tell lies or spread false rumors about them or send mean notes, texts, or other communications and try to make other people dislike them

- and do other hurtful things like that

- This may occur at school, going to and from school (on the school bus or while walking), and online.

When we talk about bullying, these things happen more than just once, and it is difficult for the person being bullied to defend himself. We also call it bullying when a person is teased more than just once in a mean and hurtful way. But we do not call it bullying when the teasing is done in a friendly and playful way. Also, it is not bullying when two people of equal strength or power argue or fight.

1) Thinking back from kindergarten until grade 12, identify the worst grade (e.g., grade 7) when you were affected the most by bullying

2) How often were you bullied during the worst grade that you answered above in Question \#1?

$\square$ I was not bullied

$\square$ It only happened once

$\square$ It happened two to three times

$\square$ Two or three times a month

$\square$ About once a week

$\square$ Several times a week

2A) Was the worst bullying incident that you experienced during that grade: Yes

No

Thinking about the worst grade you noted in Question \#1, please answer the following questions about the nature of the bullying you experienced.

3) I was called mean names, was made fun of, or teased in a hurtful way.

$\square$ It did not happened to me during that grade

$\square$ Only once or twice

$\square$ Two or three times a month

$\square$ About once a week 
$\square$ Several times a week

4) Other students left me out of things on purpose, excluded me from their group of friends, or completely ignored me.

$\square$ It did not happened to me during that grade

$\square$ Only once or twice

$\square$ Two or three times a month

$\square$ About once a week

$\square$ Several times a week

5) I was hit, kicked, pushed, shoved around, spit on, locked indoors, or had objects thrown at me.

$\square$ It did not happened to me during that grade

$\square$ Only once or twice

$\square$ Two or three times a month

$\square$ About once a week

$\square$ Several times a week

6) Other students told lies or spread false rumors about me and tried to make others dislike me.

$\square$ It did not happened to me during that grade

$\square$ Only once or twice

$\square$ Two or three times a month

$\square$ About once a week

$\square$ Several times a week

7) I had money or other things taken away from me or damaged.

$\square$ It did not happened to me during that grade

$\square$ Only once or twice

$\square$ Two or three times a month

$\square$ About once a week

$\square$ Several times a week

8) I was threatened or forced to do things I did not want to do.

$\square$ It did not happened to me during that grade

$\square$ Only once or twice

$\square$ Two or three times a month

$\square$ About once a week

$\square$ Several times a week

9) I was bullied with mean names, comments, or gestures with a sexual meaning.

$\square$ It did not happened to me during that grade

$\square$ Only once or twice 
$\square$ Two or three times a month

$\square$ About once a week

$\square$ Several times a week

10) I was bullied with mean names or comments about my actual or perceived sexuality.

$\square$ It did not happened to me during that grade

$\square$ Only once or twice

$\square$ Two or three times a month

$\square$ About once a week

$\square$ Several times a week

11) I was bullied with mean names or comments related to my perceived gender conformity.

$\square$ It did not happened to me during that grade

$\square$ Only once or twice

$\square$ Two or three times a month

$\square$ About once a week

$\square$ Several times a week

12) I was bullied with mean or hurtful messages, calls or pictures, text messages or IM's, or in other ways on my cell phone or over the Internet (computer). (Please remember that it is not bullying when it is done in a friendly and playful way).

$\square$ It did not happened to me during that grade

$\square$ Only once or twice

$\square$ Two or three times a month

$\square$ About once a week

$\square$ Several times a week

12A) If you were bullied on your cell phone or over the Internet, how was it done?

$\square$ Only on the cell phone

$\square$ Only on the Internet

$\square$ In both ways

13) I was bullied in another way during that grade.

$\square$ It did not happened to me during that grade

$\square$ Only once or twice

$\square$ Two or three times a month

$\square$ About once a week

$\square$ Several times a week

14) In which class(es) was the student or students who bullied you?

$\square$ In my class 
$\square$ In a different class but the same grade (year)

$\square$ In a higher grade(s)

$\square$ In a lower grade(s)

$\square$ In both higher and lower grades

15) Were you bullied by males or females?

$\square$ Mainly by one female

$\square$ By several females

Mainly by one male

$\square$ By several males

$\square$ By both males and females

16) By how many people were you usually bullied?

$\square$ Mainly by 1 person

$\square$ By a group of 2-3 people

$\square$ By a group of 4-9 people

$\square$ By a group of 10 or more people

$\square$ By several different people or groups of people

17) How long did the bullying last?

$\square$ It lasted 1 or 2 weeks

$\square$ It lasted about a month

$\square$ It lasted about 6 months

$\square$ It lasted about a year

$\square$ It lasted several yeas

18) Where have you been bullied?

Please select all of the places where you have been bullied (check all that apply):

\begin{tabular}{|l|l|}
\hline \multicolumn{1}{|c|}{ Elementary School until High School } & College, University, or Technical School \\
\hline$\square$ On the playground/athletic field & $\square$ In my dorm room \\
$\square$ In the hallways/stairwells & $\square$ In my dorm building or another \\
$\square$ In class (when the teacher was in the & residence hall \\
room) & $\square$ In a bathroom dorm \\
$\square$ In class (when the teach was not in the & $\square$ In a classroom building \\
room) & $\square$ In the student union or other non- \\
$\square$ In the bathroom & academic building \\
$\square$ In gym class or the gym locker & $\square$ On the campus but outside of a building \\
room/shower & $\square$ In an off campus residence \\
$\square$ In the lunchroom/cafeteria & $\square$ At work \\
$\square$ On the way to and from school & $\square$ At an off campus restaurant or store \\
$\square$ At the school bus stop & $\square$ At an off campus bar or nightclub \\
$\square$ On the school bus & $\square$ At a fraternity or sorority house \\
\hline
\end{tabular}




\section{Appendix C: Childhood Maltreatment}

These questions ask about some of your experiences growing up as a child and teenager. Although these questions are of a personal nature, please try to answer them as honestly as you can. Your responses will be kept completely confidential.

For the following questions, please answer "Yes" or "No".

1. During childhood or adolescence (before the age of 17), has a parent or caregiver ever shoved, slapped, punched, and/or hit you with a closed fist?

a) If yes, were you ever left with marks or bruises on your body?

2. During childhood or adolescence (before the age of 17), has a parent or caregiver ever kicked you; choked you; beaten you up; burned or scalded you; and/or attacked or threatened you with an object or weapon?

3. Before you turned 13 years old, did you have any sexual contact (e.g., hand-to-breast stimulation, hand-to-genital stimulation, oral sex, and/or penetrative vaginal or anal intercourse) with someone who was at least 5 years older than you?

4. Between the ages of 13 and 16, did you have any sexual contact (e.g., hand-to-breast stimulation, hand-to-genital stimulation, oral sex, and/or penetrative vaginal or anal intercourse) with someone who was at least 10 years older than you? 
Appendix D: Alcohol-Use Disorders Identification Test

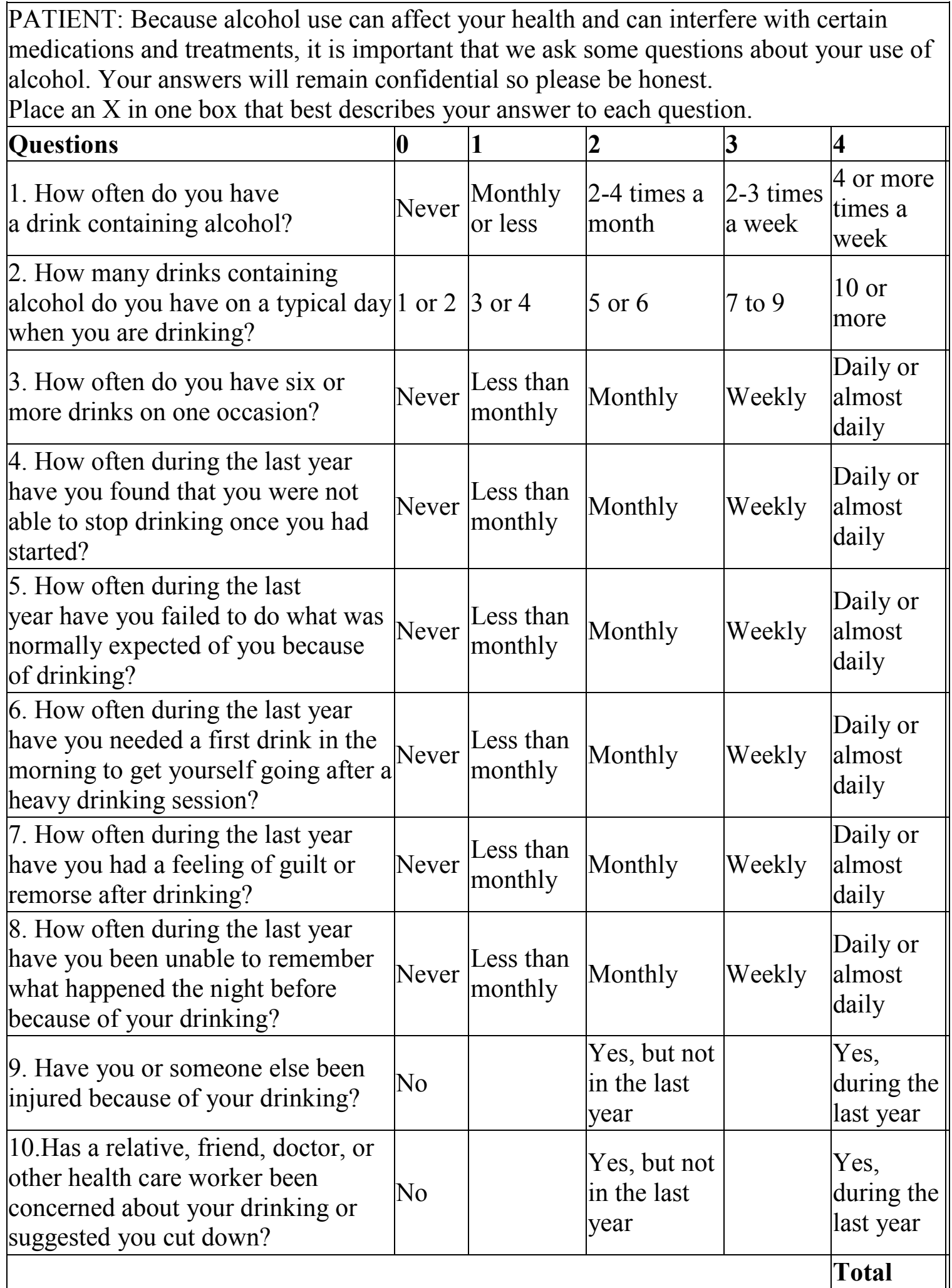


Appendix E: Cannabis Use Disorder Identification Test-Revised

\section{Have you used any cannabis over the past six months? YES / NO}

If YES, please answer the following questions about your cannabis use. Circle the response that is most correct for you in relation to your cannabis use over the past six months

1. How often do you use cannabis?

Never Monthly or less 2-4 times a month 2-3 times a week 4 or more a week

0

12

3

4

2. How many hours were you "stoned" on a typical day when you had been using cannabis?

$\begin{array}{ccccc}\text { Less than } 1 & 1 \text { or } 2 & 3 \text { or } 4 & 5 \text { or } 6 & 7 \text { or more } \\ 0 & 1 & 2 & 3 & 4\end{array}$

3. How often during the past 6 months did you find that you were not able to stop using cannabis once you had started?

Never Less than Monthly Monthly Weekly Daily or almost daily

$\begin{array}{lllll}0 & 1 & 2 & 3 & 4\end{array}$

4. How often during the past 6 months did you fail to do what was normally expected from you because of using cannabis?

Never Less than Monthly Monthly Weekly Daily or almost daily

0

12

3

4

5. How often in the past 6 months have you devoted a great deal of your time to getting, using, or recovering from cannabis?

$\begin{array}{ccccc}\begin{array}{l}\text { Never } \\ \text { daily }\end{array} & \text { Less than Monthly } & \text { Monthly } & \text { Weekly } & \text { Daily or almost } \\ 0 & 1 & 2 & 3 & 4\end{array}$

6. How often in the past 6 months have you had a problem with your memory or concentration after using cannabis? 


$\begin{array}{ccccc}\begin{array}{l}\text { Never } \\ \text { daily }\end{array} & \text { Less than Monthly } & \text { Monthly } & \text { Weekly } & \text { Daily or almost } \\ 0 & 1 & 2 & 3 & 4\end{array}$

7. How often do you use cannabis in situations that could be physically hazardous, such as driving, operating machinery, or caring for children:

$\begin{array}{ccccc}\begin{array}{l}\text { Never } \\ \text { daily }\end{array} & \text { Less than Monthly } & \text { Monthly } & \text { Weekly } & \text { Daily or almost } \\ 0 & 1 & 2 & 3 & 4\end{array}$

8. Have you ever thought about cutting down, or stopping, your use of cannabis?

Never Yes, but not in the past 6 months $\quad$ Yes, during the past 6 months

0 
Appendix F: Sexual Risk Survey

Please read the following statements and record the number that is true for you over the past 6 months for each question on the blank. If you do not know for sure how many times a behavior took place, try to estimate the number as close as you can. Thinking about the average number of times the behavior happened per week or per month might make it easier to estimate an accurate number, especially if the behavior happened fairly regularly. If you've had multiple partners, try to think about how long you were with each partner, the number of sexual encounters you had with each, and try to get an accurate estimate of the total number of each behavior. If the question does not apply to you or you have never engaged in the behavior in the question, put a " 0 " on the blank. Please do not leave items blank. Remember that in the following questions "sex" includes oral, anal, and vaginal sex and that 'sexual behavior"' includes passionate kissing, making out, fondling, petting, oral-to-anal stimulation, and hand-to-genital stimulation. Refer to the Glossary for any words you are not sure about. Please consider only the last 6 months when answering and please be honest. Your responses will be kept completely confidential.

In the past six months:

1. How many partners have you engaged in sexual behavior with but not had sex with?

2. How many times have you left a social event with someone you just met?

3. How many times have you "hooked up" but not had sex with someone you didn't know or didn't know very well?

4. How many times have you gone out to bars/parties/social events with the intent of "hooking up" and engaging in sexual behavior but not having sex with someone?

5. How many times have you gone out to bars/parties/social events with the intent of "hooking up" and having sex with someone?

6. How many times have you had an unexpected and unanticipated sexual experience?

7. How many times have you had a sexual encounter you engaged in willingly but later regretted?

For the next set of questions, follow the same direction as before. However, for questions $8-23$, if you have never had sex (oral, anal or vaginal), please put a " 0 " on each blank.

8. How many partners have you had sex with?

9. How many times have you had vaginal intercourse without a latex or polyurethane condom? Note: Include times when you have used a lambskin or membrane condom. 
10. How many times have you had vaginal intercourse without protection against pregnancy?

11. How many times have you given or received fellatio (oral sex on a man) without a condom?

12. How many times have you given or received cunnilingus (oral sex on a woman) without a dental dam or "adequate protection"?

13. How many times have you had anal sex without a condom?

14. How many times have you or your partner engaged in anal penetration by a hand ("fisting") or other object without a latex glove or condom followed by unprotected anal sex?

15. How many times have you given or received analingus (oral stimulation of the anal region, "rimming") without a dental dam or "adequate protection"?

16. How many people have you had sex with that you know but are not involved in any sort of relationship with (i.e., "friends with benefits", "fuck buddies")?

17. How many times have you had sex with someone you don't know well or just met?

18. How many times have you or your partner used alcohol or drugs before or during sex?

19. How many times have you had sex with a new partner before discussing sexual history, IV drug use, disease status and other current sexual partners?

20. How many times (that you know of) have you had sex with someone who has had many sexual partners?

21. How many partners (that you know of) have you had sex with who had been sexually active before you were with them but had not been tested for STIs/HIV?

22. How many partners have you had sex with that you didn't trust?

23. How many times (that you know of) have you had sex with someone who was also engaging in sex with others during the same time period?

\section{Glossary}

The following is a list of definitions for terms as they are used in the following survey (please read before starting - especially the definitions of "sex" and "sexual behaviour"). The terms in this survey may be used differently than the way you typically use them. If 
you find slang terminology offensive and understand the more formal terms and definitions, you may skip the a.k.a terms in parentheses.

Analingus: Oral to anal stimulation, where a person stimulates another person's anal region with one's mouth/tongue (a.k.a. "rimming", "butt/ass licking").

Anal Sex: Penis to anus stimulation, where a man's penis penetrates another person's anus (a.k.a. "butt/ass sex").

Birth Control/Protection against pregnancy: Methods used to prevent pregnancy, such as taking birth control pills, Norplant implants, birth control patches, condoms, diaphragms, contraceptive sponges, withdraw method, etc. Note: Only latex and polyurethane condoms will also effectively protect against STIs.

Condom: A male condom is a sheath (usually made of latex) that is placed on the outside of the penis and covers the entire shaft of the penis during sexual relations to help protect against pregnancy and STIs. A female condom is a soft flexible tube (usually made of polyurethane) that is inserted into the vagina before sex to protect against pregnancy and STIs. Note: Only latex \& polyurethane condoms offer adequate protection against STIs.

Cunnilingus: Oral sex on a woman, using one's mouth to stimulate a woman's genitals (a.k.a. "eating a woman out", "going down on a woman").

Dental dam (or "adequate protection"): A thin piece of latex that can be placed between the mouth and the vagina during oral sex on a woman to help prevent STIs, or placed between the mouth and anal region during oral to anal sex (analingus) to prevent STIs and bacterial infections. Although purchased dental dams are the most reliable, they can also be self-made by cutting a large square from a latex condom (people often use flavoured condoms for this) or by using a square of plastic wrap as long as there are no holes in the material and the covering adequately covers the genital region. These selfmade dental dams are considered "adequate protection" in this study.

Fellatio: Oral sex on a man, using one's mouth to stimulate a man's penis (a.k.a. "blow job", "giving head").

Hooking up: Engaged in sexual behaviour (such as making out/fondling) or sex with someone, usually outside of a relationship.

IV drugs: Intravenous drugs that are injected into the body using a needle and a syringe, drugs that you can "shoot up" such as heroin.

Oral Sex: Mouth to genital stimulation, using one's mouth to stimulate or touch the genitals of a man or a woman (a.k.a. fellatio, cunnilingus, "blow jobs", "going down on someone").

Sex: Includes oral, anal, and vaginal sex. 
Sexual behavior: Includes passionate kissing, fondling, petting, oral-to-anal stimulation and hand-to genital stimulation (includes "making out", "dry sex/humping", "fingering", analingus, "rimming" "handjobs").

Sexual partner: A person with whom you have had sex (oral, anal or vaginal) or engaged in sexual behaviour with.

STI: Stands for a sexually transmitted infection, a disease that can be given to someone through oral, genital and/or anal sex. Some STIs may also be gotten through oral to anal contact and hand to genital contact. STIs include herpes, trichomonas, chlamydia, syphilis, gonorrhea, vaginitis, genital warts, pubic lice, hepatitis B and HIV infection which leads to AIDS.

Vaginal sex: Sexual intercourse where a man's penis penetrates a woman's vagina, this is the only type of sex that can directly result in pregnancy. (Please note that rear- entry intercourse, such as "doggy-style" sex, is considered vaginal sex as long as the penis is penetrating the vagina and not the anal region). 


\section{Appendix G: Rosenberg Self-Esteem Scale}

Below is a list of statements dealing with your general feelings about yourself. If you strongly agree, circle SA. If you agree with the statement, circle A. If you disagree, circle D. If you strongly disagree, circle SD.

1. On the whole, I am satisfied with myself.

2. At times, I think I am no good at all.

3. I feel that I have a number of good qualities.

4. I am able to do things as well as most other people.

5. I feel I do not have much to be proud of.

6. I certainly feel useless at times.

7. I feel that I'm a person of worth, at least on an equal plane with others.

8. I wish I could have more respect for myself.

9. All in all, I am inclined to feel that I am a failure.

10. I take a positive attitude toward myself.
SA A D SD

SA A D SD

SA A D SD

SA A D SD

SA A D SD

SA A D SD

SA A D SD

SA A D SD

SA A D SD

SA A D SD 
Appendix H: Center for Epidemiological Studies Depression Scale-Revised

Below is a list of the ways you might have felt or behaved. Please check the boxes to tell me how often you have felt this way in the past week or so.

\begin{tabular}{|l|l|l|l|l|l|}
\hline & \multicolumn{5}{|c|}{ Last week } \\
\hline & $\begin{array}{l}\text { Not at all } \\
\text { or Less } \\
\text { than 1 day }\end{array}$ & $1-2$ days & $3-4$ days & $5-7$ days & $\begin{array}{l}\text { Nearly } \\
\text { everyday } \\
\text { for 2 weeks }\end{array}$ \\
\hline My appetite was poor. & 0 & 1 & 2 & 3 & 4 \\
\hline $\begin{array}{l}\text { I could not shake off the } \\
\text { blues. }\end{array}$ & 0 & 1 & 2 & 3 & 4 \\
\hline $\begin{array}{l}\text { I had trouble keeping my } \\
\text { mind on what I was doing. }\end{array}$ & 0 & 1 & 2 & 3 & 4 \\
\hline I felt depressed. & 0 & 1 & 2 & 3 & 4 \\
\hline My sleep was restless. & 0 & 1 & 2 & 3 & 4 \\
\hline I felt sad. & 0 & 1 & 2 & 3 & 4 \\
\hline I could not get going. & 0 & 1 & 2 & 3 & 4 \\
\hline Nothing made me happy. & 0 & 1 & 2 & 3 & 4 \\
\hline I felt like a bad person. & 0 & 1 & 2 & 3 & 4 \\
\hline $\begin{array}{l}\text { I lost interest in my usual } \\
\text { activities. }\end{array}$ & 0 & 1 & 2 & 3 & 4 \\
\hline $\begin{array}{l}\text { I slept much more than } \\
\text { usual. }\end{array}$ & 0 & 1 & 2 & 3 & 4 \\
\hline $\begin{array}{l}\text { I felt like I was moving too } \\
\text { slowly. }\end{array}$ & 0 & 1 & 2 & 3 & 4 \\
\hline I felt fidgety. & 0 & 1 & 2 & 3 & 4 \\
\hline I wished I were dead. & 0 & 1 & 2 & 3 & 4 \\
\hline I wanted to hurt myself. & 0 & 1 & 2 & 3 & 4 \\
\hline I was tired all the time. & 0 & 1 & 2 & 3 & 4 \\
\hline I did not like myself. & 0 & 1 & 2 & 3 & 4 \\
\hline $\begin{array}{l}\text { I lost a lot of weight } \\
\text { without trying to. }\end{array}$ & 0 & 1 & 2 & 3 & 4 \\
\hline
\end{tabular}




\begin{tabular}{|l|l|l|l|l|l|}
\hline & & & & & \\
\hline $\begin{array}{l}\text { I had a lot of trouble getting } \\
\text { to sleep. }\end{array}$ & 0 & 1 & 2 & 3 & 4 \\
\hline $\begin{array}{l}\text { I could not focus on the } \\
\text { important things }\end{array}$ & 0 & 1 & 2 & 3 & 4 \\
\hline
\end{tabular}


Appendix I: State-Trait Anxiety Inventory

\section{DIRECTIONS}

A number of statements which people have used to describe themselves are given below. Read each statement and then circle the appropriate number to the right of the statement to indicate how you feel right now, that is, at this moment. There are no right or wrong answers. Do not spend too much time on any one statement but give the answer which seems to describe your presents feelings best.

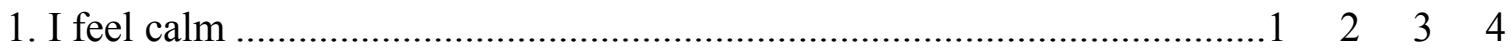

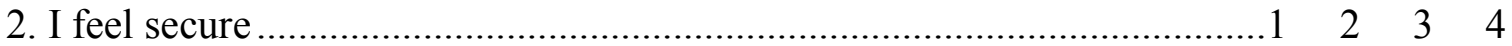

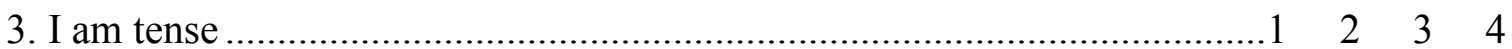

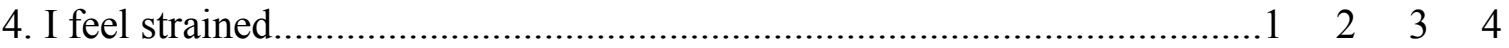

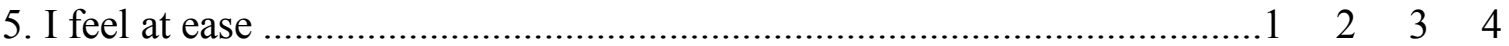

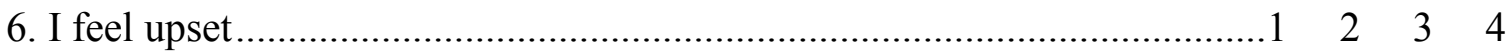

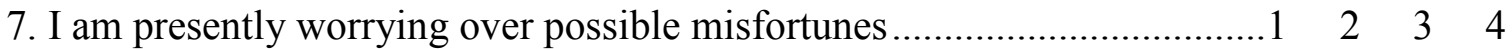

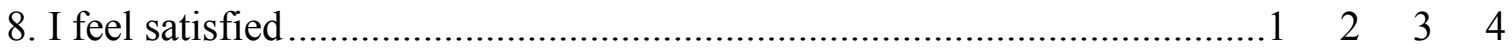

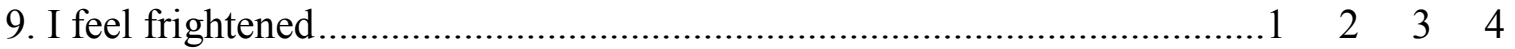

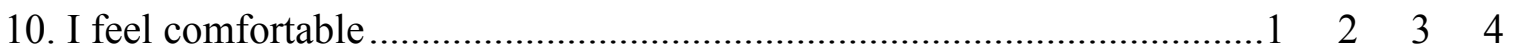

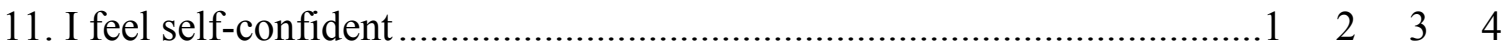

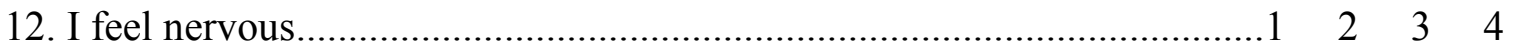

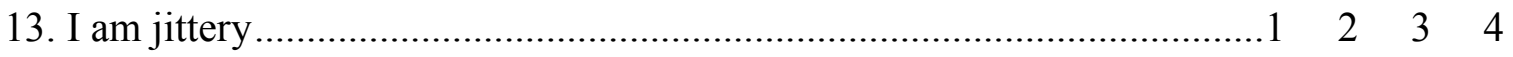

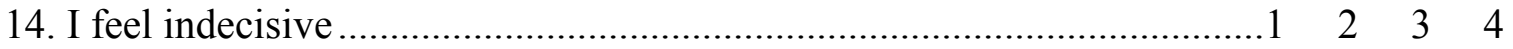

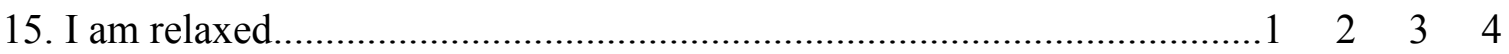

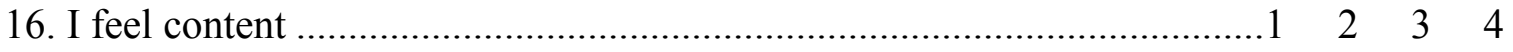

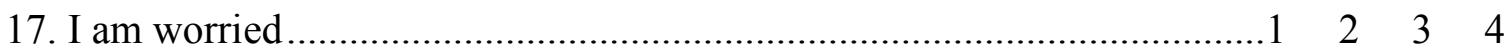

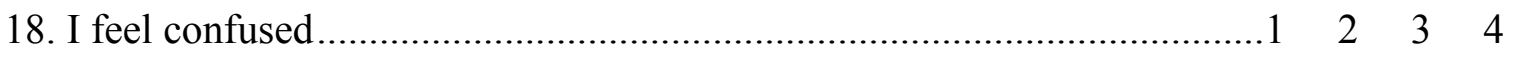


19. I feel steady

\section{DIRECTIONS}

A number of statements which people have used to describe themselves are given below. Read each statement and then circle the appropriate number to the right of the statement to indicate how you generally feel. There are no right or wrong answers. Do not spend too much time on any one statement but give the answer which seems to describe how you generally feel.

21. I feel pleasant $\begin{array}{llll}\ldots 1 & 2 & 3 & 4\end{array}$

22. I feel nervous and restless. $\begin{array}{lll}2 & 3 & 4\end{array}$

23. I feel satisfied with myself. 234

24. I wish I could be as happy as others seem to be 234

25. I feel like a failure. 234

26. I feel rested 234

27. I am "calm, cool, and collected" 234

28. I feel that difficulties are piling up so that I cannot overcome them ........1 $2 \quad 3 \quad 4 \quad 4$

29. I worry too much over something that really doesn't matter.................. $\quad 2 \quad 3 \quad 4$

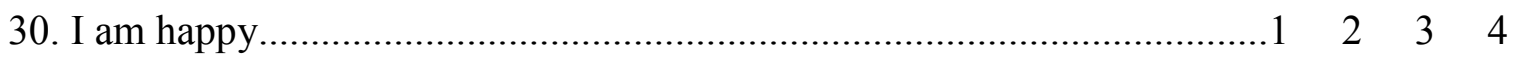

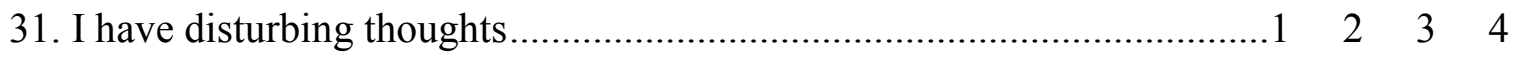

32. I lack self-confidence ..................................................................... $12 \quad 2 \quad 3 \quad 4$

33. I feel secure ............................................................................ $14 \quad 2 \quad 3 \quad 4$

34. I make decisions easily ........................................................... $2 \quad 2 \quad 3 \quad 4$

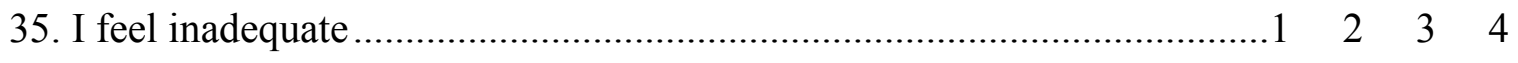

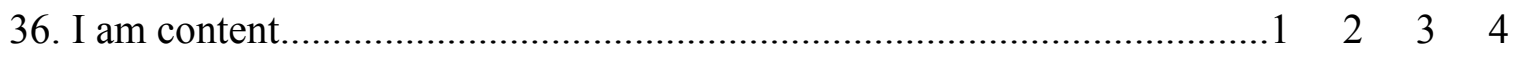


37. Some unimportant thought runs through my mind and bothers me.........1 $2 \quad 2 \quad 3 \quad 4$

38. I take disappointments so keenly that I can't put them out of my mind...1 $2 \begin{array}{lll}3 & 4\end{array}$

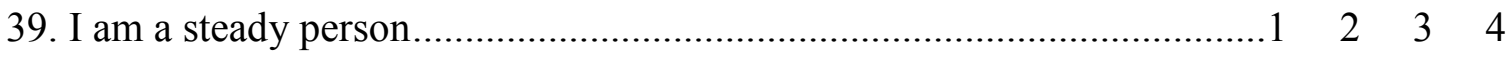

40. I get in a state of tension or turmoil as I think over my recent concerns and interests ........................................................................... $1 \quad 2 \quad 3 \quad 4$ 
Appendix J: Balanced Inventory of Desirable Responding

Using the scale below as a guide, write a number beside each statement to indicate how true it is.

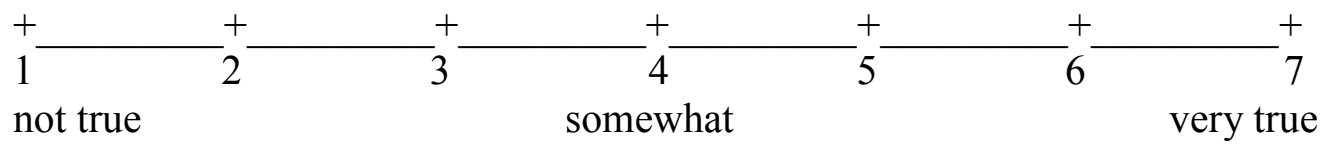

1. My first impressions of people usually turn out to be right.

2 . It would be hard for me to break any of my bad habits.

3. I don't care to know what other people really think of me.

4. I have not always been honest with myself.

5. I always know why I like things.

6 . When my emotions are aroused, it biases my thinking.

7. Once I've made up my mind, other people can seldom change my opinion.

8. I am not a safe driver when I exceed the speed limit.

9. I am fully in control of my own fate.

10. It's hard for me to shut off a disturbing thought.

11. I never regret my decisions.

12. I sometimes lose out on things because I can't make up my mind soon enough.

13. The reason I vote is because my vote can make a difference.

14. My parents were not always fair when they punished me.

15 . I am a completely rational person.

16. I rarely appreciate criticism.

17. I am very confident of my judgments

18. I have sometimes doubted my ability as a lover.

19. It's all right with me if some people happen to dislike me.

20. I don't always know the reasons why I do the things I do.

21. I sometimes tell lies if I have to.

22. I never cover up my mistakes.

23. There have been occasions when I have taken advantage of someone.

24. I never swear.

25. I sometimes try to get even rather than forgive and forget.

26. I always obey laws, even if I'm unlikely to get caught.

27. I have said something bad about a friend behind his/her back.

28. When I hear people talking privately, I avoid listening.

29. I have received too much change from a salesperson without telling him or her.

30. I always declare everything at customs.

31. When I was young I sometimes stole things.

32. I have never dropped litter on the street

33. I sometimes drive faster than the speed limit.

34. I never read sexy books or magazines.

35. I have done things that I don't tell other people about.

36. I never take things that don't belong to me.

37. I have taken sick-leave from work or school even though I wasn't really sick.

38. I have never damaged a library book or store merchandise without reporting it.

39. I have some pretty awful habits.

40. I don't gossip about other people's business. 
Appendix K: Consent Form

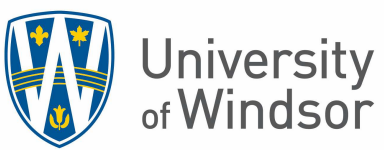

\section{CONSENT TO PARTICIPATE IN RESEARCH}

Title of Study: The Influence of Problematic Peer Relationships and Childhood Adversity on Development

You are asked to participate in a research study conducted by graduate student and principal investigator (PI) Daniel Provenzano and faculty supervisor Dr. Michael Boroughs from the Department of Psychology at the University of Windsor. Results of the study will be contributing to a Master's thesis project.

If you have any questions or concerns about the research, please feel free to contact Daniel Provenzano by phone at (519) 253-3000 ext. 4085 or email at provenz1@uwindsor.ca.

\section{PURPOSE OF THE STUDY}

The purpose of the current study is to better understand how problematic peer relationships and incidents of childhood abuse may influence mental health and engagement in health risk behaviours (involving substance use and sexual behaviour) in emerging adults.

\section{PROCEDURES}

If you volunteer to participate in this study, you will be asked to fill out questionnaires about yourself, your peer relationships, and your basic demographics (e.g., things like age, gender, etc.) online using the link provided for Qualtrics, a questionnaire website. It should take you about 30 minutes to complete the online questionnaires. You will need to complete these questionnaires in one sitting and in a private place undistracted. After completing the questionnaires, you will be asked whether or not you would like to withdraw your data from the study. If you choose to not withdraw your data, you will not be able to withdraw your data at a later date. If you choose to withdraw your data, your responses to the questionnaires will be deleted immediately. After completing the study, please clear the cache and browser history and close your web browser.

\section{POTENTIAL RISKS AND DISCOMFORTS}

Some relationships may be difficult to think about, particularly for those with a history of bullying. It may also be distressing to recall experiences of childhood maltreatment. If you find any part of this study to be too stressful, you may contact Daniel Provenzano (contact information provided above), the University of Windsor Ethics board (contact 
information provided below), or simply stop your participation. You may also freely discuss the study with parents or friends if you need to, although we would ask that you try not to talk to someone before they complete the study on their own. Sharing answers before the study ends can distort and/or change your own natural answers. We do not ask for any specific incidents or events, so there is no personal or legal liability associated with any of your answers, nor are we legally obligated to disclose any of your answers to the questions (including abuse and harm). If you have any concerns about specific behaviours or incidents, we strongly suggest that you discuss them with trusted individuals (e.g., close friends or parents). You may also contact any of the resources that are provided at the end of the study. It is important to know that you do not need to tolerate any form of abuse.

\section{POTENTIAL BENEFITS TO PARTICIPANTS AND/OR TO SOCIETY}

Possible benefits of participation involve gaining useful knowledge about the self such that some participants may learn about the link between their own current mental health and history of bullying victimization. Furthermore, participants may learn about some of the negative health outcomes associated with bullying that hopefully encourages them to denounce the behaviour, intervene in known incidents of bullying, or seek treatment if they are experiencing negative health outcomes associated with being bullied. Finally, participants may learn about mental health resources that are available to them through the university and in the community if they are experiencing distress either from the study or prior to participating. Potential benefits to the scientific/scholarly community or society that justify the involvement of participants in this study are to help to inform the development and refinement of bullying prevention interventions to address health risk behaviours and/or negative mental health outcomes associated with being bullied.

\section{COMPENSATION FOR PARTICIPATION}

Participants will receive 0.5 bonus points for 30 minutes of participation towards the psychology participant pool, if registered in the pool and enrolled in one or more eligible courses. $\square$ If you did not sign up for this study through the participant pool, then you can enter a draw to win one of three $\$ 50$ gift cards for Amazon.

\section{CONFIDENTIALITY}

Any information that is obtained in connection with this study will remain confidential and will be disclosed only with your permission. Unique, identifiable data (such as exact date of birth, names of friends and family, IP address) will not be collected other than demographic information and your name for the purposes of ensuring that you receive your compensation for participating. You do not have to reveal your answers to any of your friends, family, or anyone else other than the researchers in this study. Data collected during this study will be stored on a secure password protected computer, and your responses will be confidential. In order to best protect your confidentiality, we suggest completing the online questionnaires in private and on your own. This will limit the possibility of others (e.g., parents, siblings, friends) from seeing your responses. The 
researchers will own all data collected through Qualtrics and therefore all information will be confidential. Qualtrics data will be stored on servers in Canada. All communications to/from the Qualtrics servers are encrypted. The Qualtrics servers are protected by firewalls and Qualtrics monitors system access for unauthorized uses. However, data will be downloaded onto a password protected lab computer once data collection is completed. Once data is downloaded in the lab, the data will be immediately deleted off from Qualtrics.

\section{PARTICIPATION AND WITHDRAWAL}

Participation in this study is purely voluntary. Whether you participate, or what questions you answer, is completely up to you. If you want to withdraw from this study at any time, you may do so by clicking on "Exit Survey" without any penalty other than not receiving 0.5 course credit or not being able to enter the draw to win a $\$ 50$ gift card, and your data will be confidentially destroyed in the event of withdrawal. After completing the questionnaires, you will be asked whether or not you would like to withdraw your data from the study. If you choose to not withdraw your data, you will not be able to withdraw your data at a later date. If you choose to withdraw your data from the study at that point, your responses to the questionnaires will be deleted.

\section{FEEDBACK OF THE RESULTS OF THIS STUDY TO THE PARTICIPANTS}

Results of the study will be available to you upon request by contacting Daniel Provenzano or you may check the University of Windsor's Research Ethics Board Website to find a summary of the results of the study in Fall 2018.

\section{SUBSEQUENT USE OF DATA}

These data may be used in subsequent studies, in publications in professional journals and in conference presentations.

\section{RIGHTS OF RESEARCH PARTICIPANTS}

If you have questions regarding your rights as a research participant, contact: Research Ethics Coordinator, University of Windsor, Windsor, Ontario, N9B 3P4; Telephone: 519253-3000, ext. 3948; e-mail: ethics@uwindsor.ca

\section{SIGNATURE OF RESEARCH PARTICIPANT/LEGAL REPRESENTATIVE}

I understand the information provided for the study The Influence of Problematic Peer Relationships and Childhood Adversity on Development as described herein. My questions have been answered to my satisfaction, and I agree to participate in this study. Please print a copy of this form for your records.
[_] Yes

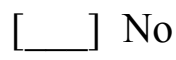
Date: 


\section{SIGNATURE OF INVESTIGATOR}

These are the terms under which I will conduct research.

Date: 
Appendix L: Debriefing Form and Community Resources

\section{DEBRIEFING LETTER}

Thank you for your participation in our study! As you may have deduced from the nature of the questions, we are interested in problematic peer relationships, childhood adversity, mental health, and health risk behaviours. For instance, we are interested in how history of bullying victimization and child maltreatment may be linked with mental health problems and engagement in substance use and sexual activity in young people. It is our belief that an understanding of all these variables together will help us learn about how they affect young people. A growing body of research is being done on these variables, which we feel are very important, and hope to present and/or publish some of the results of this study in the future. Some of the questions in this study may have been uncomfortable and/or difficult to respond. Bullying victimization and experiences of other types of child maltreatment are common and many young people find thinking about them to be upsetting and unpleasant. If you have any concerns being a victim of bullying or child maltreatment, or are experiencing any mental health problems, please feel free to contact any of the resources that are provided below. In general, you can help prevent bullying by not participating as a bully, intervening when others are being bullied (e.g., report that behaviour to an adult), and by actively disapproving of the bully's behaviour (e.g., telling them it's not cool). You may be able to reduce victimization by talking to your parents, teachers, and/or friends and by trying to make supportive friendships. Bullying is a public health crisis affecting millions of children, adolescents, and young adults worldwide each year. Previous studies have found negative physical and mental health outcomes linked with a history of being bullied. In particular, bullying victimization is associated with low self-esteem, loneliness, anxiety, post-traumatic stress disorder, depression, suicide, eating disorders, substance use, sexual risk taking, and sickness (i.e., more colds, sore throats, and inflammation). What is especially concerning is that these negative health outcomes can persist into adulthood even though individuals may have experienced bullying in childhood or adolescence. In general, you can help prevent bullying by not participating as a bully, intervening when others are being bullied (e.g., report that behaviour to an adult), and by actively disapproving of the bully's behaviour (e.g., telling them it's not cool). You may be able to reduce victimization by talking to your parents, teachers, and/or friends and by trying to make supportive friendships.

If you have any further questions or concerns, please feel free to contact Daniel Provenzano at provenz1@uwindsor.ca or (519) 253-3000 ext. 4085, or if regarding the study's ethics, the University of Windsor Research Ethics Office at (519) 253-3000 Ext. 3948, ethics@uwindsor.ca. Results of the study will be available to you upon request in Fall 2018 by contacting Daniel Provenzano. Thank you very much for participating in this study! 


\section{University
of Windsor}

\section{COMMUNITY RESOURCE LIST}

Brentwood Recovery Home

2335 Dougall Avenue

Windsor, Ontario N8X1S9

Phone: 519-253-2441

Canadian Mental Health Association Windsor-Essex County Branch

1400 Windsor Avenue

Windsor, Ontario N8X 3L9

Phone: 519-255-7440

Community Crisis Centre (Walk-in Service; 1st Floor Jeanne Mance Building) 1030 Ouellette Ave.

24 hour Crisis Telephone Line: 519-973-4435

ConnexOntario

Drug and Alcohol Helpline: 1-800-565-8603

Mental Health Helpline: 1-866-531-2600

Distress Center

Phone: 519-256-5000

Family Services Windsor-Essex

1770 Langlois Ave.

Windsor, Ontario N8X4M5

Phone: 519-966-5010

Good2Talk

24-hour Student Helpline 1-866-925-5454

Maryvale Adolescent and Family Services

940 Prince Rd

Windsor, ON N9C $2 \mathrm{Z5}$

(519) 258-0484

Psychological Services and Research Center

2629 Riverside Drive West

Windsor, Ontario N9B 1B4

Phone: 519-253-3000 ext. 7012 or 519-973-7012 
Sandwich Community Health 3320 College Avenue

Windsor, Ontario N9C 0E1

Phone: 519-258-6002 ext. 222

Sexual Assault Crisis Centre

1770 Langlois Ave

Windsor, Ontario N8X 4M5

Phone: 519-253-3100

24-hour crisis hotline: 519-253-9667

Teen Health Centre

1361 Ouellette Avenue

Windsor, Ontario N8X $1 \mathrm{~J} 6$

Phone: 519-253-8481 
Appendix M: Recruitment Advertisements

Participant Pool Advertisement

Study Name: The Influence of Problematic Peer Relationships and Childhood Adversity on Development

Brief Abstract: The purpose of the current study is to better understand how problematic peer relationships and incidents of childhood abuse may influence mental health and engagement in health risk behaviours (involving substance use and sexual behaviour) in emerging adults.

Detailed Description: None

Eligibility Criteria: Students between the ages of 17 and 25 years old.

Duration: 30 minutes

Points: 0.5 course credit

Preparation: Before beginning the study, please set aside 30 minutes as the study must be completed in one sitting. Also, make sure you complete the study in private and on your own. 


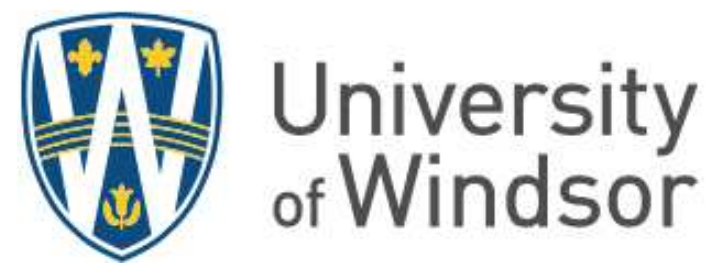

\section{SURVEY PARTICIPANTS NEEDED!}

My name is Daniel Provenzano and I am a graduate student in the department of psychology. I am looking for participants to fill out my 30-minute research survey online.

If you are a student between the ages of 17 and 25 , you are eligible to participate!

\section{You can enter a draw to win one of three $\$ 50$ gift certificates for your time and efforts!}

If you would like to participate in the this study, please contact me at provenz1@uwindsor.ca

Thank you for your interest.

\footnotetext{
*A few questions will ask about incidents of childhood abuse, whereas other questions will ask about sexual health. This study has received ethics clearance through the University of Windsor Research Ethics Board.
} 


\section{VITA AUCTORIS}

NAME:

PLACE OF BIRTH: Toronto, ON

YEAR OF BIRTH: $\quad 1990$

EDUCATION:

Queen's University, B.A. (Honours), Kingston, ON, 2013

Brock University, M.A., St. Catharines, ON, 2016 